FABRÍCIO JUNQUEIRA

\title{
MODELAGEM DE SISTEMAS FLEXÍVEIS DE MOVIMENTAÇÃO DE MATERIAIS ATRAVÉS DE REDES DE PETRI INTERPRETADAS
}

\author{
Dissertação apresentada à Escola \\ Politécnica da Universidade de São \\ Paulo para a obtenção do título de \\ Mestre em Engenharia.
}


FABRÍCIO JUNQUEIRA

\title{
MODELAGEM DE SISTEMAS FLEXÍVEIS DE MOVIMENTAÇÃO DE MATERIAIS ATRAVÉS DE REDES DE PETRI INTERPRETADAS
}

\author{
Dissertação apresentada à Escola \\ Politécnica da Universidade de São \\ Paulo para a obtenção do título de \\ Mestre em Engenharia.
}

Área de Concentração:

Engenharia Mecânica

Orientador: Paulo Eigi Miyagi 
Aos meus pais Osvaldo e

Maria José e ao meu irmão Leonardo. 
FICHA CATALOGRÁFICA ELABORADA PELA BIBLIOTECA DA ENGENHARIA MECÂNICA/NAVAL DA ESCOLA POLITÉCNICA (EPMN) - USP.

Junqueira, Fabrício

Modelagem de Sistemas Flexíveis de Movimentação de Materiais Através de Redes de Petri Interpretadas, São Paulo, 2001.

$128 \mathrm{p}$.

Dissertação (Mestrado) - Escola Politécnica da Universidade de São Paulo. Departamento de Engenharia Mecatrônica e Sistemas Mecânicos. 


\section{Agradecimentos}

Ao meu orientador, Prof. Dr. Paulo Eigi Miyagi, pela sua constante orientação e incentivo para o desenvolvimento deste trabalho.

Ao grupo SED-SH pelas discussões e contribuições.

À FAPESP pela bolsa-auxílio.

Ao $\mathrm{CNPq}$ pelo suporte complementar às atividades do projeto.

Aos meus pais e irmão pelo apoio e amor que me deram ao longo da vida.

À Eliane, pelo seu amor e carinho.

Aos meus companheiros de república, pela amizade e apoio desde os tempos da graduação.

Aos amigos da sala MC01 e aos funcionários da Eng. Mecânica.

A todos que direta ou indiretamente contribuíram para a realização deste trabalho. 


\section{Sumário}

LISTA DE FIGURAS …....................................................................................................................................................................... IV

LISTA DE SIGLAS E ABREVIATURAS ...............................................................................................................VII

RESUMO ...................................................................................................................................................................................VIII

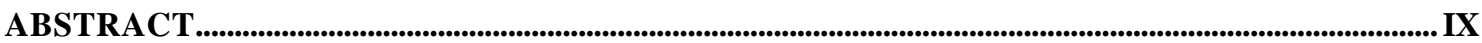

1. INTRODUÇÃ

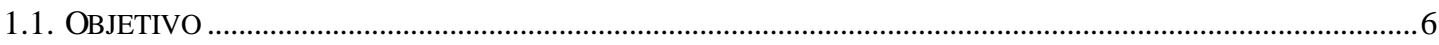

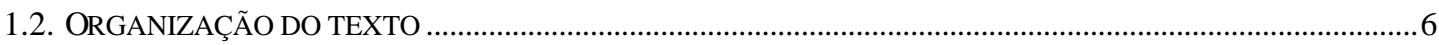

2. SISTEMA DE MOVIMENTAÇÃO DE MATERIAIS ................................................................................8

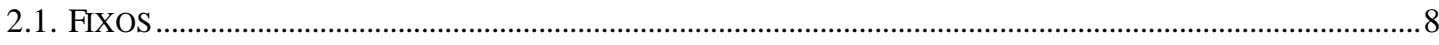

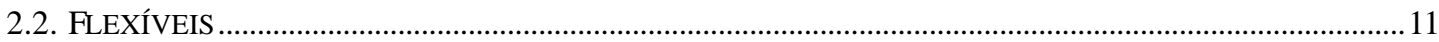

2.3. PRINCIPAIS PROBLEMAS DE MOVIMENTAÇÃO DE MATERIAIS EMPREGANDO-SE TRANSPORTADORES

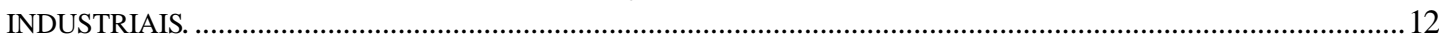

2.3.1. Problemas de roteirização de transportadores ......................................................................... 13

2.3.2. Problemas de programação de tarefas .................................................................................... 23

2.3.3. Problemas de roteirização e programação de tarefas para transportadores (problemas

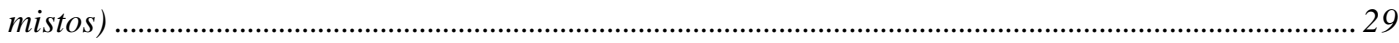

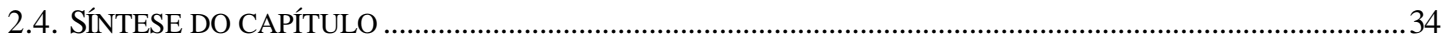

3. FERRAMENTAS / METODOLOGIAS EMPREGADAS NA MODELAGEM DE SISTEMAS A

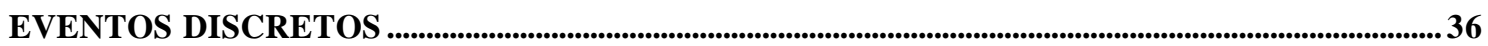

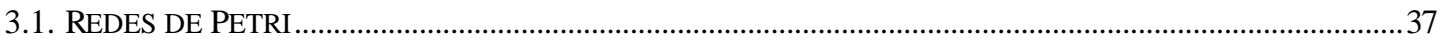

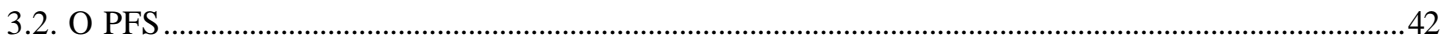

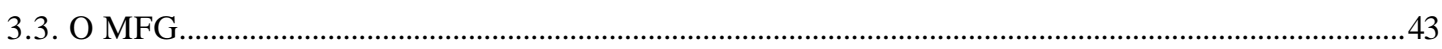

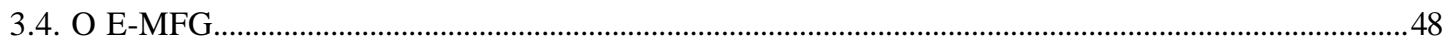

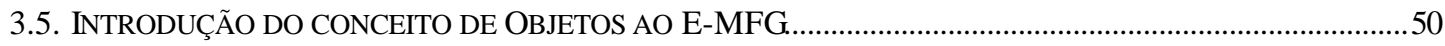

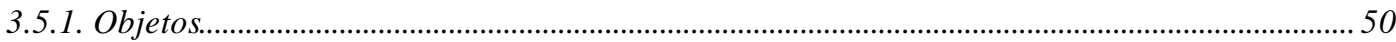

3.5.2. Migração de uma abordagem orientada exclusivamente para processos para uma abordagem híbrida orientada a processos e a objetos na modelagem de sistemas de movimentação

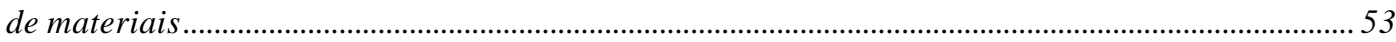

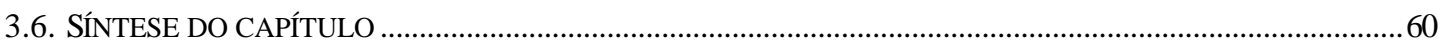

4. METODOLOGIA PARA A MODELAGEM DE SISTEMAS FLEXÍVEIS DE MOVIMENTAÇÃO DE MATERIAIS EM AMBIENTE FABRIL.................................................................61

4.1. MALHA DE MOVIMENTAÇÃO..................................................................................................................64

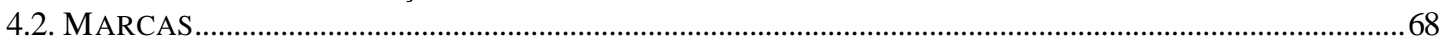

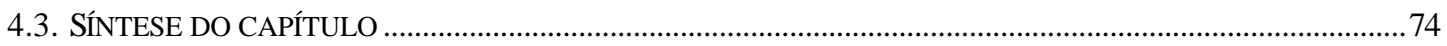

5. APLICAÇÃO PARA O PROJETO DE UM SISTEMA DE CONTROLE.............................................76

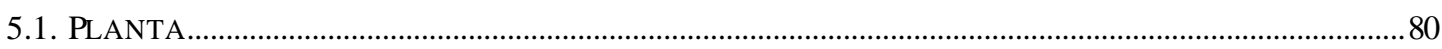

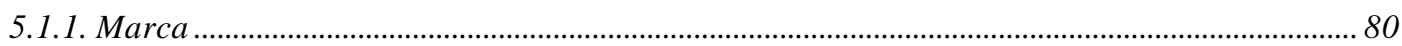

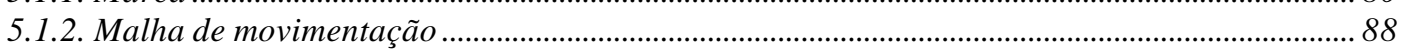

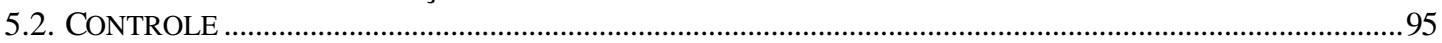

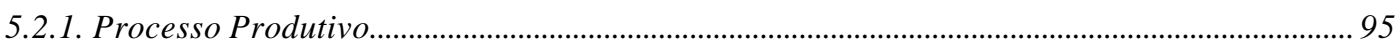

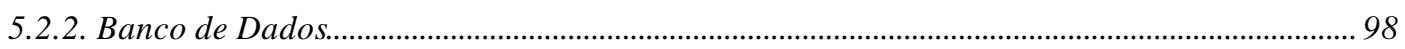

5.2.3. Sistema de monitoração de necessidades e solicitação de recursos de movimentação ........... 99

5.2.4. Heurística de designação de recursos de movimentação .......................................................... 102

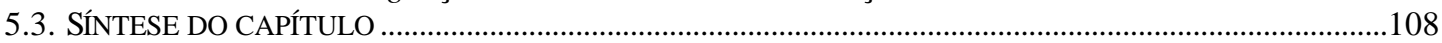

6. COMENTÁRIOS FINAIS E CONCLUSÕES.............................................................................................109

ANEXO A ......................................................................................................................................................................112 
B.1. MODELAGEM DO SISTEMA DE MOVIMENTAÇÃO DE MATERIAIS ENTRE EMPRESAS.

B.2. MODELAGEM DO SISTEMA DE MOVIMENTAÇÃO DE MATERIAIS ENTRE CENTROS DE CUSTOS DE UMA EMPRESA .121

B.3. MODELAGEM DO SISTEMA DE MOVIMENTAÇÃO DE MATERIAIS ENTRE MÁQUINAS DE UM CENTRO DE CUSTOS.

B.4. SÍNTESE DO ANEXO.... .125 


\section{Lista de figuras}

FIGURA 2.1 - EXEMPLO DE UMA POSSÍVEL SOLUÇÃO (B) PARA UM PROBLEMA DE CAIXEIRO VIAJANTE (TENDO COMO DADO DE ENTRADA (A) OU UM GRAFO DENSAMENTE CONEXO) [BODIN ET AL., 1983].

FIGURA 2.2 - EXEMPLO DE UMA POSSÍVEL SOLUÇÃO (B) PARA UM PROBLEMA DE MÚLTIPLOS CAIXEIROS VIAJANTES (TENDO COMO DADO DE ENTRADA (A) OU UM GRAFO DENSAMENTE CONEXO) [BODIN ET AL., 1983].

FIGURA 2.3 - EXEMPLO DO PROBLEMA DE CARTEIRO CHINÊS(A) GRAFO COM AS POSSÍVEIS CONEXÕES ENTRE OS NÓSE UMA POSSÍVEL SOLUÇÃO (D) [BODIN ET AL., 1983].

FIGURA 2.4 - EXEMPLO DE POSSÍVEL SOLUÇÃO (B) PARA UM PROBLEMA DE ROTEIRIZAÇÃO DE TRANSPORTADOR, TENDO COMO DADO DE ENTRADA (A) OU UM GRAFO DENSAMENTE CONEXO [BODIN ET AL., 1983]

FIGURA 2.5 - EXEMPLO DE POSSÍVEL SOLUÇÃO (B) PARA UM PROBLEMA DE ROTEIRIZAÇÃO DE TRANSPORTADOR COM MULTIPLOS CENTROS DE DISTRIBUIÇÃO (TENDO COMO DADO DE ENTRADA (A) OU UM GRAFO DENSAMENTE CONEXO) [BODIN ET AL., 1983]

FIGURA 2.6 - EXEMPLO DE POSSÍVEL SOLUÇÃO (B) PARA UM PROBLEMA DE CARTEIRO CHINÊS COM RESTRIÇÃO DE CAPACIDADE E COM DEMANDA LOCALIZADA NO ARCO (A) [BODIN ET AL., 1983].......22

FIGURA 2.7 - EXEMPLO DE ROTEIRIZAÇÃO COM RESTRIÇÃO DE COMPRIMENTO DE ROTA ((A) REPRESENTA UM PROBLEMA INICIAL E (B) UMA POSSÍVEL SOLUÇÃO) [BODIN ET AL., 1983].

FIGURA 2.8 - EXEMPLO DE POSSÍVEL SOLUÇÃO (B) PARA UM PROBLEMA DE ROTEIRIZAÇÃO SEM RESTRIÇÃO DE COMPRIMENTO DE ROTA INDICADO NO GRAFO (A) [BODIN ET AL., 1983] ..........................................26

FIGURA 2.9 - EXEMPLO DE SOLUÇÃO DE ROTEIRIZAÇÃO (B) COM DOIS TIPOS DE TRANSPORTADORES DO PROBLEMA (A) [BODIN ET AL., 1983]

FIGURA 2.10 - EXEMPLO DE SOLUÇÃO DE ROTEIRIZAÇÃO (B) COM MÚLTIPLOS DEPÓSITOS DO PROBLEMA (A) [BODIN ET AL., 1983]

FIGURA 2.11 - EXEMPLO DE SOLUÇÃO DE ROTEIRIZAÇÃO (B) COM CARGA TOTAL DE UM PROBLEMA (A) [BODIN ET AL., 1983]

FIGURA 2.12 - EXEMPLO DE SOLUÇÃO DE ROTEIRIZAÇÃO (B) COM CARGA PARCIAL DO PROBLEMA (A) [BODIN ET AL., 1983]

FIGURA 3.1 - REPRESENTAÇÃO DO CICLO DE ANÁLISE [PETERSON, 1981].

FIGURA 3.2 - REPRESENTAÇÃO DE UMA REDE DE PETRI [PETERSON, 198

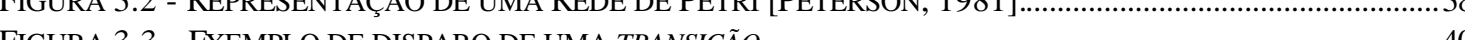

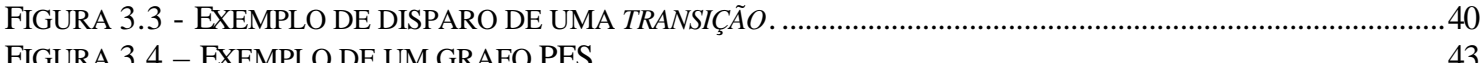

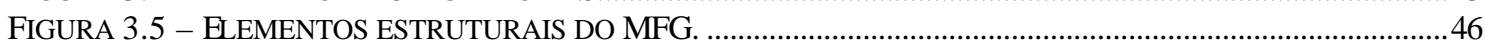

FIGURA 3.6 - MACRO ELEMENTOS DO MFG (N INDICA O NÚMERO ATUAL DE MARCAS DENTRO DO LUGAR).

FIGURA 3.7 - REPRESENTAÇÃO DE UM NOVO ELEMENTO (A) E UMA NOVA CARACTERÍSTICA (B)

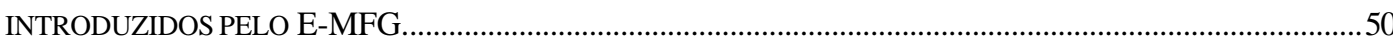

FIGURA 3.8 -ILUSTRAÇÃO DE UMA MALHA DE MOVIMENTAÇÃO. ................................................................54

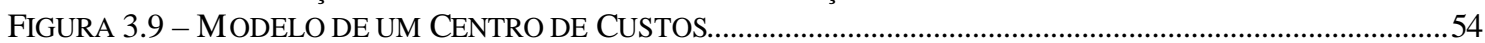

FIGURA 3.10 - EXEMPLO DE DETALHAMENTO DE UM SEGMENTO DE MALHA DE MOVIMENTAÇÃO. ...............55

FIGURA 3.11 - EXEMPLO DE MODELO DE TRANSPORTADOR. ............................................................................55

FIGURA 3.12 - INTEGRAÇÃO DOS MODELOS DOS CENTROS DE CUSTOS COM O MODELO DOS

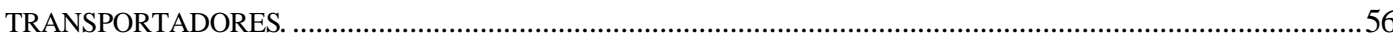

FIGURA 3.13 - INCLUSÃO DE MAIS UM CENTRO DE CUSTOS À MALHA ORIGINAL (FIGURA 3.8) ......................56

FIGURA 3.14 - ALTERAÇÃO DO MODELO DA FIGURA 3.12 AO SE INSERIR UM NOVO CENTRO DE CUSTOS....57

FIGURA 3.15 - POSSÍVEIS MODIFICAÇÕES NO MODELO AO SE ALTERAR O NÚMERO DE TRANSPORTADORES.

FIGURA 3.16 - NOVA REPRESENTAÇÃO PARA O MODELO DO CENTRO DE CUSTOS (FIGURA 3.9) AO SE ADOTAR A ABORDAGEM HÍBRIDA ORIENTADA A PROCESSOS E A OBJETOS. .............................................58

FIGURA 3.17 - REPRESENTAÇÃO DE ENCAPSULAMENTO DO MODELO DO TRANSPORTADOR (FIGURA 3.11).59 FIGURA 4.1 - METODOLOGIA PARA A MODELAGEM DE SISTEMAS DE MOVIMENTAÇÃO DE MATERIAIS EM

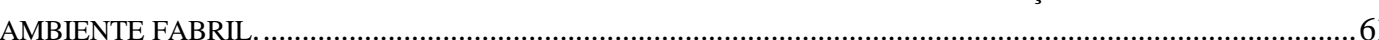

FIGURA 4.2 - MODELO REPRESENTATIVO DA MALHA DE MOVIMENTAÇÃO.......................................................64

FIGURA 4.3 - REPRESENTAÇÃO, EM PFS, DA REGIÃO EM DESTAQUE DA FIGURA 4.1.....................................65

FIGURA 4.4 - POSSÍVEIS DETALHAMENTOS DAS LIGAÇÕES ENTRE OS NÓS DA MALHA DE MOVIMENTAÇÃO (ATIVIDADE DE [TRANSPORTE ENTRE $I$ E $J]$ ). 
FIGURA 4.5 - POSSÍVEIS DETALHAMENTO DA ATIVIDADE [CENTRO DE CUSTO $I$ ] REFERENTE AO TRATAMENTO DOS TRANSPORTADORES. 69

FIGURA 4.6 - POSSÍVEIS DETALHAMENTO DA ATIVIDADE [CENTRO DE CUSTO $I$ ], SENDO ESTE UM NÓ GARAGEM / CENTO DE DISTRIBUIÇÃO.

FIGURA 4.7 - POSSÍVEL MODELO DE TRANSPORTADOR PARA O PROBLEMA DE PROGRAMAÇÃO E ROTEIRIZAÇÃO DE TRANSPORTADORES COM CARGA TOTAL

FIGURA 5.1 - PFS / E-MFG ILUSTRANDO A INTEGRAÇÃO DOS SUB MODELOS. ................................................79

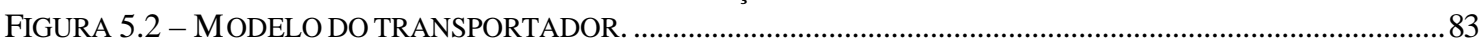

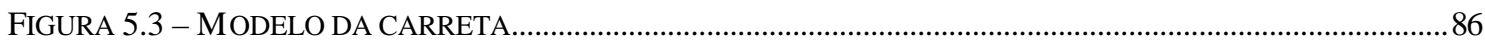

FIGURA 5.4 - MODELO REPRESENTATIVO DA MALHA DE MOVIMENTAÇÃO....................................................8

FIGURA 5.5 - REPRESENTAÇÃO PARCIAL DA MALHA ORIGINAL UTILIZANDO-SE O PFS...................................8

FIGURA 5.6 - DETALHAMENTO DAS LIGAÇÕES DE MOVIMENTAÇÃO (ATIVIDADE DE [TRANSPORTE ENTRE IE $J]$ ).

FIGURA 5.7 - DETALHAMENTO DA ATIVIDADE [CENTRO DE CUSTO $I$ ] REFERENTE AO TRATAMENTO DOS TRANSPORTADORES.

FIGURA 5.8 - DETALHAMENTO DA ATIVIDADE [TRATAMENTO DAS CARRETAS]...........................................93

FIGURA 5.9 - DETALHAMENTO DO PFS REFERENTE AO TRATAMENTO DOS MATERIAIS: (A) EM CENTROS DE CUSTOS ONDE OCORRE PROCESSAMENTO DE MATERIAIS , (B) EM CENTROS DE CUSTOS QUE DESEMPENHAM FUNÇÃO DE ALMOXARIFADO OU FONTE DE MATERIAIS E (C) EM CENTROS DE CUSTOS QUE DESEMPENHAM FUNÇÃO DE EXPEDIÇÃO OU “SORVEDOURO” DE MATERIAI. ....................................94

FIGURA 5.10 - REPRESENTAÇÃO GRÁFICA DOS PROCESSOS PRODUTIVOS UTILIZANDO O MODELO DA MALHA

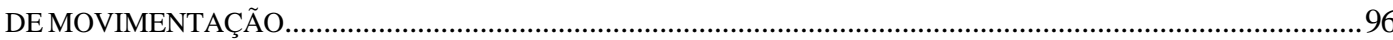

FIGURA 5.11 - DETALHAMENTO EM PFS / E-MFG DO PROCESSO PRODUTIVO ...............................................97

DO MATERIAL A: (A) DETALHAMENTO EM PFS; (B) DETALHAMENTO DA ATIVIDADE [MOVIMENTAÇÃO DE $I$ PARA $J$ ] E; (C) DETALHAMENTO DA ATIVIDADE [CENTRO DE CUSTOS $I$ ] .................................................99

FIGURA 5.12 - CURVAS NORMAIS: (A) 50\% DE NÍVEL DE ATENDIMENTO E (B) 70\% \%.....................................99

FIGURA 5.13 - MODELO DE UM COMPONENTE DO [SISTEMA DE MONITORAÇÃO DE NECESSIDADES E SOLICITAÇÃO DE RECURSOS DE MOVIMENTAÇÃO] .................................................................................101

FIGURA 5.14 - GRAFO QUE IDENTIFICA AS POSSIBILIDADES DE DESIGNAÇÃO DE TRANSPORTADORES E CARRETAS VAZIAS PARA ATENDEREM UMA NECESSIDADE DE MOVIMENTAÇÃO.....................................105

FIGURA 5.15 - GRAFO QUE IDENTIFICA AS POSSIBILIDADES DE DESIGNAÇÃO DE TRANSPORTADORES PARA ATENDEREM A NECESSIDADE DE MOVIMENTAÇÃO DE CARRETAS CHEIAS..............................................105

FIGURA 5.16 - GRAFO QUE IDENTIFICA AS POSSIBILIDADES DE DESIGNAÇÃO DE TRANSPORTADORES E CARRETAS, CONSIDERANDO OS CASOS DAS FIGURAS 5.14 E 5.15 SIMULTÂNEAMENTE.......................106

FIGURA 5.17 - GRAFO COM AS REQUISIÇÕES SELECIONADAS PARA SEREM ATENDIDAS PELOS RECURSOS DE MOVIMENTAÇÃO.

FIGURA 5.18 - VISUALIZAÇÃO TRIDIMENSIONAL DO PROBLEMA DE DESIGNAÇÃO DA FIGURA 5.17.............107

FIGURA A.1 - MODIFICAÇÃO DO ATRIBUTO §ROTA A SER TOMADA •(PARTE DO GRAFO DA FIGURA 5.7).........113

FIGURA A.2 - ATRIBUTO DAS MARCAS QUANDO O TRANSPORTADOR ENGATA A CARRETA (PARTE DO GRAFO

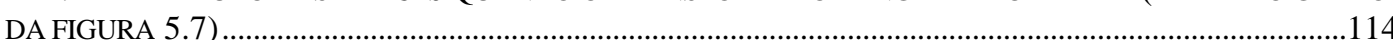

FIGURA A.3 - ALTERAÇÃO DOS ATRIBUTOSDAS MARCAS NA OPERAÇÃO DE ENGATE......................................114

FIGURA A.4 - FINAL DA OPERAÇÃO DE ENGATE (A INVERSÃO DAS LINHAS FOI FEITA APENAS PARA FACILITAR A INDICAÇÃO DOS ATRIBUTOS QUE SÃO LEVADOS EM CONSIDERAÇÃO) - (PARTE DO GRAFO DA FIGURA 5.7) ..............................................................................................................................114

FIGURA A.5 - MODIFICAÇÃO DO ATRIBUTO §ROTA A SER TOMADA •(PARTE DO GRAFO DA FIGURA 5.7)........115

FIGURA A.6 - O TRANSPORTADOR DEIXA A CARRETA (PARTE DO GRAFO DA FIGURA 5.7)............................115

FIGURA A.7 - ALTERAÇÃO DOS ATRIBUTOS DAS MARCAS NA OPERAÇÃO DE DESENGATE. ..............................116

FIGURA A.8 - FINAL DA OPERAÇÃO DE DESENGATE (A INVERSÃO DAS LINHAS FOI FEITA APENAS PARA FACILITAR A INDICAÇÃO DOS ATRIBUTOS QUE SÃO LEVADOS EM CONSIDERAÇÃO) - (PARTE DO GRAFO DA FIGURA 5.7).

FIGURA B.1 - MALHA DE MOVIMENTAÇÃO CONECTANDO EMPRESAS DE UMA MESMA CADEIA DE SUPRIMENTOS.

FIGURA B.2 - REPRESENTAÇÃO, EM PFS, DA MALHA DE MOVIMENTAÇÃO QUE INTERLIGA EMPRESAS (FIGURA B.1)

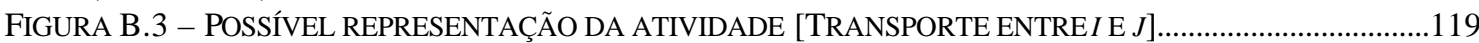

FIGURA B.4 - POSSÍVEL REPRESENTAÇÃO DA ATIVIDADE [EMPRESA $I]$ ].........................................................119

FIGURA B.5 - POSSÍVEL REPRESENTAÇÃO DE UM MODELO DE TRANSPORTADOR (CAMINHÃO) PARA REALIZAR A MOVIMENTAÇÃO DE MATERIAIS ENTRE EMPRESAS.

FIGURA B.6 - REPRESENTAÇÃO DE UMA POSSÍVEL MALHA DE MOVIMENTAÇÃO INTERNA A UM CENTRO DE CUSTOS 
FIGURA B.7 - REPRESENTAÇÃO, EM PFS, DA MALHA DE MOVIMENTAÇÃO QUE INTERLIGA AS MÁQUINAS

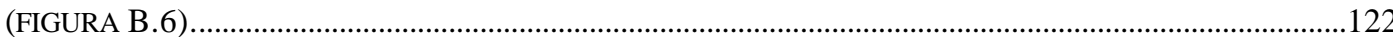

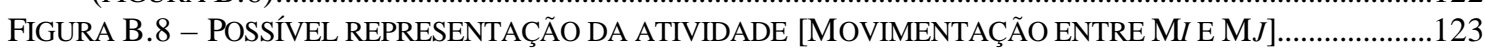

FIGURA B.9 - POSSÍVEL REPRESENTAÇÃO DA ATIVIDADE [MÁQUINA I] .........................................................123

FIGURA B.10 - POSSÍVEL DETALHAMENTO DA ATIVIDADE [PROCESSA MATERIAL]........................................124 FIGURA B.11 - POSSÍVEL REPRESENTAÇÃO DE UMA EMPILHADEIRA EMPREGADA NA MOVIMENTAÇÃO DE MATERIAIS ENTRE MÁQUINAS UTILIZANDO PALETES.. 


\section{Lista de siglas e abreviaturas}

AGV - Autonomous Guided Vehicle.

CPN - Colored Petri Net.

E-MFG - Enhanced Mark Flow Graph.

ERP - Enterprise Resource Planning.

F-MFG - Functional Mark Flow Graph

FIFO - First In, First Out (primeiro que entra é o primeiro que sai).

MFG - Mark Flow Graph.

$\mathrm{NP}$ - a ordem de complexidade (esforço computacional) cresce exponencialmente com o tamanho do problema.

OPN - Object Petri Net.

PFS - Production Flow Schema.

PFS-R - Production Flow Schema with Resources.

PNO - Petri Net Objects

PPCPE - Planejamento, Programação e Controle da Produção e Estoques.

RdP - Rede de Petri.

SED - Sistema a Eventos Discretos.

UML - United Modelling Language

VAT - Veículo Autônomo de Transporte. 


\section{Resumo}

Os sistemas de manufatura há muito vêm sendo objeto de interesse por profissionais e pesquisadores devido à busca de melhores técnicas visando o aumento da produtividade bem como pelo aumento da competitividade empresarial ao longo dos anos. Dentre seus componentes, o sistema de movimentação de materiais merece atenção especial pois, apesar de não aumentar o valor do produto, é responsável por manter o fluxo de materiais entre máquinas, células de manufatura, centros de custos ou mesmo entre empresas, que é imprescindível para qualquer sistema produtivo. Neste contexto, o presente trabalho propõe uma metodologia para a modelagem de sistemas flexíveis de movimentação de materiais e partes em ambiente fabril, focando-se em sistemas cuja movimentação possa ser realizada por VATs (Veículos Autônomos de Transporte).

Considerando-se o sistema de movimentação de materiais como sendo um sistema a eventos discretos (SEDs), pode-se empregar técnicas derivadas das Redes de Petri como o PFS (Production Flow Schema) e o E-MFG (Enhanced Mark Flow Graph) na modelagem de tais sistemas. Para tanto, foram introduzidos conceitos de orientação a objetos ao E-MFG de forma a ampliar sua capacidade de modelagem, possibilitando a migração de um paradigma de modelagem orientada a processos para um de modelagem híbrida orientada a processos e a objetos.

Como estudo de caso, apresenta-se a modelagem de uma simplificação do sistema de movimentação de materiais da Mercedes Benz do Brasil, situada em São Bernardo do Campo, São Paulo, para a qual se aplica a metodologia proposta.

Palavras-chaves: Sistemas a Eventos Discretos, Rede de Petri, Modelagem de Sistemas de Movimentação de Materiais, Simulação Discreta. 


\section{Abstract}

Manufacturing systems have been object of interest of many professionals and researchers through the years due to the search of better methods for raising goods productivity and managerial competitiveness. Among its components, the material movement system deserves special attention because even not increasing the product value, it is responsible for keeping the flow of materials between machines, manufacturing cells, cost centers and also between companies, which is indispensable for any productive system. In this context, this work proposes a methodology for modeling flexible systems for materials and parts movement in the industrial environment, focusing on systems whose movement can be performed by AGVs (Autonomous Guided Vehicles).

Considering the materials movement system as a Discrete Event System (DES), techniques derived from Petri Nets as PFS (Production Flow Schema) and E-MFG (Enhanced Mark Flow Graph) can be used for modeling those systems. To this purpose, concepts of object orientation are introduced to E-MFG in order to increase its modeling capacity, allowing the migration from the process oriented modeling paradigm to an hybrid object and process oriented modeling.

A simplification of the materials movement system of the plant of "Mercedes Benz do Brasil", which is located in São Bernado do Campo, São Paulo, was used as a study case to illustrate the methodology presented.

Key-words: Discrete Event Systems, Petri Nets, Materials Movement Systems Modeling, Discrete Simulation. 


\section{Introdução}

Por dois séculos, até aproximadamente 1960, a história da industrialização foi caracterizada pelo aumento da produtividade. Dentre os meios para isso estão a divisão do trabalho, mecanização e aumento da escala, entre outros por exemplo, [Bolwijn \& Kumpe, 1990].

Segundo estes autores, até 1960 o mercado mundial era caracterizado pelo aumento quantitativo da produção onde pode-se dizer que tudo o que se produzia podia ser vendido e, nesta época, embora o preço fosse um fator para se aumentar as vendas, a pressão que se exercia não era grande.

A partir de então esta situação começa a mudar. Para continuarem crescendo, as empresas necessitavam estender seus "braços" para outras regiões ou países. Iniciou-se uma competição por preços fazendo com que muitas empresas fossem restruturadas, até mesmo mudassem de região ou país. O preço se tornou um fator importante para o sucesso visto que os clientes podiam selecionar preços comparando produtos feitos em diversos países.

No final dos anos 60 a competição mudou novamente. Os consumidores passaram a se questionar sobre a qualidade, tempo gasto no concerto, etc. dos produtos adquiridos. Eles passaram a prestar mais atenção na qualidade dos produtos comprados, fazendo com que isto se tornasse um importante fator para o sucesso de uma empresa.

Uma nova mudança se iniciou no final dos anos 70 onde os consumidores passaram a exercer o poder de escolha e a capacidade das empresas aparentemente excedia a demanda. As empresas tiveram que se modernizar, reduzir o intervalo de tempo entre o lançamento de novos produtos para poderem conquistar um público mais exigente em várias partes do mundo. 
Dos anos 90 em diante passa a ter importância um novo fator: inovação, a habilidade de renovar rapidamente e não apenas de se adaptar e é neste período que estamos ou ao menos deveríamos estar.

Outro aspecto que pode ser notado é que nem todas as empresas entraram e / ou saíram destas fases ao mesmo tempo, e nem mesmo os departamentos ou setores de uma empresa o fizeram de modo simultâneo. Estas mudanças aconteceram e vêem acontecendo de forma gradual e com diferentes velocidades [Bolwijn \& Kumpe, 1990].

Em outras palavras, Muscat \& Fleury [1993] classificam as estratégias competitivas, no que diz respeito à manufatura, como podendo ser de cinco tipos:

- custos - é adequada apenas nos casos de produtos cujos mercados apresentam pequena competição; os produtos são padronizados e há baixo nível de exigência por parte dos clientes;

- qualidade - é adequada quando a satisfação das necessidades dos clientes é vista como primordial;

- tempo - que comporta duas possibilidades básicas: (a) assegurar qualidade aos clientes no menor prazo possível; e (b) atender aos clientes dentro de uma faixa de tempo, com a menor variação possível;

- flexibilidade - diz respeito à capacidade de mudança do que é oferecido pelo sistema de produção ao cliente, para atender as suas necessidades que se alteram no curto prazo;

- inovação - é a estratégia utilizada pelas empresas que desejam estar sempre à frente de seus competidores em termos de um produto diferenciado e com características sem precedentes. 
Ainda com relação a estas estratégias, verifica-se que na prática das empresas mais capacitadas (competitivas) do mundo existe uma evolução temporal no emprego das estratégias, que é caracterizada pela seguinte sequiência [Muscat \& Fleury, 1993]: (1) custos, (2) qualidade, (3) tempo, (4) flexibilidade e (5) inovação.

Conforme verificado nas empresas, a utilização das estratégias se dá cumulativamente [Muscat \& Fleury, 1993]. Assim, se a empresa adota a estratégia de qualidade, ela está adotando, ao mesmo tempo, a estratégia de custos. No último estágio de evolução, a empresa participará do mercado segundo a estratégia de inovação e terá também as competências necessárias à competição por flexibilidade, tempo, qualidade e custos. A acumulação de competências está altamente correlacionada com o sucesso da empresa em ambientes complexos e dinâmicos. Caso a mudança estratégica não ocorra cumulativamente, a empresa terá pontos fracos que a deixarão vulnerável com relação aos competidores.

De acordo com pesquisa realizada pela Fundação Vanzolini [Muscat \& Fleury, 1993], por força das condições que prevaleceram no mercado brasileiro as empresas multinacionais estavam em geral preocupadas com o monitoramento de seus custos. Também foi observado que as empresas brasileiras e as "multinacionais brasileiras" estavam mais preocupados com questões de qualidade, mesmo sabendo que a melhoria dos custos era essencial para a sua competitividade.

Este quadro aparenta ser um reflexo dos tempos de alta inflação e de protecionismo praticado através de altas taxas alfandegárias impostas aos produtos importados, reduzindo sua competitividade - devido ao seus alto custo de aquisição por parte dos clientes - e possibilitando que as empresas no Brasil pudessem postergar a sua modernização (seja ela em termos tecnológicos, seja em termos de gestão). 
Com base no exposto por Bolwijn \& Kumpe [1990] e por Muscat \& Fleury [1993], pode-se notar que enquanto as empresas estrangeiras estão entrando na era da competição por inovação a maioria das empresas no Brasil está num processo de transição da era da qualidade para a era do tempo, sendo que muitas ainda não se encontram suficientemente capacitadas em custos para garantir uma maior competitividade.

Outro ponto importante é que muitas empresas não conseguem atingir as competências necessárias para serem competitivas após a abertura dos mercados e entram em processo de sucateamento. Outras passam a incorporar filosofias estratégicas com relação a tempo, flexibilidade, etc. sem ao menos terem consolidado sua capacitação em qualidade e custos, o que faz com que elas não tenham condições de usufruir as vantagens de uma empresa competitiva.

Dentro deste contexto, este trabalho enfoca o problema e a necessidade de uma técnica para aprimorar o sistema de movimentação de partes / materiais em instalações industriais, que está diretamente relacionado tanto a custos quanto a tempos de produção e que é um pré-requisito fundamental para se assegurar a flexibilidade do sistema produtivo. Além disso, sem o domínio deste tipo de sistema não se pode pensar em inovação. Dentre as possíveis soluções de movimentação de materiais em sistemas produtivos, a investigação será focalizada nos sistemas com VATs (veículos autônomos de transporte) que incluem não somente os sistemas com AGVs (Autonomous Guided Vehicles) como também sistemas com operadores de empilhadeiras e/ou os transportadores que percorrem as instalações movimentando materiais entre os diversos 
centros de custo ${ }^{1}$ em função do seu alto grau de versatilidade dentro de um sistema produtivo.

A movimentação de materiais em sistemas produtivos, assim como outras tarefas, pode ser abordado como uma sucessão de eventos discretos e modelados como um SED (sistemas a eventos discretos) [Ho \& Cao, 1991]. Desta forma, pode-se utilizar ferramentas como as Redes de Petri [Cardoso \& Valette, 1997; Reisig, 1982; 1992] e seus derivados como o PFS/MFG² [Miyagi, 1996] (incluindo-se também suas variações como o PFS-R/E-MFG ${ }^{3}$ [Santos Filho,1998]) a fim de desenvolver-se modelos próprios para o problema em questão.

Existem também outras ferramentas que podem ser utilizadas na análise destes sistemas tais como os softwares de simulação discreta (por exemplo: ProModel, Arena, AutoMod, etc. [Baird \& Leavy, 1994; Banks, 1995]), porém estas ferramentas possuem restrições para a especificação e implementação de estratégias de controle, inclusive para sistemas de movimentação de materiais - exemplo disso é o software ProModel onde os materiais são processados nos centros de custos através de uma única lógica FIFO (“first in, first out”) e os recursos de movimentação só podem ser programados segundo procedimentos pré-definidos. Além disso, técnicas de simulação discreta envolvem a abstração de conceitos e decisões para a análise do sistema que não podem ser diretamente implementados ou convertidos em especificações de controle. Por outro lado, teorias como as Redes de Petri foram concebidas para a especificação funcional de sistemas concorrentes. Assim justifica-se um estudo de como as potencialidades destas

\footnotetext{
${ }^{1}$ Centro de custo é todo local onde se realiza uma atividade ou um conjunto de atividades nos materiais que ali são levados.

${ }^{2}$ PFS - Production Flow Schema; MFG - Mark Flow Graph.

${ }^{3}$ PFS-R - PFS com Recursos; E-MFG - MFG Estendido.
} 
abordagens podem ser combinadas para estudo e projeto de sistemas de movimentação de partes no contexto de sistemas produtivos.

Salienta-se aqui, que o trabalho proposto está relacionado principalmente às propostas introduzidas por Miyagi [1996] e Santos Filho, D. J. [1998].

\subsection{Objetivo}

O objetivo deste trabalho é estudar e desenvolver uma metodologia ${ }^{4}$ para a construção de modelos de sistemas $^{5}$ de movimentação de materiais em instalações fabris, enfatizando-se a utilização de VATs (os quais concedem maior flexibilidade ao processo produtivo), para que tanto possam ser utilizados em análises através de simulação como para a implementação de estratégias de controle.

Para tanto, adota-se uma abordagem baseada na teoria de sistemas a eventos discretos e na aplicação de técnicas derivadas de Redes de Petri, como a metodologia PFS/E-MFG, mediante a qual são desenvolvidos modelos do objeto de controle, que servirão como suporte para a especificação do controle.

\subsection{Organização do texto}

Apresenta-se no capítulo 2 os principais sistemas de movimentação de materiais utilizados em ambiente industrial, enfocando os sistemas flexíveis cuja movimentação se dá por veículos (tratores, VATs, empilhadeiras, etc.). Ainda neste contexto, apresentam-se os problemas característicos de organização da movimentação de materiais utilizando-se transportadores mais comumente encontrados em bibliografias.

\footnotetext{
${ }^{4}$ Abstraindo metodologia como sinônimo de um conjunto de métodos.

${ }^{5}$ Sistema é um conjunto de componentes separados que interagem entre si. [Peterson, 1981].
} 
No capítulo 3 aborda-se ferramentas / metodologias empregadas na modelagem de sistemas a eventos discretos, enfatizando-se a metodologia PFS / E-MFG (redes derivadas da teoria de Redes de Petri) e propõe-se a utilização do E-MFG de forma híbrida orientada a processos e a objetos na modelagem de sistemas flexíveis de movimentação de materiais.

É apresentado no capítulo 4 a metodologia proposta para a modelagem de sistemas flexíveis de movimentação de materiais em ambiente fabril.

No capítulo 5, é apresentado um estudo de caso baseado em um problema real, onde se emprega a metodologia apresentada no capítulo 4 e é demonstrado como o modelo obtido pode ser convertido para a especificação e operacionalização de um sistema de controle.

Por fim, no capítulo 6 são apresentadas as observações finais e as principais conclusões obtidas, bem como sugestões para realização de trabalhos futuros. 


\section{Sistema de movimentação de materiais}

Neste capítulo procura-se apresentar de forma abrangente os sistemas de movimentação de materiais comumente encontrados nas empresas. Inicialmente estes são classificados como fixos ou flexíveis de acordo com suas características. Na seqüência, enfoca-se os sistemas flexíveis que realizam a movimentação de materiais através de veículos onde são apresentados alguns dos problemas característicos e possíveis soluções na organização da movimentação dos transportadores.

Com relação aos sistemas de movimentação de materiais apresentados [Martins \& Laugeni, 1998], é possível classificá-los em fixos ou flexíveis, onde cada um será discutido individualmente a seguir:

\subsection{Fixos}

São sistemas de movimentação de materiais que possuem seu movimento limitado por trilhos ou guias e mudanças no arranjo físico das instalações implicam em mudanças nos equipamentos de transporte. Dentre os equipamentos disponíveis, podese citar entre outros:

- correias - os transportadores de correias são em geral utilizados para transportar grande quantidade de materiais (muito comum para transporte de minérios). Podem atingir alguns quilômetros de comprimento mas sua versatilidade permite também a sua utilização em trechos menores para o transporte econômico de volumes. São utilizados também no transporte de sacos e possui como principais vantagens o fato de reduzirem a necessidade de mão-de-obra e a possibilidade de variação do ritmo de trabalho; 
- correntes - este tipo de transporte resolve satisfatoriamente os problemas de contaminação nos processos de pintura, tratamento térmico e limpeza. Trata-se de um sistema de roletes, apoiados na aba inferior de duas vigas "I" em paralelo e uma corrente sem fim para a movimentação. Possuem como vantagem o fato de poderem ser utilizados nas três dimensões e movimentam materiais de vários tamanhos, pesos, formas, inclusive a elevadas temperaturas. Possui custos de instalação, manutenção, energia elétrica e peças para reposição relativamente baixos;

- fitas metálicas - indicados quando se necessita atravessar fornos, câmaras frigoríficas ou de secagem, trabalhar com material que necessite de leito de chapa perfurada, transportar peças metálicas na vertical ou sobre leito imantado;

- roletes - praticamente não há manutenção e todos ou quase todos os materiais não a granel podem ser transportados por este sistema, em caixas ou sobre pranchas de madeira, engradados ou diretamente em contato com os roletes, dependendo do formato ou tipo de carga;

- roscas - indicados para o transporte de materiais pulverizados ou granulados não abrasivos ou corrosivos em distâncias não superior a 60 metros. São comumente usados em silos, moinhos, indústria farmacêutica, etc.;

- vibratórios - este é composto basicamente de uma calha ou tubo posto em oscilação mecânica por um conjunto atuador que produz vibrações lineares;

- magnéticos - são empregados para movimentarem peças de ferro, aço ou folhas-deflandres; funcionam até debaixo d'água, permitem mudança de posição das peças transportadas, requer pouco espaço para a instalação, pouca manutenção, pode envolver qualquer ângulo de inclinação no transporte industrial, trabalha silenciosamente e permite o aproveitamento das áreas situadas em planos elevados; 
- pneumáticos - são utilizados na movimentação de materiais a granel granulados ou em pó, podendo funcionar em qualquer tipo de trajetória - retos, curvos, ascendentes ou descendentes. Como vantagens, este desfruta de vedação completa, pequeno espaço ocupado pela sua aparelhagem, versatilidade do sistema, baixo custo de manutenção. Possuem baixa flexibilidade pois as rotas são pré determinadas e mudanças de arranjo físico exigem mudança na instalação das esteiras e em muitos casos a compra de novas devido ao seu aspecto "Taylor Made";

- pontes rolantes - são utilizadas no transporte e elevação de cargas em instalações industriais como fundições, usinas siderúrgicas, linhas de montagem, etc. Empregadas em instalações que permitem o aproveitamento total da área útil sob a ponte rolante;

- talhas - similares às pontes rolantes, estas possuem menor capacidade de carga; podem possuir intercambialidade de trilhos que permitam uma maior flexibilidade porém esta flexibilidade é limitada às regiões cobertas pelos trilhos e uma mudança no arranjo físico implicaria em alto tempo de mudança nos trilhos;

- guindastes - são compostos de coluna e lança com guincho, acionado por dispositivo mecânico ou elétrico. São em geral montados sobre veículos com motor a explosão que fornece também a força necessária para a operação do guindaste. A aplicação desta modalidade de equipamento é recomendada no transporte interno e quando as cargas pesam mais de 5 toneladas;

- elevadores - utilizado na elevação de pessoas, cargas, veículos, etc. Os elevadores de carga se assemelham aos utilizados no transporte de pessoas, exceto pelo fato de serem mais rústicos e em geral possuem maior capacidade de carga de acordo com a sua aplicação. 


\subsection{Flexíveis}

São sistemas de movimentação de materiais onde mudanças no arranjo físico não implicam em mudanças nos equipamentos de transporte, pois os movimentos não sofrem limitações físicas por trilhos, por exemplo. Pode-se citar entre outros:

- empilhadeiras - quando se necessita de transporte e da capacidade de empilhar carga;

- transportadores - são principalmente utilizados no meio industrial para a movimentação de cargas nos pátios e de peças entre os centros de custo. Por poderem transportar uma grande variedade de materiais (basta para isso alterar a sua interface - carreta, palete, etc. - com o material / carga) podem ser considerados sistemas de movimentação de alta flexibilidade;

- trailers e veículos especiais para transporte a granel - estes podem ser considerados acessórios acoplados às empilhadeiras ou aos transportadores, como as carretas anteriormente citadas;

- manual - o mais flexível, porém com pequena capacidade de carga e alto risco de provocar lesões e problemas de saúde no operador.

Atentando-se para a garantia da competitividade das empresas, seja pela produtividade, flexibilidade e / ou qualidade dos produtos e serviços, um dos sistemas mais complexos e reconhecido como de maior potencial dentre os sistema de movimentação anteriormente expostos, são os sistemas de veículos industriais (empilhadeiras, transportadores, VATs, tratores, etc.), que podem ter seus caminhos e movimentos dinamicamente alterados (visto que não possuem seus movimentos limitados por trilhos ou guias) e podem transportar uma grande diversidade de 
materiais, bastando para isto alterar a sua interface com o material (utilizar carretas específicas).

Devido a esta importância, no item seguinte aborda-se os problemas de roteirização e programação de tarefas mais citados na literatura e também aplicáveis aos sistemas de movimentação de materiais com veículos industriais.

\subsection{Principais problemas de movimentação de materiais empregando-se transportadores industriais.}

Observa-se que foram identificados poucos documentos científicos específicos sobre a movimentação de materiais em ambiente fabril, porém nota-se que os mesmos conceitos e modelos empregados em problemas de distribuição e roteirização podem ser empregados quando se aborda sistemas flexíveis de movimentação de materiais em ambiente fabril.

Neste contexto, Bodin et al. [1983] fazem uma revisão de artigos e livros publicados sobre o assunto até aquela época onde cita-se que a minimização de custos é o principal objetivo da maioria das técnicas de roteirização de itens e de programação de tarefas e que porém podem haver outros objetivos muito mais relevantes como segurança e conveniência.

As saídas para os sistemas de roteirização e de programação são basicamente as mesmas: para cada item (transportador, por exemplo), define-se a rota (seqüência de locais a serem visitados) e os horários (identifica os horários em que o item deve atender a cada um dos pontos). O único ponto que distingue os sistemas são as restrições impostas a cada um, que podem variar desde a restrição de horário às restrições de recursos [Bodin et al., 1983]. 
Estes autores também citam uma tabela com as características dos problemas de roteirização e de programação (tabela 2.1):

De acordo com as restrições, ainda, pode-se ter diferentes tipos de problemas a seguir detalhados.

\subsubsection{Problemas de roteirização de transportadores}

Este caso envolve a determinação de uma sequiência de atividades, independentes de horário, ou seja, não há restrições sobre o horário em que um determinado pedido deva ser atendido. É um problema puramente espacial. As abordagens mais conhecidas, de acordo com o caso são:

\section{A. Caixeiro viajante}

Neste caso, procura-se determinar o menor custo de um ciclo impondo que o transportador: possui capacidade infinita e passe por todos os nós apenas uma vez (figura 2.1). Este é um problema classificado como "NP $P^{6}$ hard" e o algoritmo que fornece a solução ótima consome tempo de processamento superior às técnicas heurísticas ${ }^{7}$, fazendo com que as pesquisas caminhem na busca de heurísticas capazes de resolver com eficiência e rapidez um dado problema.

\footnotetext{
${ }^{6} \mathrm{NP}$ - a ordem de complexidade (esforço computacional) cresce exponencialmente com o tamanho do problema.

7 Uma heurística pode ser definida como um procedimento que busca uma solução para um dado problema gerando uma seqüência de estados pela aplicação de uma função denominada vizinha. Esta função considera um estado do espaço de busca, de onde se gera um conjunto de estados que são adicionados na sequiência de estados previamente mencionada. A melhor solução encontrada no final deste processo não é usualmente o ótimo global, mas uma "boa" solução. As heurísticas podem ser classificadas em dois tipos: heurísticas de busca global e local. Nas de busca local, cada estado é uma tarefa total para as variáveis do problema, e então, o espaço de busca corresponde ao conjunto de soluções factíveis do problema. Na busca global, por outro lado, o estado não corresponde necessariamente às soluções factíveis do problema já que o conjunto de soluções factíveis é um subconjunto do espaço total de busca [Rodriguez et al., 1998].
} 
Tabela 2.1 - Relação de problemas de roteirização de transportadores [Bodin et al., 1983]

\begin{tabular}{|l|l|}
\hline Característica & Opções possíveis \\
\hline $\begin{array}{l}\text { Tamanho da } \\
\text { frota }\end{array}$ & $\begin{array}{l}\text { Um veículo } \\
\text { Múltiplos veículos }\end{array}$ \\
\hline Tipo da frota & $\begin{array}{l}\text { Homogênea (veículo de um tipo) } \\
\text { Heterogênea (veículos de múltiplos tipos) } \\
\text { Veículos especiais }\end{array}$ \\
\hline $\begin{array}{l}\text { Base (ou ponto } \\
\text { de distribuição) }\end{array}$ & $\begin{array}{l}\text { Uma instalação } \\
\text { Múltiplas instalações }\end{array}$ \\
\hline $\begin{array}{l}\text { Natureza da } \\
\text { demanda }\end{array}$ & $\begin{array}{l}\text { Deterministica (conhecida) } \\
\text { Estocástica } \\
\text { Satisfação parcial da demanda admitida }\end{array}$ \\
\hline $\begin{array}{l}\text { Localização da } \\
\text { demanda }\end{array}$ & $\begin{array}{l}\text { Nos nós } \\
\text { Nos arcos } \\
\text { Mista }\end{array}$ \\
\hline $\begin{array}{l}\text { Característica } \\
\text { da rede }\end{array}$ & $\begin{array}{l}\text { Direcionada } \\
\text { Não direcionada } \\
\text { Mista } \\
\text { Euclidiana }\end{array}$ \\
\hline $\begin{array}{l}\text { Restrições } \\
\text { capacidade de } \\
\text { veículo }\end{array}$ & $\begin{array}{l}\text { Imposta (a mesma para todos) } \\
\text { Imposta (transportadores de capacidade diferente) } \\
\text { Não imposta (capacidade ilimitada) }\end{array}$ \\
\hline $\begin{array}{l}\text { Máximo tempo } \\
\text { de viagem }\end{array}$ & $\begin{array}{l}\text { Imposto (o mesmo para todas as rotas) } \\
\text { Imposto (diferente para diferentes rotas) } \\
\text { Não imposto }\end{array}$ \\
\hline Operações & $\begin{array}{l}\text { Apenas carga } \\
\text { Apenas descarga } \\
\text { Mista (carga e descarga) } \\
\text { Cargas parciais (carga e descarga) }\end{array}$ \\
\hline Vustos & $\begin{array}{l}\text { Fixóveis ou custos de transporte } \\
\text { Custos de transporte comuns }\end{array}$ \\
\hline Objetivos & $\begin{array}{l}\text { Minimizar o custo total das rotas } \\
\text { Minimizar a soma dos custos fixos e variáveis } \\
\text { Minimizar o número de veículos requisitados } \\
\text { Maximizar a função utilidade baseada no serviço ou conveniência } \\
\text { Maximizar a função utilidade baseada na prioridade do cliente }\end{array}$ \\
\hline
\end{tabular}




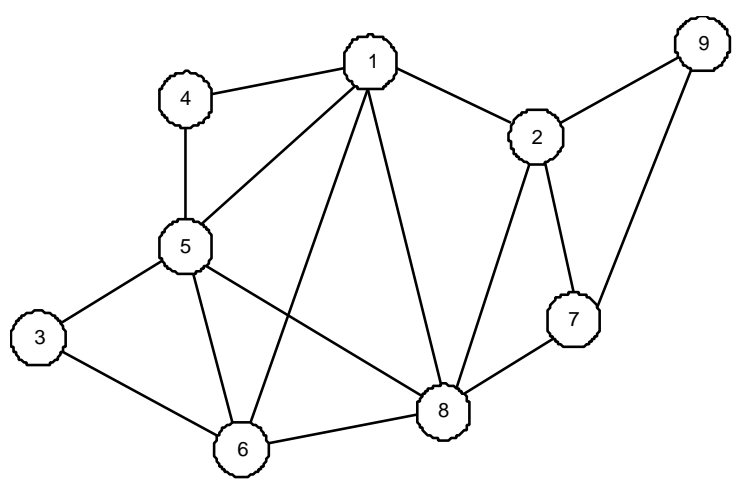

(a)

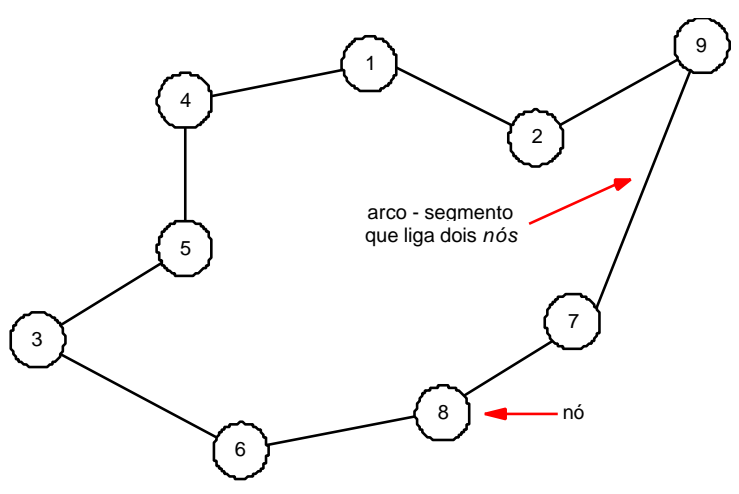

(b)

Figura 2.1 - Exemplo de uma possível solução (b) para um problema de caixeiro viajante (tendo como dado de entrada (a) ou um grafo densamente conexo ${ }^{8}$ ) [Bodin et al., 1983].

Bodin et al. [1983] apresentam várias heurística, dentre elas, a proposta por Rosenkrantz se destaca das demais por apresentar simultaneamente menor número de operações computacionais $\left(\mathrm{n}^{2}\right.$, onde $\mathrm{n}$ é o número de nós da rede) e o menor comprimento de rota $\left(\frac{1}{2} \log _{2}(n)+\frac{1}{2}\right.$ a rota que seria obteria utilizando um algoritmo $)$ quando se analisa o pior caso. Sua heurística consiste em:

- começar com qualquer nó como início do caminho;

- achar o nó mais próximo do último nó incluído no caminho. Incluir este nó no caminho;

- repetir a etapa anterior até todos os nós estarem contidos no caminho. Então, unir o primeiro e o último nós.

Pearn [1998] desenvolveu também uma variação para o problema do caixeiro viajante - o Problema do Comprador Viajante. Este é um problema que pode ser utilizado no contexto de compra de partes e materiais para a sua manufatura visando-se a minimização dos custos de transporte e da mercadoria comprada. Sua heurística inicia 
com uma solução inicial que possui o menor custo de transporte e compra da primeira mercadoria de uma lista. A cada iteração a heurística considera o próximo item e avalia se é possível reduzir os custos. A heurística termina quando forem considerados todos os itens da lista de compras e nenhuma redução adicional de custos puder ser realizada.

\section{B. Múltiplos caixeiros viajantes}

É uma generalização do problema anterior. Considera-se que os transportadores iniciam suas rotas a partir de um único ponto de distribuição. Não há restrições quanto ao número de nós visitados pelos transportadores, apenas que cada um deve visitar todos os nós pertencentes à sua rota e que um nó não pode pertencer a duas rotas e seu objetivo é minimizar a distância total percorrida pelos transportadores (figura 2.2).

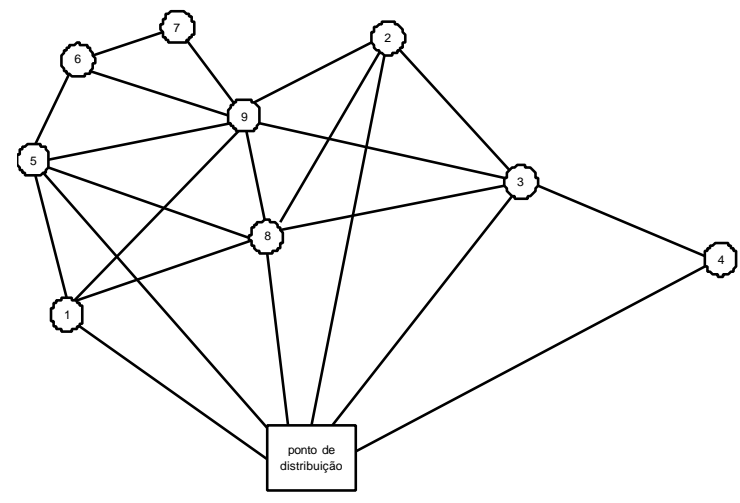

(a)

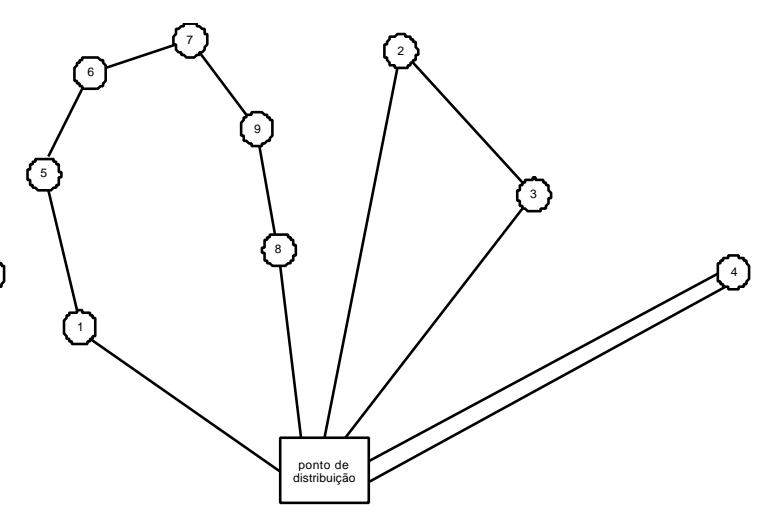

(b)

Figura 2.2 - Exemplo de uma possível solução (b) para um problema de múltiplos caixeiros viajantes (tendo como dado de entrada (a) ou um grafo densamente conexo) [Bodin et al., 1983].

\footnotetext{
${ }^{8}$ Trata-se de um grafo onde cada nó está diretamente ligado (isto é, existe um caminho) à todos os demais nós do grafo.
} 
Uma proposta de Bodin et al. [1983] é criar um número de centros de distribuição igual ao número de transportadores e se solucionar o problema como no caso do caixeiro viajante. Cada seguimento de rota intercalado por centros de distribuição é uma rota pertencente a um dos transportadores.

\section{Carteiro chinês}

Neste caso, procura-se determinar o menor custo impondo que o transportador passe por todos os arcos ao menos uma vez (figura 2.3).

Em Christofides [1986] encontra-se um algoritmo para solucionar este problema, que consiste em:

- passo 1 - construir a matriz de custos mínimos entre os nós que possuem número ímpar de arcos conectando-os a outros nós, utilizando um algoritmo de caminho mínimo;

- passo 2 - ligar os nós selecionados, aos pares, de forma a se ter o menor custo total (figura $2.3(b)$ );

- passo 3 - criar arcos "artificiais" paralelos aos arcos obtidos no passo anterior (figura $2.3(\mathrm{c})$ );

- passo 4 - a soma dos custos de todos os segmentos do caminho formado é o caminho de menor custo (um exemplo de caminho é a sequiência $1 \rightarrow 2 \rightarrow 1 \rightarrow 5 \rightarrow$ $2 \rightarrow 3 \rightarrow 5 \rightarrow 3 \rightarrow 4 \rightarrow 5 \rightarrow 6 \rightarrow 1)$ 


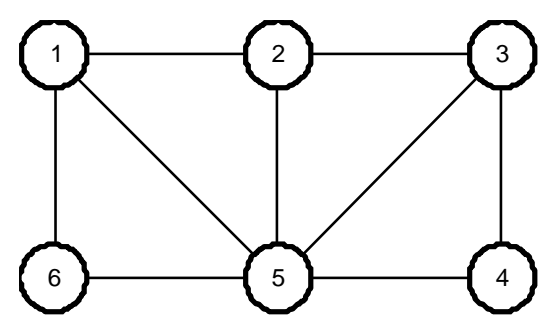

(a)

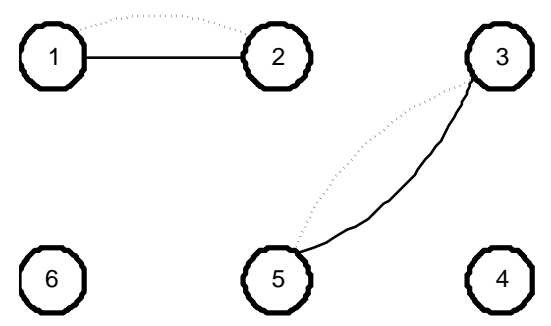

(c)

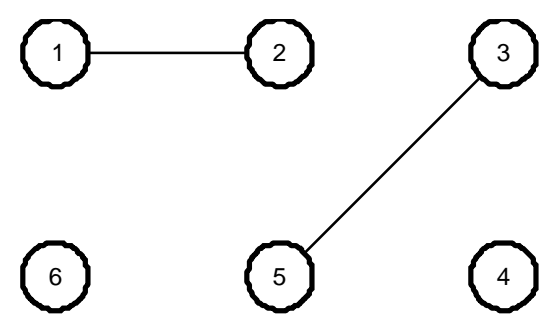

(b)

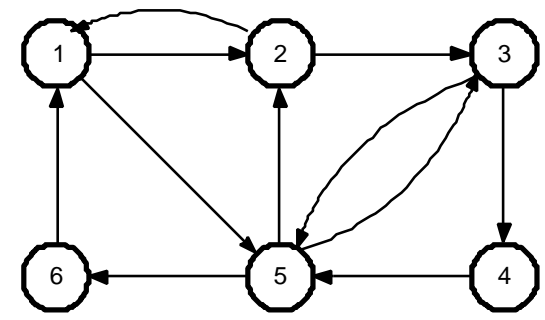

(d)

Figura 2.3 - Exemplo do problema de carteiro chinês (a) grafo com as possíveis conexões entre os nós e uma possível solução (d) [Bodin et al., 1983].

Pearn et al.[1998] desenvolveram uma heurística para uma variante deste problema considerando-se um mix de $\operatorname{arcos}$ orientados e $\operatorname{arcos}$ não orientados. Esta heurística é composta de duas sub rotinas:

- rotina 1 - converte-se o grafo em uma rede uniforme (todas os sentidos dos arcos são ignoradas e resolve-se como o problema do carteiro chinês); transforma-se o grafo em uma rede simétrica (acha-se os caminhos de menor custo); eliminam-se ou criam-se $\operatorname{arcos}$ considerando-se as orientações do grafo original; elimina-se os ciclos;

- rotina 2 - transforma-se o grafo em um rede simétrica (constrói-se um novo grafo, encontra-se o fluxo de menor custo, constrói-se uma rede simétrica); converte-se o novo grafo como um circuito de Euler ${ }^{9}$.

\footnotetext{
${ }^{9}$ Um circuito de Euler é um circuito que atravessa todos os arcos do grafo uma e somente uma vez [Christofides, 1986].
} 


\section{Roteirização por nós, com um ponto de distribuição e vários transportadores}

Assume-se um único ponto de distribuição de onde partem os vários transportadores de capacidade finita, onde se visa minimizar a distância percorrida (figura 2.4).

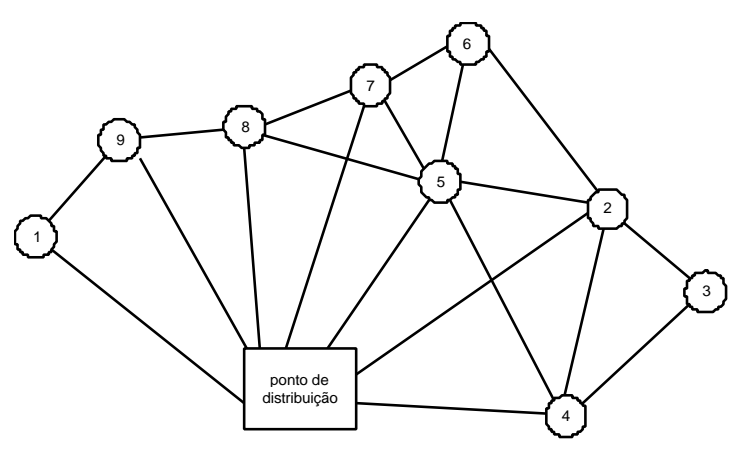

(a)

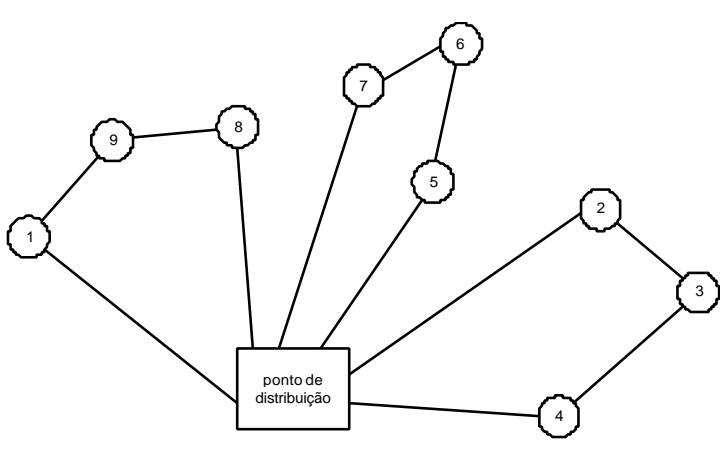

(b)

Figura 2.4 - Exemplo de possível solução (b) para um problema de roteirização de transportador, tendo como dado de entrada (a) ou um grafo densamente conexo [Bodin et al., 1983]

Em Swait Jr. [1990] e Bodin et al. [1983] encontra-se uma descrição da heurística proposta por Clarke \& Wright em 1960, a qual recebe o nome de seus criadores e que trabalha da seguinte forma:

- cada cliente nó é servido por um transportador específico de tal forma que o transportador $k$ sai de um nó designado como ponto de distribuição; assim, se d(i, j) é a distância do nó denominado cliente $i$ ao nó denominado cliente $j$, sendo que $\mathrm{i}=\mathrm{j}$ $=0$ representa o nó ponto de distribuição, tem-se ainda que a distância percorrida pelo k-ésimo transportador é $\mathrm{d}(0, \mathrm{i})+\mathrm{d}(\mathrm{i}, 0), \mathrm{i}=1, \ldots, \mathrm{n}$;

- o próximo passo procura combinar nós clientes em rotas de tal maneira a se obter economias globais na distância percorrida pela frota. Define-se a economia e(i, j), proporcionada pela combinação dos nós clientes i e j na mesma rota, como sendo a diferença entre o comprimento total das duas rotas originais $(d(0, i)+d(i, 0)+d(j$, 
$0)+d(0, j))$ e o comprimento da nova rota combinada com i e j $(d(0, i)+d(i, j)+$ $d(j, 0))$, resultando numa economia $e(i, j)=d(i, 0)+d(0, j)-d(i, j)$;

- a combinação de rotas ocorre seqüencialmente na ordem da maior para a menor economia; o processo continua até que não seja possível obter reduções na distância total percorrida pela frota.

Bodin também apresenta um método de aproximação por varredura onde, considera-se todos os transportes contidos no interior de um círculo, tendo-se como centro o ponto de distribuição, escolhe-se um ponto de início para uma varredura de forma circular, particionando-a em setores conforme se atinja a capacidade do transportador. Em seguida, trata-se cada setor como um problema de caixeiro viajante.

\section{E. Roteirização por nós, com vários pontos de distribuição e vários transportadores}

É uma generalização do problema anterior só que cada transportador saí e retorna ao mesmo ponto de distribuição (figura 2.5).

Bodin et al. [1983] apresentam heurísticas similares a "aproximação por varredura" onde primeiramente se distribui os nós entre os pontos de distribuição com base na sua distância com relação a estes e em seguida aplica-se a heurística de aproximação por varredura já vista. 


\section{F. Roteirização por nós com demanda estocástica, com vários pontos de distribuição e vários transportadores}

Idem ao "problema de roteirização por nós, com um ponto de distribuição e vários transportadores" exceto pelo fato de que a demanda não é conhecida com certeza, isto é, ela pode ser descrita por um distribuição de Poisson com média $\lambda$.

Uma solução apresentada em Bodin et al. [1983] é se majorar as demandas considerando-se um intervalo de segurança e de tal forma que a demanda de cada ponto não ultrapasse a capacidade do transportador.

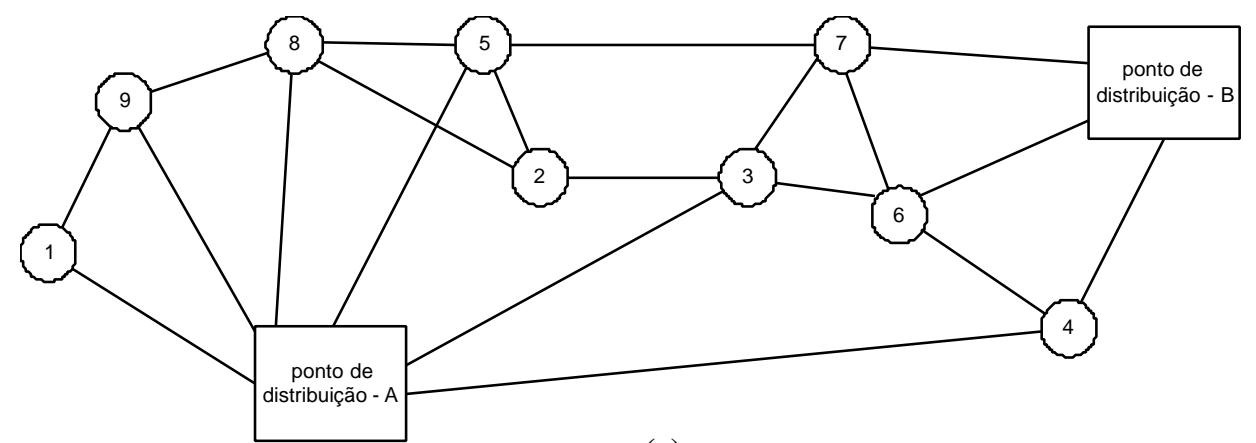

(a)
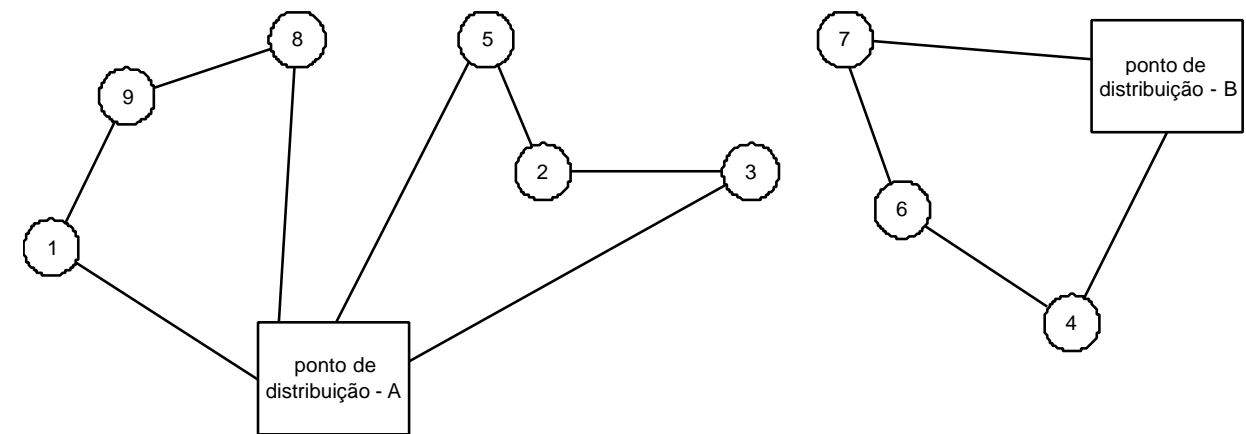

(b)

Figura 2.5 - Exemplo de possível solução (b) para um problema de roteirização de transportador com multiplos centros de distribuição (tendo como dado de entrada (a) ou um grafo densamente conexo) [Bodin et al., 1983]. 


\section{G. Carteiro chinês com restrição de capacidade}

Similar ao problema do Carteiro Chinês, porém onde os transportadores possuem limitação de capacidade e torna-se necessário designar mais de um transportador para atender as demandas, procurando-se, ao mesmo tempo, minimizar o custo total de transporte (figura 2.6).

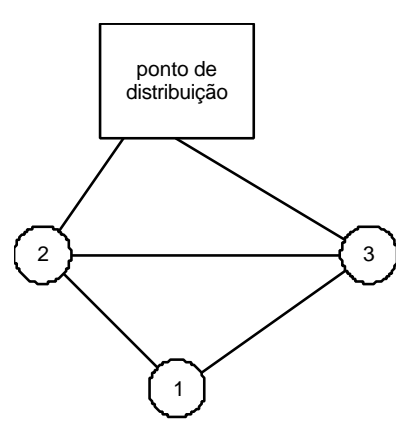

(a)

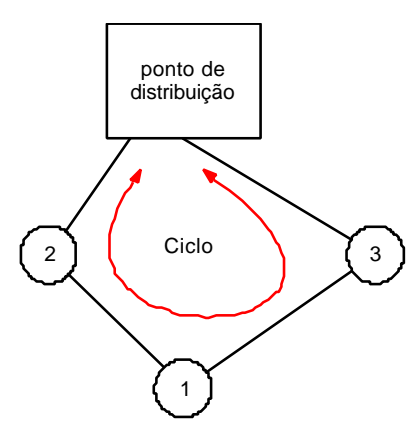

(b)

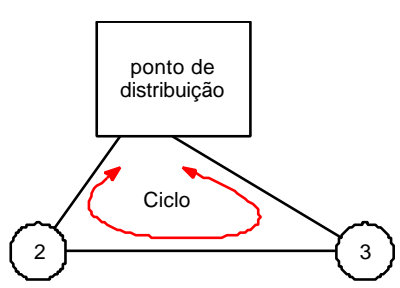

Figura 2.6 - Exemplo de possível solução (b) para um problema de carteiro chinês com restrição de capacidade e com demanda localizada no arco (a) [Bodin et al., 1983].

Bodin et al. [1983] apresentam a seguinte heurística para este problema:

- todos os arcos com demanda não nula de produtos são servidos por ciclos distintos;

- iniciando-se com o ciclo mais externos (de maior comprimento / custo), observar se demandas contidas em ciclos internos (de menor comprimento / custo) podem ser atendidas por este ciclo;

- submetendo-se às restrições de capacidade, acoplar os dois ciclos que contemplem a maior economia;

- repetir o passo acima até terminar. 


\subsubsection{Problemas de programação de tarefas}

Assemelha-se ao problema de roteirização, porém tem-se o tempo associado às atividades.

Bodin apresenta uma heurística simples, classificada como uma heurística "gulosa", comum a todos os problemas citados a seguir e onde é necessário apenas adaptar as restrições do caso em questão. Os passos são:

- ordenar as tarefas pela hora de início e atribuir a primeira tarefa ao primeiro transportador;

- para as demais tarefas, se for possível atribuir a tarefa a um transportador que já está sendo utilizado, contemplando-se as restrições, e que envolva o menor tempo de atendimento. Do contrário, associar a carga a um transportador ainda não utilizado.

As abordagens segundo Bodin são:

\section{A. Programação de transportadores com um único centro de distribuição com restrição de comprimento de rota}

As restrições são impostas de forma a limitar o tempo que o transportador pode ficar afastado do centro de distribuição (depósito) ou com relação à distância que este pode percorrer até retornar ao centro para serviços (para abastecimento, manutenção, etc.). Na figura 2.7, esquerda, tem-se as possíveis rotas (uma rota é considerada possível se o horário de término de atendimento de uma operação acrescido do tempo de deslocamento do transportador é inferior ao horário de início da operação seguinte) e na figura 2.7, direita, tem-se uma possível solução. Nos nós estão inscritos os horários mínimo e máximo em que o nó deve ser atendido e a identificação (número) do nó. O 
depósito é representado duas vezes (início e fim do grafo) para se ter um grafo mais “limpo" e, conseqüentemente, mais fácil de se visualizar.

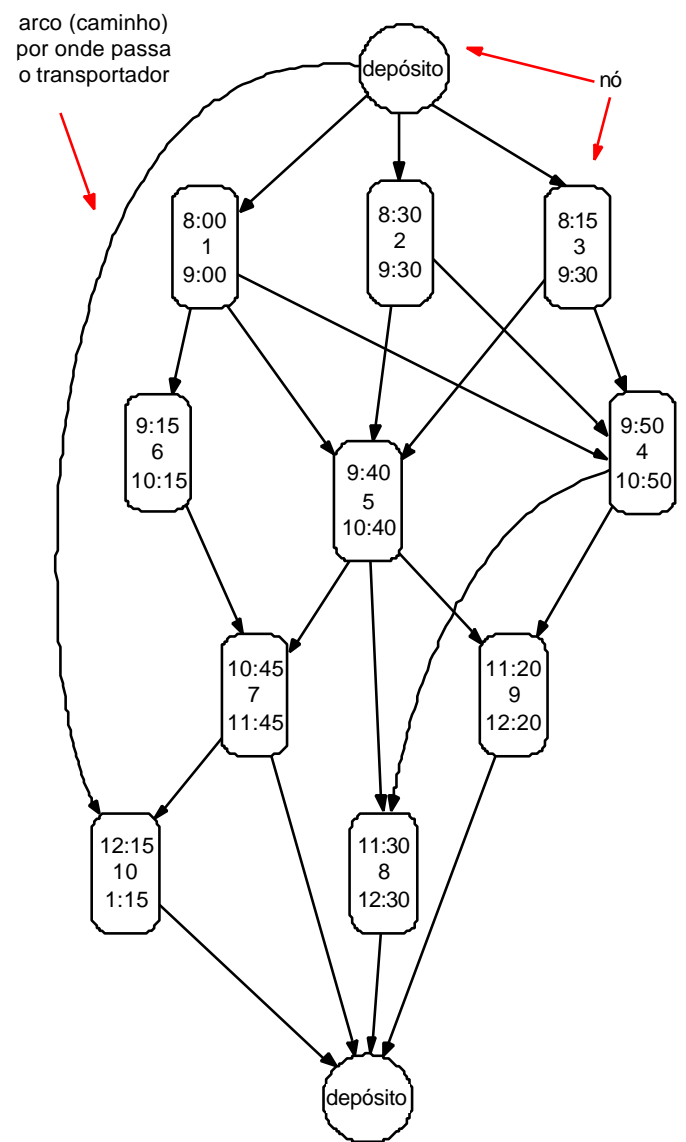

(a)

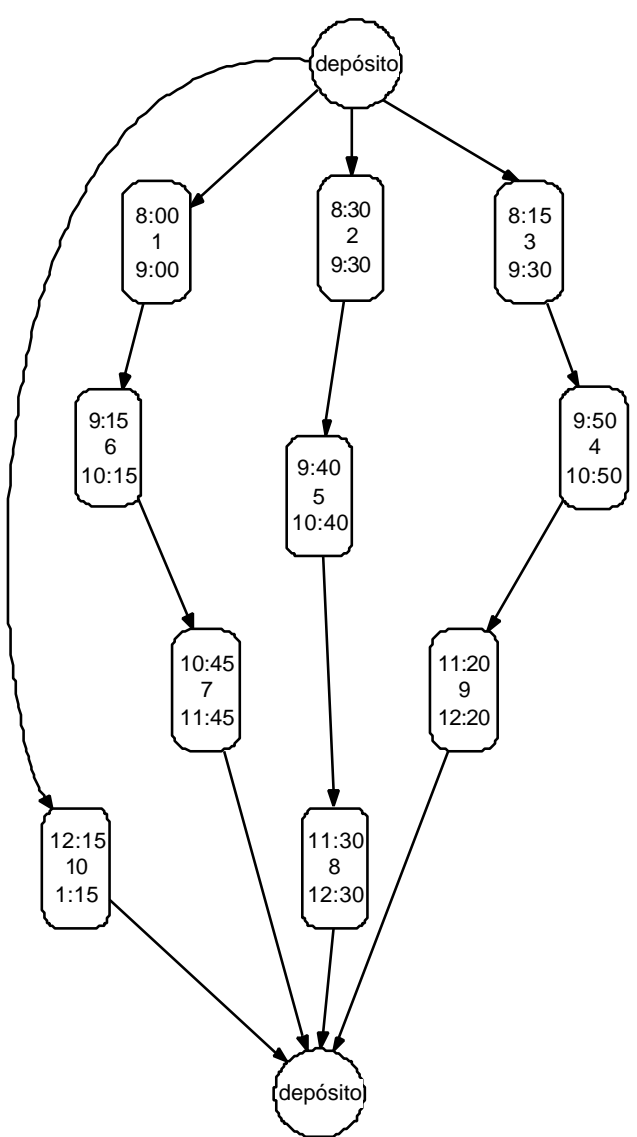

(b)

Figura 2.7 - Exemplo de roteirização com restrição de comprimento de rota ((a) representa um problema inicial e (b) uma possível solução) [Bodin et al., 1983].

Golden et al. [1997] propõem uma heurística baseada em Busca Tabu que visa a minimização dos custos de transporte ao mesmo tempo em que se constrói rotas limitadas por um intervalo de comprimentos máximo e mínimo. Sua heurística contempla tanto restrições de distância quanto de tempo e seu procedimento gera, a partir de uma solução inicial; 3 a 5 rotas por particionamento e em seguida otimiza-as utilizando-se algumas técnicas como troca de nós entre rotas, inserção ou remoção de nós, etc. 
Ainda seguindo a linha de utilização de Busca Tabu, Gendreau et al. [1994] propõem uma outra heurística com restrições de capacidade e comprimento de rota, visando o menor custo de transporte com restrições tais como:

- cada rota inicia e termina no mesmo ponto;

- cada nó é visitado apenas uma vez e por um único transportador;

- não se pode exceder a capacidade de carga do transportador e o comprimento de rota não pode ultrapassar um limite pré estabelecido;

- cada nó deve pertencer a apenas uma rota;

- cada nó requer um tempo de serviço e o tempo total não deve ultrapassar o que foi pré estabelecido.

Identifica-se uma primeira solução transformando o problema inicial em um problema de caixeiro viajante, considerando as restrições impostas. Alterando-se a seqüência com que os nós são visitados, outras soluções são tentadas e a melhor é selecionada. Para prevenir ciclos (testar mais de uma vez cada possibilidade), as tentativas mais recentes são postas em uma lista Tabu.

\section{B. Programação de transportadores com um único centro de distribuição}

Este problema requer o particionamento das tarefas em uma rede acíclica com um conjunto de caminhos onde uma função de custos deva ser minimizada. Cada caminho corresponde à programação de tarefas de cada transportador. A função objetivo que minimiza o número de caminhos, efetivamente minimiza o custo de capital já que o número de transportadores requisitados é igual ao número de caminhos. Se um peso correspondente ao tempo em que o transportador anda em vazio for associado a cada arco, a função objetivo que minimiza o peso total dos arcos minimiza também os custos 
de operação já que estes são em geral proporcionais ao tempo de viagem dos transportadores. Se o capital e os custos de operação puderem ser quantificados, então um objetivo combinado pode ser usado para minimizar o custo total do sistema. A figura 2.8 ilustra uma possível solução para o problema descrito, onde os horários inscritos nos nós do grafo indicam as restrições de horários mínimo e máximo em que o nó deve ser atendido e a identificação (número) do nó.

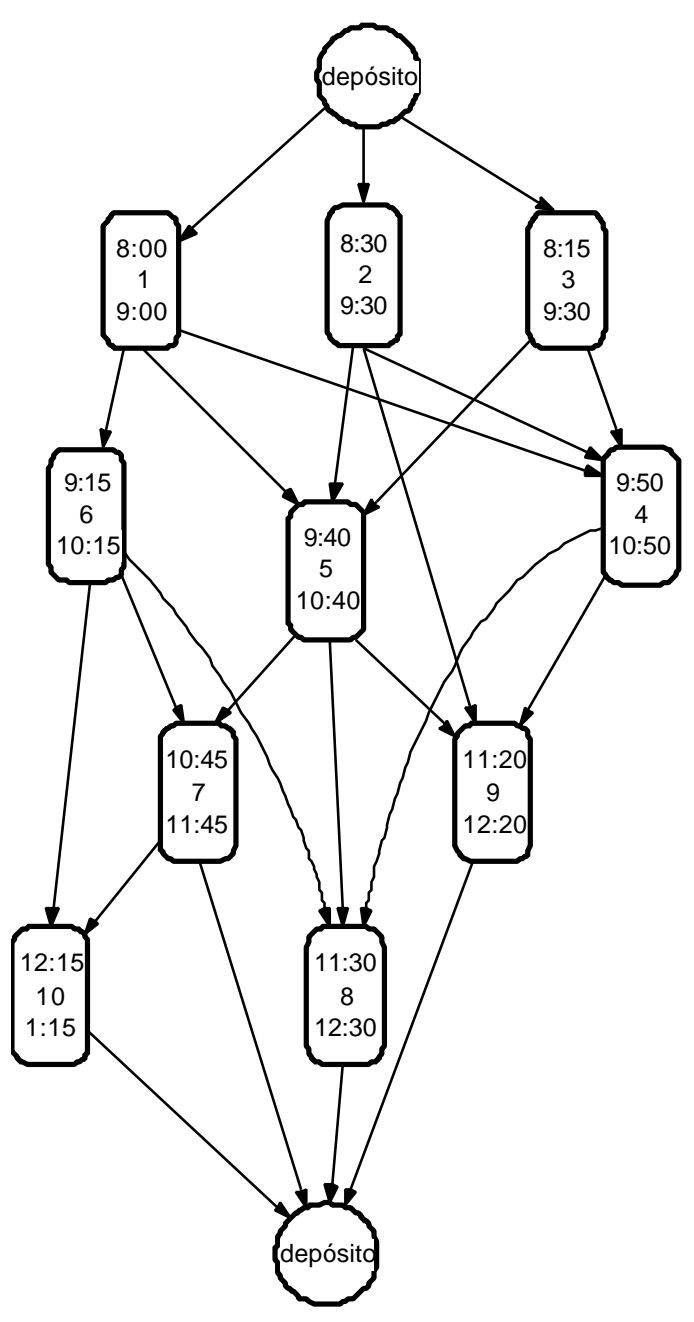

(a)

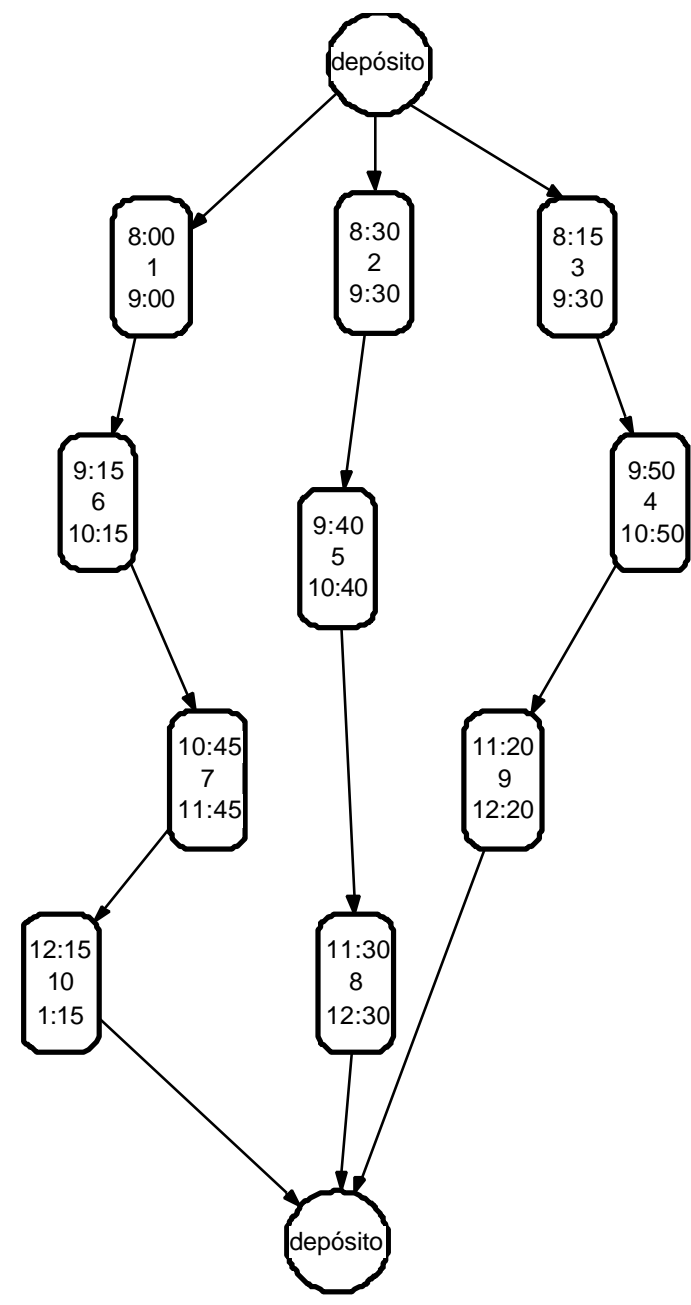

(b)

Figura 2.8 - Exemplo de possível solução (b) para um problema de roteirização sem restrição de comprimento de rota indicado no grafo (a) [Bodin et al., 1983]. 


\section{Programação de transportadores com um único centro de distribuição com vários tipos de transportadores}

Possibilita que transportadores com diferentes características sejam utilizados para atender às mesmas tarefas. Esta característica, na maioria dos casos, é função da capacidade do transportador. A figura 2.9 ilustra uma possível solução para o problema em questão, onde nos nós estão inscritos os horários mínimo e máximo em que este deve ser atendido e sua identificação (número). A fim de se ilustrar a diferença entre os transportadores, considera-se que existam centros de distribuição (depósitos) diferentes de acordo com um tipo de transportador.

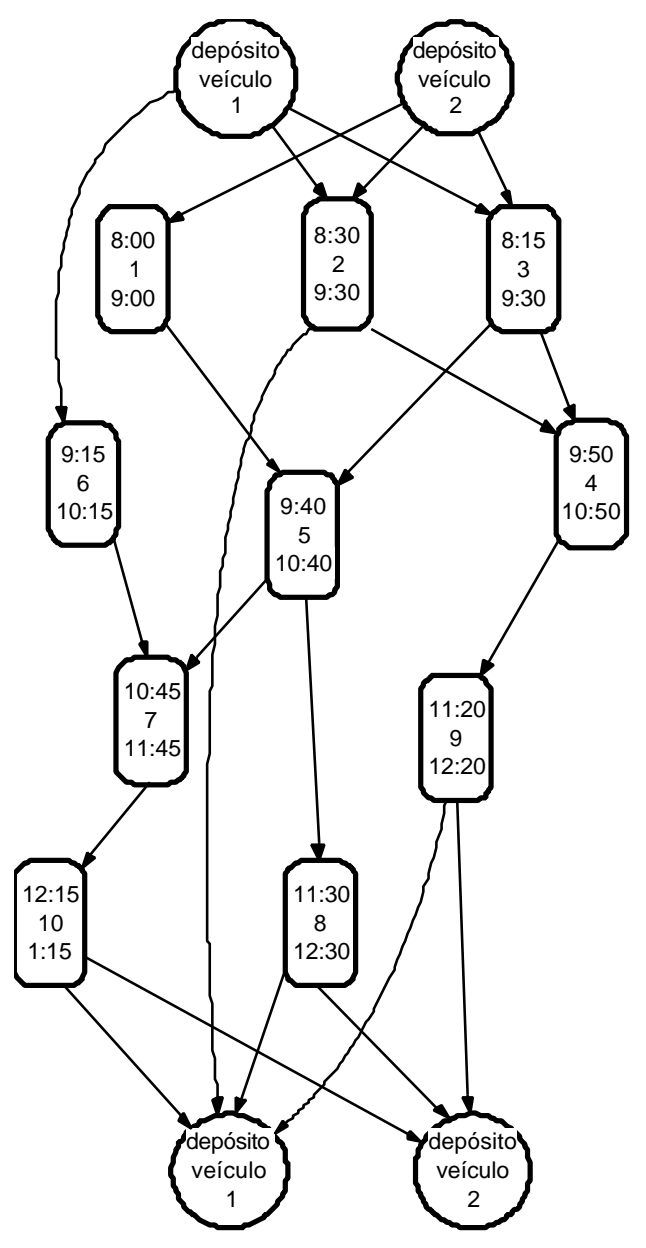

(a)

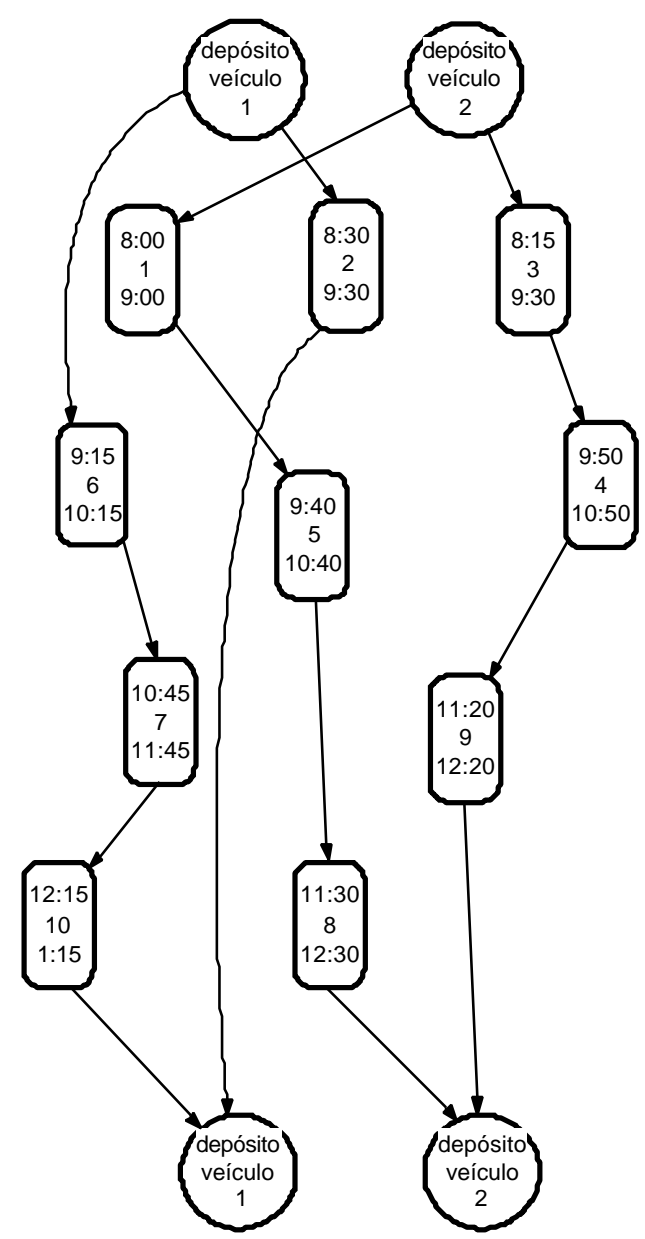

(b)

Figura 2.9 - Exemplo de solução de roteirização (b) com dois tipos de transportadores do problema (a) [Bodin et al., 1983]. 


\section{Programação de transportador com múltiplos centros de distribuição}

Neste caso as tarefas podem ser atendidas por mais de um centro de distribuição e, assim como no problema de roteirização de transportadores, cada transportador deve sair e retornar ao mesmo centro de distribuição e o tamanho da frota de cada centro deve estar contida entre um mínimo e um máximo (figura 2.10).

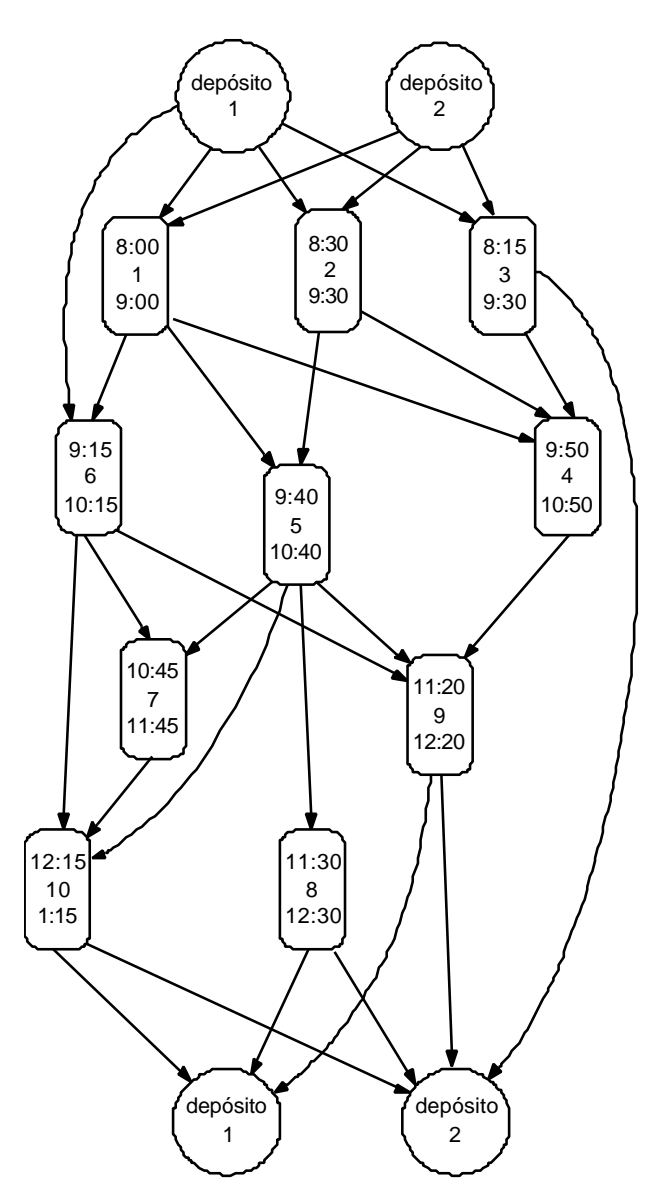

(a)

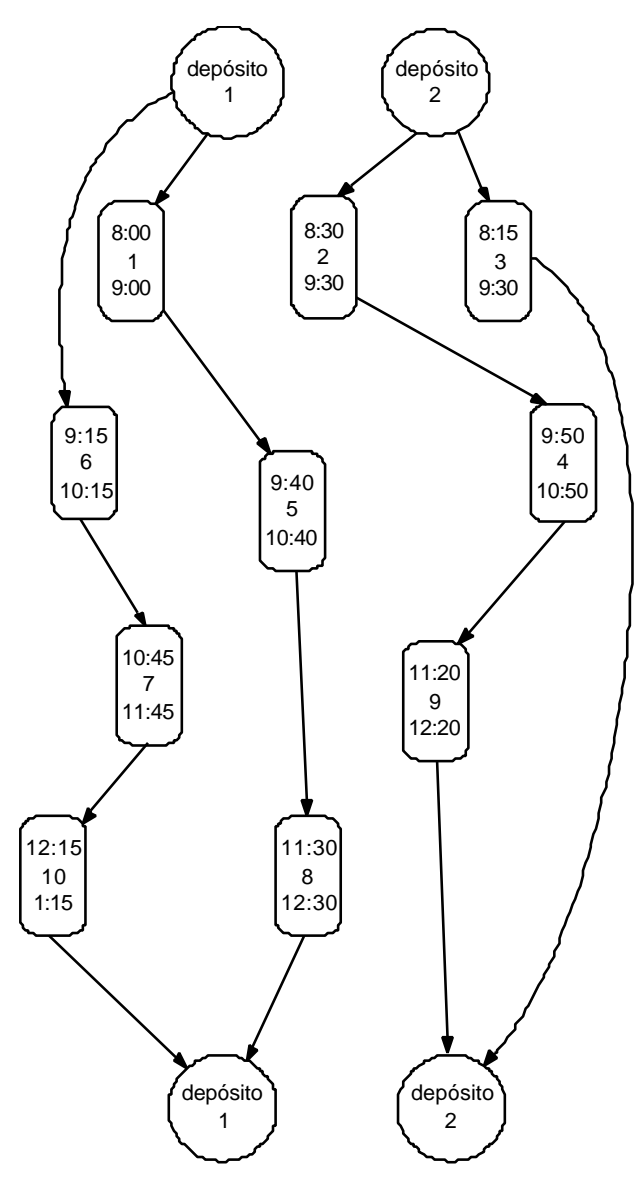

(b)

Figura 2.10 - Exemplo de solução de roteirização (b) com múltiplos depósitos do problema (a) [Bodin et al., 1983].

Este é um caso investigado por muito autores e em geral abordado através de heurísticas devido à sua complexidade computacional. Uma abordagem proposta por Sumichrast et al. [1995] é a do limite inferior onde se utiliza de vários transportadores iguais para o transporte de materiais entre vários centros de custos, visando a 
minimização das distâncias e dos custos, mantendo-se algumas restrições como tempo de utilização dos transportadores, número de operários necessários, etc. Sua heurística encontra uma solução inicial factível, determinando-se o menor custo de atendimento dos centros de custos e, em seguida, utilizando-se o processo de trocas de ClarkeWright, permuta-se seguimentos de rotas entre os transportadores, desde que haja uma economia e as rotas permaneçam factíveis.

Dell' Amico et al. [1993] abordam este problema impondo que:

- cada rota deva ser coberta por apenas um transportador;

- cada transportador utilizado deve cobrir uma rota factível e retornar para o seu centro de distribuição;

- o número de transportadores estacionados em um centro de distribuição (e usado na solução) não pode exceder um certo número;

- o número de transportadores utilizados para cobrir as rotas e o custo total de transporte devem ser minimizados.

A heurística procura agregar um novo nó a uma rota já existente, satisfazendo os horários de coleta e entrega, e se isto não for possível, o programa cria uma nova rota utilizando-se um novo transportador. Esta heurística se destaca por permitir a utilização de um número mínimo de transportadores.

2.3.3. Problemas de roteirização e programação de tarefas para transportadores (problemas mistos)

É o caso mais freqüente e são caracterizados por "precedências nas atividades" e "restrições de janela de tempo". A precedência de tarefas impõe que para um mesmo 
transportador, a carga seja antes "pega" e depois "entregue", por exemplo. Um segundo conjunto de restrições envolve o atendimento das tarefas dentro de janelas de tempo específicas. Isto implica que uma determinada tarefa deve ser atendida dentro de um intervalo de tempo específico. Desta forma, qualquer rota que contenha esta particular tarefa deve saber que o tempo de entrega deve estar contido neste intervalo de tempo. Nesta discussão, o intervalo de tempo é um período de tempo contíguo e este tipo de janela é chamada janela de tempo simples. Na maioria dos estudos, não existe preocupação com o tempo de deslocamento do transportador de um nó garagem ao primeiro ponto do roteiro e nem do último ponto de volta ao nó garagem. Isso se deve ao fato destas distâncias terem sido consideradas como sendo muito pequenas quando comparadas com as rotas e, a inclusão destas no modelo só aumentariam a complexidade deste. A seguir, apresentam-se os problemas que mais nos interessam no presente contexto:

\section{A. Programação e roteirização de transportadores com carga total}

Um problema de distribuição comum é que se assume que uma carreta ${ }^{10}$ está $^{-}$ completamente carregada. O termo "carga total" é utilizado devido ao fato do transportador pegar a carreta em um ponto e só deixá-la em seu destino, ou seja, a carga da carreta tem um único destino e, a capacidade de transportador é de apenas uma carreta. A demanda é especificada como sendo o número de carretas transportadas entre um par origem / destino. Fornecidos os dados de demanda, existem dois tipos de problemas de decisão: minimizar o custo de distribuição total para atender todas as origens / destinos ou determinar o tamanho da frota necessário para atender um

\footnotetext{
${ }^{10}$ Recurso adicional para a movimentação de materiais, realizando a interface entre os materiais e o transportador.
} 
conjunto de demandas origem / destino. Na figura 2.11 os nós $\mathrm{C}_{\mathrm{i}}$ são centros geradores de carga e os nós $\mathrm{D}_{\mathrm{i}}$ são nós de entrega das cargas (descarga). O "domicílio" é a garagem do transportador. Na figura em questão o roteiro foi gerado para apenas um transportador (observa-se que o conjunto de linhas tracejadas e contínuas formam apenas um ciclo).

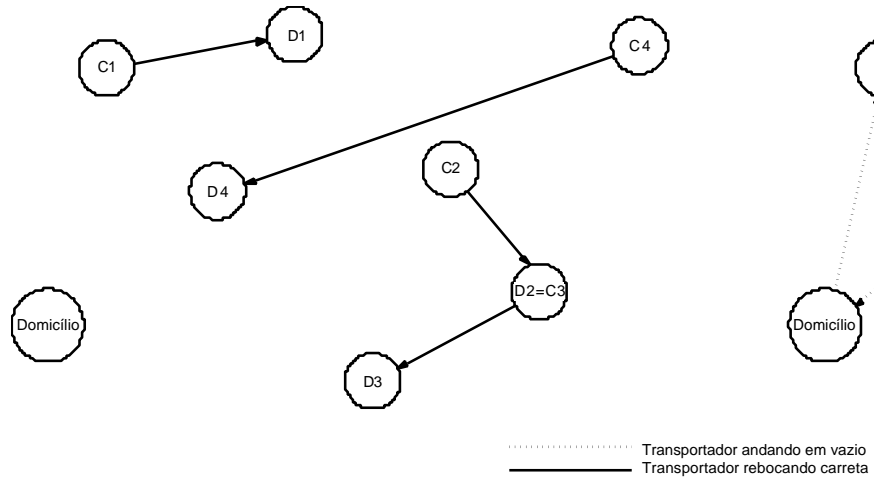

(a)

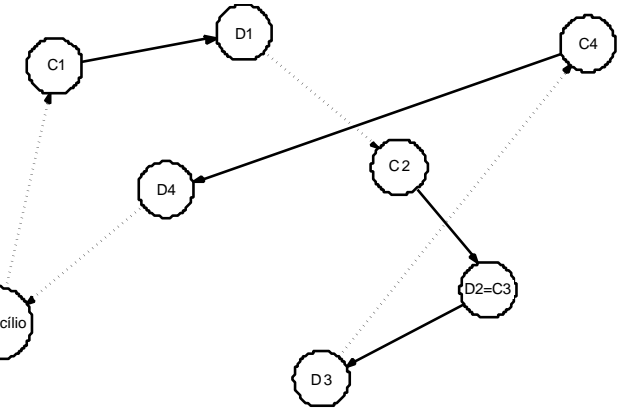

(b)

Figura 2.11 - Exemplo de solução de roteirização (b) com carga total de um problema (a) [Bodin et al., 1983].

Bodin et al. [1983] apresentam duas heurísticas para este problema. A primeira consiste em se encontrar uma rota que cubra todas as entregas com o menor custo. Esta se utiliza de uma heurística de carteiro chinês onde cada arco entre um par de nós está associado ao número de transportes a serem realizados. Num segunda estágio, cada transporte (par origem / destino) é visto como um único nó (isto se deve ao fato de que é obrigatório o percurso do trecho compreendido entre estes nós) e cada arco possui um custo de transporte associado e, se utiliza uma heurística de caixeiro viajante para gerar uma rota mínima que cubra todos os nós. Em seguida esta rota é particionada em várias outras factíveis e os transportes entre um mesmo par origem / destino são distribuídos ao longo do período de tempo considerados: o horário que as operações devem ser 
realizadas, o atendimento às janelas de tempo e se o operador não excede a sua jornada de trabalho.

A segunda heurística é uma heurística "gulosa” de inserção, onde os transportes são agrupados, um a um, para gerar a rota dos transportadores, tomando como critério a economia resultante dividida pelo aumento marginal no tempo da rota. Neste procedimento se define uma rota por vez.

\section{B. Programação e roteirização de transportadores com carga parcial}

Este problema é similar ao anterior exceto pelo fato de que as demandas por cada origem / destino não precisam ser cargas completas. Desta forma, o que se observa é um roteiro onde ocorrem várias cargas (nós com um " $\mathrm{C}$ ” inscrito, onde o valor acima deste refere-se à capacidade do transportador que a carga está ocupando) e descargas (nós com um "D" inscrito, sendo que o valor acima indica quanto da carga proporcionalmente à capacidade do transportador foi deixada) de materiais de uma mesma carreta (figura 2.12). As restrições neste tipo de problema são as precedências do par origem / destino, janelas de tempo e regras de trabalho do operador.

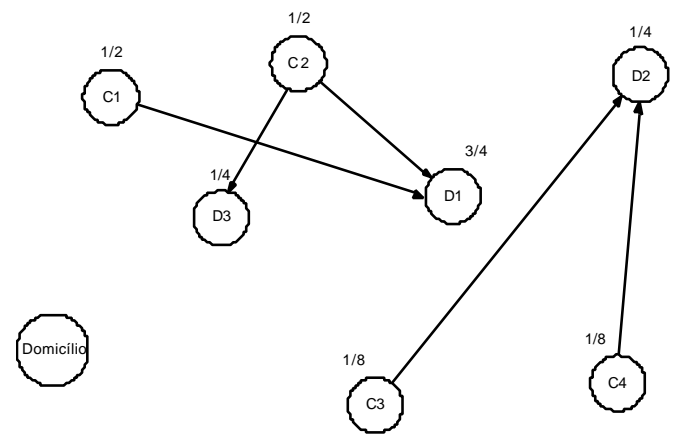

(a)

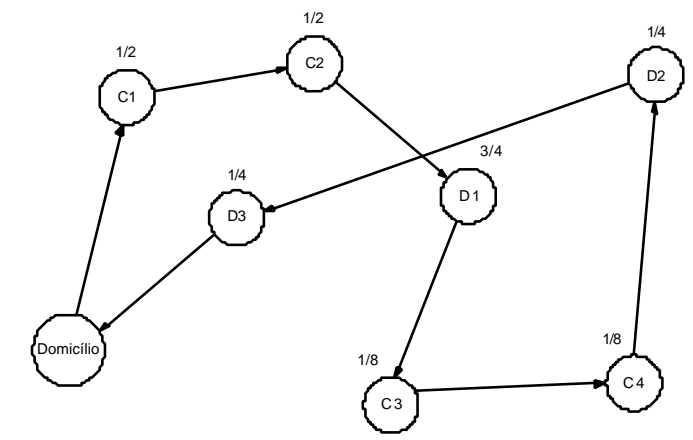

(b)

Figura 2.12 - Exemplo de solução de roteirização (b) com carga parcial do problema (a) [Bodin et al., 1983]. 
Bodin et al. [1983] apresentam uma heurística composta de três passos:

- definição de um componente de agregação que une pares de nós origens e nós destinos e que serão servidos como um grupo;

- definição de um elemento de roteirização que gera as rotas com base na distância total;

- definição de um componente de agendamento que determina os horários de carregamento e entrega.

\section{Programação e roteirização do tipo "dial-a-ride"}

Neste caso, supondo-se uma entidade responsável pelos serviços de transporte atendendo a vários clientes que requisitam um transportador ou agendam um "serviço". Cada cliente especifica um par de nós (origem / destino) além de poder ou não especificar os horários desejados de carga e descarga. Se todos os clientes demandarem serviços imediatos, então o problema de agendamento e roteirização é feito em tempo real e o problema é conhecido como dinâmico ou "real time dial-a-ride problem". Caso seja possível gerar um banco de dados de pedidos antes de se definir as rotas, este problema passa a ser chamado "estatic dial-a-ride problem". Ambos possuem restrições, por exemplo, a carga deve ser pega antes de ser entregue. Em alguns casos, são especificados horários de carga e descarga o que introduz no modelo mais uma restrição.

Bodin et al. [1983] citam três problemas:

- com um transportador e sem janela de tempo - onde as restrições impostas são de que a capacidade do transportador não pode ser excedida; o número máximo de 
trocas não pode ser excedido (limita o número de iterações computacionais necessárias para o algoritmo); exista um caminho ligando os nós $i$ e $j$;

- um transportador com janela de tempo - uma rota inicial válida é estabelecida; dada a rota, uma programação cujos horários de atendimentos são atendidos é formada (a programação define a hora exata de carga e entrega); a ordem em que se serve os clientes é alterada sempre que se tem uma melhoria na programação baseada na nova rota; este procedimento se mantém sempre que for possível encontrar uma nova rota cuja programação seja melhorada;

- roteirização com múltiplos transportadores e janela de tempo - o programa determina a janela de tempo para cada carregamento / entrega referentes às requisições de cada cliente; a janela de tempo de cada cliente é o mínimo tempo que se leva para ir do ponto de carga até o de entrega; deve-se garantir que a entrega para cada cliente atenda a sua janela de tempo.

\subsection{Síntese do capítulo}

Apresentaram-se neste capítulo os sistemas de movimentação de materiais mais comuns em ambiente industrial. Deu-se destaque aos sistemas flexíveis de movimentação baseados em VATs que apresentam maior potencial de utilização em ambientes industriais onde se necessita de mudanças no seqüenciamento da produção sem no entanto alterar o arranjo físico das instalações.

Por fim, ainda com relação aos sistemas flexíveis de movimentação de materiais baseados em VATs, foram apresentados alguns dos problemas mais citados sobre a organização da movimentação em bibliografias por serem aplicáveis à movimentação de materiais em ambiente industrial e por possuírem características que possibilitam que sejam abordados como sistemas a eventos discretos (SEDs). Desta forma, pode-se 
utilizar algumas ferramentas para a modelagem, simulação e especificação de controle de tais sistemas como pode ser visto nos próximos capítulos. 


\section{Ferramentas / metodologias empregadas na modelagem de sistemas a eventos discretos}

Modelos baseados em sistemas a eventos discretos são intensamente usados para descrever, analisar e controlar processos em ambientes de rede de computadores e manufatura. O que caracteriza este processo é o fato de sua dinâmica ser governada pela ocorrência de eventos discretos. Assim, a evolução de estados destes sistemas é baseado em regras que definem as condições para a ocorrência de eventos e o resultado destes eventos [Cassandras \& Strickland, 1992].

A movimentação de materiais em sistemas produtivos, assim como outros processos concebidos pelo homem, pode ser abordado como uma sucessão de eventos discretos e modelados como um SED (sistemas a eventos discretos) [Ho \& Cao, 1991]. Isto é, ferramentas como as Redes de Petri [Cardoso \& Valette, 1997; Reisig, 1982; 1992] e seus derivados como o PFS/MFG [Miyagi, 1996] (incluindo-se também suas variações como o PFS-R/E-MFG [Santos Filho,1998]) podem ser consideradas para estudar o problema em questão.

Existem também outras ferramentas que podem ser utilizadas na análise destes sistemas tais como os programas específicos de simulação discreta (por exemplo: ProModel, Arena, AutoMod, etc. [Baird \& Leavy, 1994; Banks, 1995]), porém estas ferramentas possuem restrições para a conversão dos modelos em especificações de estratégias de controle de sistemas de movimentação. O uso de programas específicos de simulação discreta envolvem a abstração de conceitos e decisões para a análise do sistema que não podem ser diretamente implementados ou interpretados em estratégias de controle. Por outro lado, teorias como as Redes de Petri foram concebidas para a modelagem e especificação funcional de sistemas que possuem características de 
concorrência, sincronismo e paralelismo, além de possuir representação gráfica que evidencia o funcionamento do sistema.

Neste capítulo serão abordadas as Redes de Petri com maior enfoque às Redes de Petri Interpretadas PFS e E-MFG, sendo que, nesta última, é introduzido o conceito de objetos afim de conceder a esta maior capacidade e simplicidade de modelagem e maior representatividade.

\subsection{Redes de Petri}

A Rede de Petri (RdP) é uma técnica de modelagem gráfica e matemática originalmente desenvolvida por C. A. Petri em meados de 1960 para caracterizar operações de concorrência em computadores. Ela foi posteriormente estendida para capturar os aspectos fundamentais de sistemas de alta complexidade, incluindo atributos, relações de tempo e eventos estocásticos, onde o desafio é a manutenção da simplicidade conceitual do grafo [Moore \& Brennan, 1996].

Esta é conhecida como uma poderosa ferramenta para modelagem e análise de sistemas concorrentes, assíncronos, distribuídos e paralelos [Cardoso \& Valette, 1997; Reisig, 1982; 1992; Inamasu, 1995] e é de interpretação relativamente simples e fácil devido à sua interface gráfica. Peterson [1981] apresenta um processo cíclico de modelagem, análise e melhoria do sistema, até que a análise do modelo não revele mais problemas inaceitáveis (figura 3.1). Uma outra abordagem também apresentada por Peterson [1981] é o desenvolvimento de um modelo em Redes de Petri para uma análise mais robusta de forma a se eliminarem todos os erros e em seguida implementar as mudanças para melhora do desempenho do sistema. A primeira abordagem é usualmente utilizada para se representar sistemas existentes e a segunda para se implementar novos sistemas. 


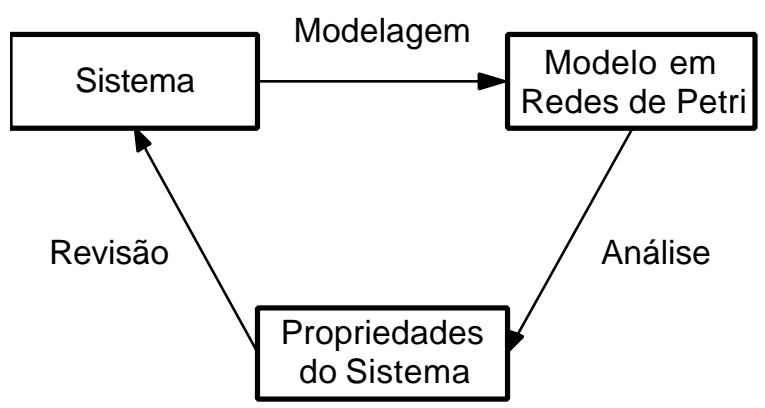

Figura 3.1 - Representação do ciclo de análise [Peterson, 1981].

As Redes de Petri são grafos compostos de lugares (representados por círculos), transições (representado por barras), arcos orientados interligando os componentes anteriores e marcas (são utilizadas para definir o estado de uma Rede de Petri). São também consideradas multigrafos direcionados bipartidos (figura 3.2) pois vários arcos orientados podem sair de um nó para os demais, existindo a restrição de que os arcos só interligam elementos de natureza diferente [Peterson, 1981].

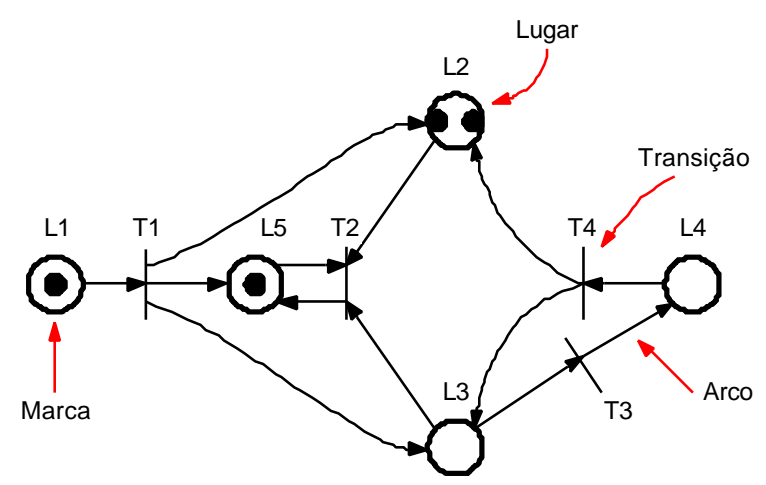

Figura 3.2 - Representação de uma Rede de Petri [Peterson, 1981].

A execução de uma Rede de Petri é definida pelo número de marcas e sua distribuição na rede que é alterada com o disparo de transições. As marcas residem nos lugares e condicionam o disparo das transições da rede. Uma transição dispara 
removendo as marcas dos seus lugares de entrada (pré-condições) e criando novas marcas em seus lugares de saída (pós-condições) (figura 3.3 (a) e (b)).

As principais características da Rede de Petri, segundo Rillo [1987] apud Inamasu [1995] são:

- $\quad$ permitir a representação de diferentes tipos de sistemas;

- $\quad$ ser um modelo que pode ser formalizado matematicamente;

- ser um modelo gráfico de aprendizado relativamente fácil, funcionando como linguagem de comunicação entre especialistas de diversas áreas;

- permitir a representação de paralelismo e sincronização;

- representar aspectos estáticos e dinâmicos;

- permitir a representação de estados parciais;

- possuir métodos e ferramentas de análise, inclusive comerciais.

Moore \& Brennan [1996] apresentam mais algumas características das Redes de Petri:

- pode-se considerar regras de tempo associadas com transições para representar o tempo requerido para completar uma atividade. A regra pode ser estocástica, baseada em uma função de probabilidade, um valor computado, ou uma constante. Regras de decisão são associadas com os lugares e resolvem casos onde mais de uma transição está habilitada pela mesma marca ou conjunto de marcas (figura 3.3 (c) (transições em conflito);

- pode-se considerar atributos nas marcas para especificar um conjunto de características associadas com a marca. O valor destes atributos pode ser mudado nas transições e podem ser passados para algoritmos externos e o resultado incorporado ao modelo de Redes de Petri; 
- pode-se considerar outros tipos de $\operatorname{arcos}$, que proporcionam uma lógica adicional à transição: o arco habilitador que habilita a transição, caso o lugar a que se refere esteja marcado, sem consumir a marca e o arco inibidor, que desabilita a transição caso o lugar a que se refere esteja marcado.

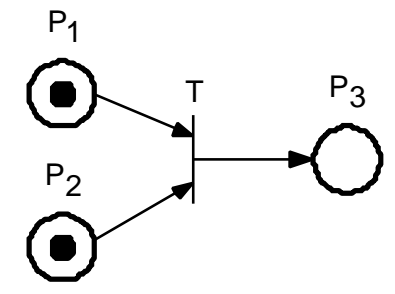

(a) Antes do disparo de T

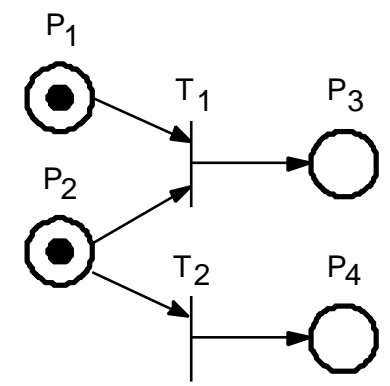

T1 e T2 estão habilitadas Disparo de T1 disabilita T2

(c) Exemplo de transições em conflito

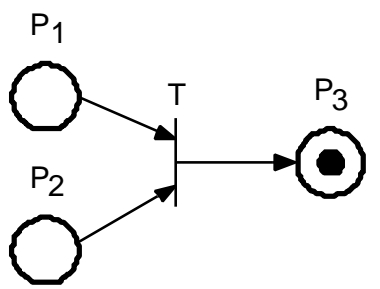

(b) Após o disparo de T

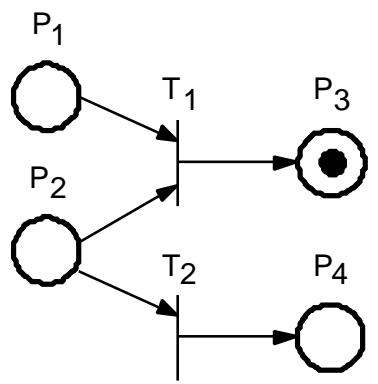

Figura 3.3 - Exemplo de disparo de uma transição.

As Redes de Petri possuem também variações tais como [Murata, 1989]:

- RdP "ordinária" - onde, o seu elemento lugar possui capacidade ilimitada para marcas;

- RdP Lugar/Transição (limitada) - ao contrário das RdP “ordinárias” esta rede possui capacidade finita em seu elemento lugar;

- RdP temporizada - as transições neste caso, possuem um parâmetro que representa o tempo que a marca leva para sair da pré-condição até atingir a pós-condição. Como evolução desta variante, tem-se as RdP estocásticas; 
- RdP coloridas - são RdP com marcas individualizadas possibilitando que as transições se comportem de forma diferenciada de acordo com o tipo das marcas individualizadas.

Entretanto em aplicações práticas de projeto e controle de sistemas complexos e de grande porte, a ferramenta apresenta limitações. Visando sanar estas limitações, foram propostos novas ferramentas derivadas das RdP tais como GRAFCET David \& Alla, 1992], MFG [Hasegawa et al., 1988], PFS [Miyagi, 1996; Miyagi \& Arata, 1997] e outros [Santos Filho \& Miyagi, 1996; Santos Filho, 1998] que são conhecidas como Redes de Petri interpretadas ${ }^{11}$.

Entre as propriedades mais importantes que as redes interpretadas exploram nas aplicações práticas pode-se citar:

- regras explícitas de interpretação dos elementos da rede;

- vivacidade ("liveness") - que caracteriza se rede possui ou não estados de "deadlock" (travamento do sistema);

- alcançabilidade ("reachability") - que caracteriza um tipo de "distância" entre dois estados da rede.

Baseado nas características funcionais de sistemas a eventos discretos e nas especificações de controle do sistema produtivo, foi desenvolvida a metodologia PFS/MFG, onde, a partir do modelo conceitual do sistema representado por um grafo PFS [Miyagi, 1996], realiza-se o detalhamento das atividades, utilizando o E-MFG, até o nível desejado (modelo funcional) [Santos Filho, 1998]. 


\section{2. $O$ PFS}

Em sistemas de pequeno porte observa-se com facilidade o relacionamento entre as partes e o desenvolvimento de modelos destes sistema utilizando Redes de Petri torna-se uma tarefa fácil. Porém, a medida em que os sistemas vão se tornando maiores e mais complexos, as relações entre os componentes deste deixam de ser tão visíveis. Para sanar esta dificuldade, foi proposta por Miyagi [1996] uma metodologia denominada PFS (Production Flow Schema), que ao invés de se desenvolver diretamente a estratégia de controle do sistema a eventos discretos, isto é, o modelo em nível detalhado, adota-se primeiro a modelagem do sistema em nível conceitual e em seguida passa-se a detalhar gradativamente cada elemento, indo-se de um nível macro até o seu nível mais detalhado, ou seja, até se atingir um nível de detalhamento que se possa representar o sistema utilizando-se grafos específicos para controle como o MFG, GRAFCET, etc.

No PFS não existe o conceito de marcas ou marcações. As inscrições em seus elementos indicam apenas quando (em relação a outros elementos) e como estas operam (por indicação textual). As redes PFS têm como objetivo principal mostrar explicitamente os componentes que formam o sistema e quais relações existem entre cada um deles.

O PFS pode ser representado por três elementos básicos (figura 3.4), que são:

- elementos ativos - correspondente às atividades (macro eventos que representam a realização de operações como processamento, montagem, desmontagem);

- elementos passivos - correspondente às inter-atividades (lugares onde material, energia ou informações entram, ficam temporariamente armazenados e saem);

\footnotetext{
${ }^{11}$ Interpretadas para classes específicas de sistemas.
} 
- $\operatorname{arcos}$ - que representam as relações entre os elementos ativos e passivos e indicam o sentido do fluxo de itens (materiais, informações, etc.). Este não representa necessariamente um elemento real do sistema, em geral, descreve uma relação lógica, abstrata entre os componentes.

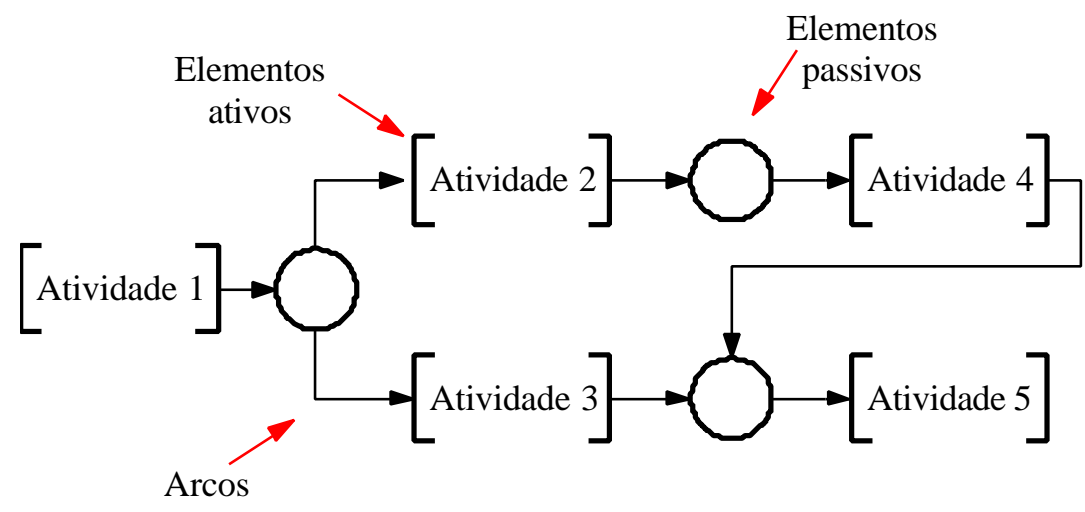

Figura 3.4 - Exemplo de um grafo PFS.

\section{3. $O M F G$}

O Mark Flow Graph (MFG) desenvolvido e adotado como uma forma padronizada de especificação de controle no Japão é um grafo derivado da rede de Petri onde as funções de entrada e saída, a propriedade de "safeness" "12, livre de contato, etc. são devidamente consideradas, visando a modelagem e o controle dos SED de modo mais simples e eficaz [Miyagi, 1996].

\footnotetext{
12 Safeness - com relação à marcação inicial, não é admitido que seja colocada mais de uma marca no interior de um lugar (box). Além disso, pelas condições de habilitação de disparo, e pelas regras de disparo, é impossível que surjam novas marcas nos boxes que já estão marcados. Com isto, após qualquer seqüência de disparo de transições, existe no máximo apenas uma marca no interior de cada box. Desta forma, o MFG é essencialmente "safe" e, além disso, os sistemas representados por ele não apresentam situações de contato [Miyagi, 1996].
} 
Segundo Santos Filho [1993] o MFG possui:

- a capacidade de descrição do comportamento dinâmico do sistema de forma consistente;

- a capacidade de realização de uma descrição funcional para uma estruturação do processo de modelagem;

- disponibilidade de modelos matemáticos eficientes para a análise do sistema e seu projeto;

- a capacidade de realização adequada e eficiente de interfaces homem-máquina e máquina-máquina nos diversos níveis.

O MFG é composto pelos seguintes elementos estruturais [Miyagi, 1996; Santos Filho, 1993]:

- box: indica uma condição e é representado por um bloco quadrado (figura 3.5 (a));

- transição: indica um evento e é representado por uma barra vertical (figura 3.5 (c));

- arco orientado: conecta boxes e transições para indicar a relação entre uma condição e os pré e pós-eventos que o definem. Não existe limite para o número de arcos que entram ou saem de um box ou transição, apenas deve-se observar que entre um par box - transição deve existir apenas um arco que os liga (figura 3.5 (e));

- marca: indica a manutenção de uma condição e é representada por um ponto negro no interior do box correspondente a esta condição (figura 3.5 (f));

- porta: habilita ou inibe a ocorrência dos eventos correspondentes às transições sendo denominadas porta habilitadora (um arco que possui um círculo negro na extremidade conectada à transição - figura $3.5(\mathrm{~g})$ ) ou porta inibidora (um arco que possui um círculo branco na extremidade conectada à transição - figura 3.5 (h)), conforme a sua natureza. Estas, por sua vez podem ser sub classificadas em porta 
externa ou porta interna de acordo com a origem do sinal. A origem do sinal de uma porta interna é um box e a origem do sinal de uma porta externa é de alguma entidade que não faz parte do grafo, ou seja, ela indica a entrada de um sinal binário gerado por algum dispositivo externo;

- arco de sinal de saída: este arco envia um sinal binário do box para uma entidade externa do grafo e é representado por uma linha que conecta estes dois elementos (figura 3.5 (i)). Quando houver uma marca no box o sinal é "1" e, do contrário, é "0".

As portas e arcos de sinal de saída são formas de representação explícitas das condições de controle.

O conceito de marcações e regras de disparo das transições é basicamente o mesmo das Redes de Petri. De fato, o MFG pode ser considerado uma interpretação específica de uma classe de Rede de Petri denominada Rede de Petri Condição - Evento (C/E nets).

A extensão que considera a inclusão do conceito de tempo no MFG, envolve os seguintes elementos:

- box temporizado: quando uma marca aparece neste tipo de box, ela deve necessariamente permanecer neste box um intervalo de tempo (figura 3.5 (b));

- transição temporizada: uma vez que todas as condições de disparo estejam satisfeitas, esta transição só dispara após decorrido um intervalo de tempo. Se durante este tempo uma das condições deixa de ser satisfeita, a contagem do tempo é anulada. Será reiniciada somente após todas as condições estarem novamente satisfeitas (figura 3.5 (d)). 


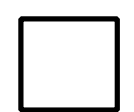

(a) box

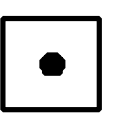

(f) boxe marca

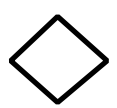

(b) box termporizado

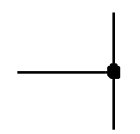

(g) porta habilitadora e transição

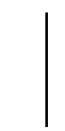

(c) transição

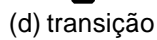

temporizada

(e) $\operatorname{arco}$ orientado

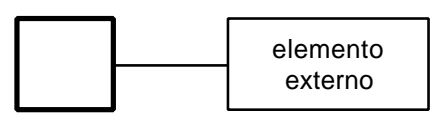

(i) arco de sinal de saída

Figura 3.5 - Elementos estruturais do MFG $^{13}$.

Com base nos elementos acima descritos, é possível gerar macro elementos, isto é, uma modularização do MFG (também denominado de F-MFG (Functional Mark Flow Graph) [Matsusaki, 1998]), efetiva para modelagem, análise e controle de sistemas produtivos. A seguir cita-se alguns macro elementos considerados:

- box capacidade: possui um símbolo $\mathrm{N}$ associado que indica a sua capacidade de alojar em seu interior $\mathrm{N}$ marcas (figura 3.6 (a));

- box agrupador: tem a função equivalente a uma montagem onde $\mathrm{N}$ marcas entram e apenas uma sai (figura $3.6(\mathrm{~b})$ );

- box dispersor: tem a função similar a de uma desmontagem, onde uma marca entra e $\mathrm{N}$ marcas saem (figura 3.6 (c)).

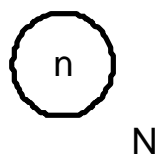

(a) box capacidade

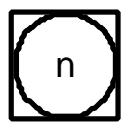

N (b) box agrupador

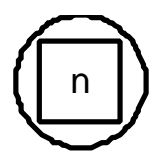

$\mathrm{N}$

(c) box dispersor

Figura 3.6 - Macro elementos do MFG (n indica o número atual de marcas dentro do lugar).

\footnotetext{
${ }^{13}$ Historicamente o MFG original não inclui os elementos temporizados.
} 
Uma das principais características do MFG, que o torna uma classe de Redes de Petri mais efetiva em aplicações práticas que a original, é o fato dele ser desenvolvido especificamente para a modelagem e realização de controle, considerando por exemplo as seguintes características desejáveis nos sistemas de controle:

- "safeness" no controle de SED é uma característica indispensável e, através da aplicação do MFG, as condições que garantem o "safeness" são intrinsecamente consideradas durante o projeto e análise do sistema;

- no MFG existe um controle detalhado das marcas no interior de cada box, e com isto o modelo pode ser tratado também por uma lógica binária. O MFG convertido para esta lógica binária pode ser diretamente utilizado para programar um $\mathrm{CP}$ (Controlador Programável), ou através de uma interpretação adequada para organizar sistemas mais complexos;

- com o MFG, o controle de SED evolui conforme a troca de sinais entre o controlador (grafo MFG) e o objeto de controle, isto é, o controlador envia sinais (através dos arcos de saída) para os dispositivos que fazem com que uma tarefa seja realizada e, ao receber o sinal de confirmação do término da tarefa gerado pelos dispositivos (através das portas externas), passa para a etapa seguinte de controle.

No MFG as tarefas são descritas pelos boxes que podem enviar sinais de estado pelos arcos de saída, o início e término das tarefas são descritas pelas transições condicionados aos sinais das entidades externas. Desta forma, o MFG pode representar adequadamente não só o sistema de controle de SED mas também as conexões entre o controlador e o objeto de controle. 


\subsection{O E-MFG}

O E-MFG é uma derivação do MFG que visa proporcionar maior flexibilidade para a modelagem de sistemas complexos sem perder, no entanto, a sua simplicidade na representação. Suas principais alterações foram a introdução de atributos nas marcas e a associação de regras de produção às transições para representar regras adicionais de disparo [Santos Filho, 1993], tornando-o, em se tratando de modelagem de sistemas de movimentação de materiais, uma das ferramentas mais versáteis. Para que isto fosse possível, seus elementos estruturais básicos tiveram algumas de suas características modificadas e novos elementos foram criados:

- box: indicam as pré e pós-condições, mantendo a natureza condição / evento do sistema;

- box capacidade: funciona de forma análoga ao do F-MFG, porém este permite estabelecer regras de chegada e saída das marcas devido ao fato destas serem distintas;

- box agrupador: semelhante ao do F-MFG com a possibilidade de preservar as informações dos itens (atributos das marcas) que forem agrupados;

- box dispersor: análogo ao do F-MFG, recebendo apenas uma marca individual composta na entrada. A partir do atributo relativo à composição, é possível acessar as informações (atributos) de maneira a recuperar o conteúdo e a ordem de composição das marcas individuais primitivas;

- box controlador: box onde se associa um conjunto de regras para a atualização dos atributos das marcas, as quais são regras de produção do tipo se...então cujos fatos referem-se ao estado dos atributos e a atualização destes fatos também está associada à alteração do estado destes atributos (figura 3.7 (a)); 
- box temporizador: é análogo ao do MFG onde o intervalo de tempo pode ser determinado a partir do estado de alguns dos atributos da marca;

- transição: representa a ocorrência de eventos e admite inscrições que representam regras adicionais restritivas para a evolução do estado do sistema;

- transição temporizada: idem ao do MFG onde o intervalo de tempo pode ser determinado a partir do estado de alguns dos atributos da marca;

- marcas: indicam a manutenção de uma condição, podem ser individualizadas por atributos (figura 3.7 (b)), onde pode-se associar diversas informações referentes ao produto, ao processo, etc., podendo este assumir qualquer tipo ${ }^{14}$;

- marca individual composta: é uma marca que contém os atributos referentes à composição de várias marcas individuais simples

- arcos orientados: estabelecem uma relação causal entre os eventos e as condições, podem conter inscrições variáveis que manipulam a transmissão dos atributos das marcas individuais;

- portas habilitadoras / inibidoras: portas que habilitam ou inibem, respectivamente, a ocorrência de eventos. Esta condição adicional é especificada através de inscrições fixas relacionadas aos atributos agregados às marcas;

- arcos de sinal de saída: podem transmitir informações às entidades externas relativas ao estado dos atributos de uma determinada marca através da especificação de inscrições variáveis nestes $\operatorname{arcos.}$

\footnotetext{
${ }^{14}$ O tipo determina os valores que uma variável pode ter (representação interna destes valores) e as operações que podem ser realizadas com essa variável [Cantù, 1995].
} 


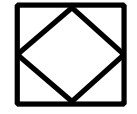

(a) box controlador

\section{Marca $=\S 91, a 2, a 3 \bullet$}

(b) marca e atributos

Figura 3.7 - Representação de um novo elemento (a) e uma nova característica (b) introduzidos pelo E-MFG.

\subsection{Introdução do conceito de Objetos ao E-MFG}

O E-MFG procura combinar conceitos do MFG e de atributos individualizados para maior eficiência na modelagem e representatividade de sistemas produtivos porém, ao se estudar os sistemas de movimentação de materiais através de VATs ${ }^{15}$ verificou-se que a introdução do conceito de objetos tem potencial para uma maior capacidade e simplicidade de modelagem e representatividade.

Desta forma, neste item, procura-se introduzir os conceitos de objetos e, através de exemplos, demonstrar como este envolve uma nova abordagem de modelagem de sistemas utilizando-se o E-MFG.

\subsubsection{Objetos}

A definição de objetos baseia-se em três conceitos fundamentais [por ex.: Cantù, 1995]:

- classe - é um "tipo ${ }^{16}$ de dado" (por ex.: transportador, material) que determina os valores que uma variável pode ter. A classe tem um estado (por ex.: transportador parado, transportador carregando, etc.), uma representação (descrição dos estados e dinâmica do transportador), podem ter algumas operações (carga e descarga de

\footnotetext{
${ }^{15}$ Veículos Autônomos de Transporte.

${ }^{16} \mathrm{O}$ tipo determina os valores que uma variável pode ter (e a representação interna desses valores) e as operações que podem ser realizadas com essa variável [Cantù, 1995].
} 
materiais) e / ou comportamentos. Uma classe possui dados internos e pode possuir métodos (respostas às instruções para parar/movimentar e instruções para carregar/descarregar materiais, por exemplo), na forma de procedimentos ou funções. Uma classe usualmente descreve as características genéricas e o comportamento de uma série de objetos muito semelhantes. Desta forma, pode-se considerar um objeto como uma instância / representação do tipo de dado definido pela classe;

- herança - é a possibilidade de se definir uma nova classe baseando-se em uma já existente (ex.: supondo-se uma classe transportador_1 sem capacidade definida, pode-se definir uma nova classe, transportador_2, baseada na primeira, com capacidade de duas toneladas);

- polimorfismo - indica a capacidade de um objeto assumir várias formas, ou seja, permite-se que se referencie objetos de classes diferentes por meio da mesma variável.

Ao se abordar o conceito de objetos relacionados às Redes de Petri constata-se que existem três tendências sendo estudadas: objetos dentro de Redes de Petri (conhecidas como Redes de Petri de alto nível) versus Redes de Petri dentro de objetos [Bastide, 1995] e uma terceira que considera as duas anteriores Zha, 2000; Lakos, 1995a, 1995b, 1996]. Com a utilização da primeira abordagem visa-se incrementar a quantidade de informação contida nas marcas, as quais são objetos derivados de uma classe e são descritas em alguma linguagem orientada a objetos. Nesta abordagem, é implementada uma única Rede de Petri representando a estrutura de controle do sistema, enquanto as marcas modelam a sua estrutura de dados.

A segunda abordagem, Redes de Petri dentro de objetos, é utilizada para modelar, através das Redes de Petri, as características e o comportamento dos objetos. 
Neste caso, a marcação da rede indica o estado interior do objeto. O interesse fundamental neste tipo de abordagem é o de utilizar construções orientadas a objetos para estruturar o sistema. Como o sistema é dividido em muitos objetos, torna-se necessário a integração entre estes e, mais uma vez, as Redes de Petri podem ser utilizadas para se desenvolver formas de comunicação e interação entre os objetos.

Wang et al. [1998] aplicam a abordagem descrita para modelar um sistema de manufatura automatizado, modelando inicialmente os componentes dos sistema (robôs, máquinas, buffers, etc.) e em seguida os inserindo em um processo produtivo também modelado em Redes de Petri. Delatour \& Paludetto [1998] abordam uma metodologia UML / PNO (Unified Modelling Language / Petri Net Objects) que se assemelha à metodologia PFS / MFG visto que este descreve "o que o analista pode definir como objetos completos sem conhecer bem suas partes”, ou seja, parte-se de um modelo conceitual até a obtenção de um modelo funcional detalhado. De forma semelhante Srinivasan \& Venkatasubramanian [1998] utilizam uma abordagem top-down para descrever as operações de uma planta química.

A terceira abordagem propõe que não apenas a marca seja um dado orientado a objetos mas também que toda a Rede de Petri o seja [Zha, 2000]. Conceitualmente todo elemento é um objeto e pode ser utilizado em qualquer contexto. Conseqüentemente as marcas são objetos que podem conter uma Rede de Petri possibilitando a modelagem de sistemas em vários níveis. Isso implica que as Redes de Petri orientadas a objetos suportam a possibilidade de vários níveis de atividades na rede e o encarregado da modelagem é livre para escolher como as várias atividades serão compostas, ou seja, se um determinado objeto será ativo, passivo ou ambos [Lakos, 1995a]. Todo este conceito de Redes de Petri orientadas a objetos (OPN) abordado por Lakos [1995a, 1995b, 1996] é sustentado nas Redes de Petri Coloridas CPN, ou seja, as redes OPN podem ser 
transcritas para CPN. Nas OPN cada Rede de Petri pode ser definida como uma classe, a qual pode ser instanciada em diferentes contextos, seja por um elemento da rede, seja pela marca.

Considera-se que esta abordagem destaca-se em relação às anteriores, visto que além de as englobar, possibilita diferentes formas de se relacionar os objetos e, com base nesta é que se insere, neste trabalho, o conceito de objetos ao E-MFG afim de tornar mais intuitivo e simples a modelagem de sistemas de movimentação de materiais.

3.5.2. Migração de uma abordagem orientada exclusivamente para processos para uma abordagem híbrida orientada a processos e a objetos na modelagem de sistemas de movimentação de materiais

Ao se abordar sistemas relativamente simples de movimentação de materiais, compostos apenas de uma malha de movimentação e de transportadores utilizando-se a metodologia PFS/E-MFG, observou-se que quando existe variação no número de nós da malha de movimentação ou mesmo o número de transportadores que a percorre é necessário refazer parte do modelo. Evidentemente este trabalho pode ser problemático para sistemas mais complexos. Tratando-se os transportadores como objetos e os encapsulando nas marcas que percorrem a rede representativa da malha de movimentação, é possível reduzir o retrabalho, aproveitando um mesmo modelo para a análise de cenários ${ }^{17}$ distintos.

Para ilustrar a vantagem de se utilizar uma abordagem híbrida orientada a processos e a objetos para a modelagem de sistemas de movimentação de materiais adota-se um exemplo simplificado contendo apenas uma malha de movimentação e um 
transportador. A figura 3.8 ilustra uma malha de movimentação composta por dois nós, denominados como Centros de Custos (todo local onde se realiza uma atividade ou um conjunto de atividades nos materiais que ali são levados) e por dois segmentos orientados, indicando o sentido em que os transportadores se movimentam.

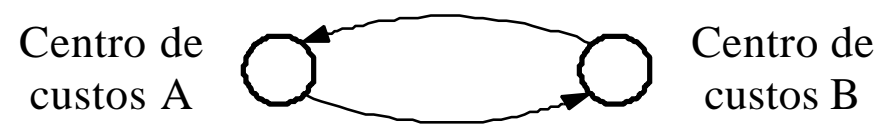

Figura 3.8 -Ilustração de uma malha de movimentação.

Cada um dos Centros de Custos pode ser modelado, utilizando-se a metodologia PFS/E-MFG como ilustrado na figura 3.9. Nele o transportador chega (T1) e fica esperando para ser carregado / descarregado (B1), ocorre a operação de carga ou descarga (B2) e em seguida ele fica esperando a ordem para se deslocar ao próximo Centro de Custos (B3)

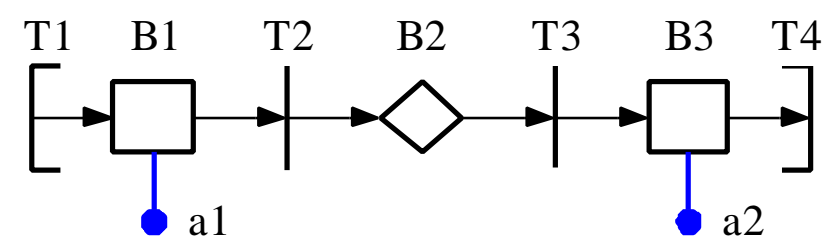

Figura 3.9 - Modelo de um Centro de Custos.

A figura 3.10 ilustra o detalhamento de um arco da malha de movimentação onde B4 é representado por um box temporizador, fazendo-se referência a movimentação de transportadores que é proporcional à distância que separa os dois Centros de Custos e a velocidade do transportador.

\footnotetext{
${ }^{17}$ Um exemplo seria variar o número de transportadores afim de se dimensionar a frota que atenda as necessidade de movimentação da empresa.
} 


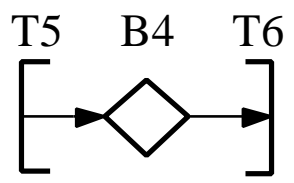

Figura 3.10 - Exemplo de detalhamento de um segmento de malha de movimentação.

O transportador foi modelado de forma simplificada - apenas dois estados onde este pode estar parado (B5) ou se movimentando (B6) (figura 3.11).

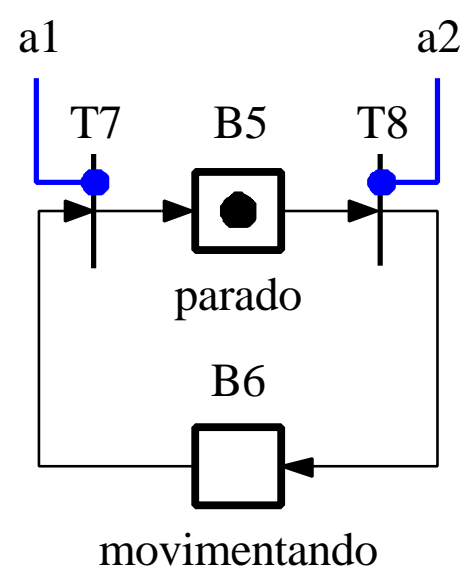

Figura 3.11 - Exemplo de modelo de transportador.

Tomando-se como referência a malha da figura 3.8 e supondo-se a utilização de apenas um transportador (figura 3.11), observa-se que há a necessidade de se incluir duas novas transições (T17 e T18) na parte do modelo referente ao do transportador (figura 3.12). 


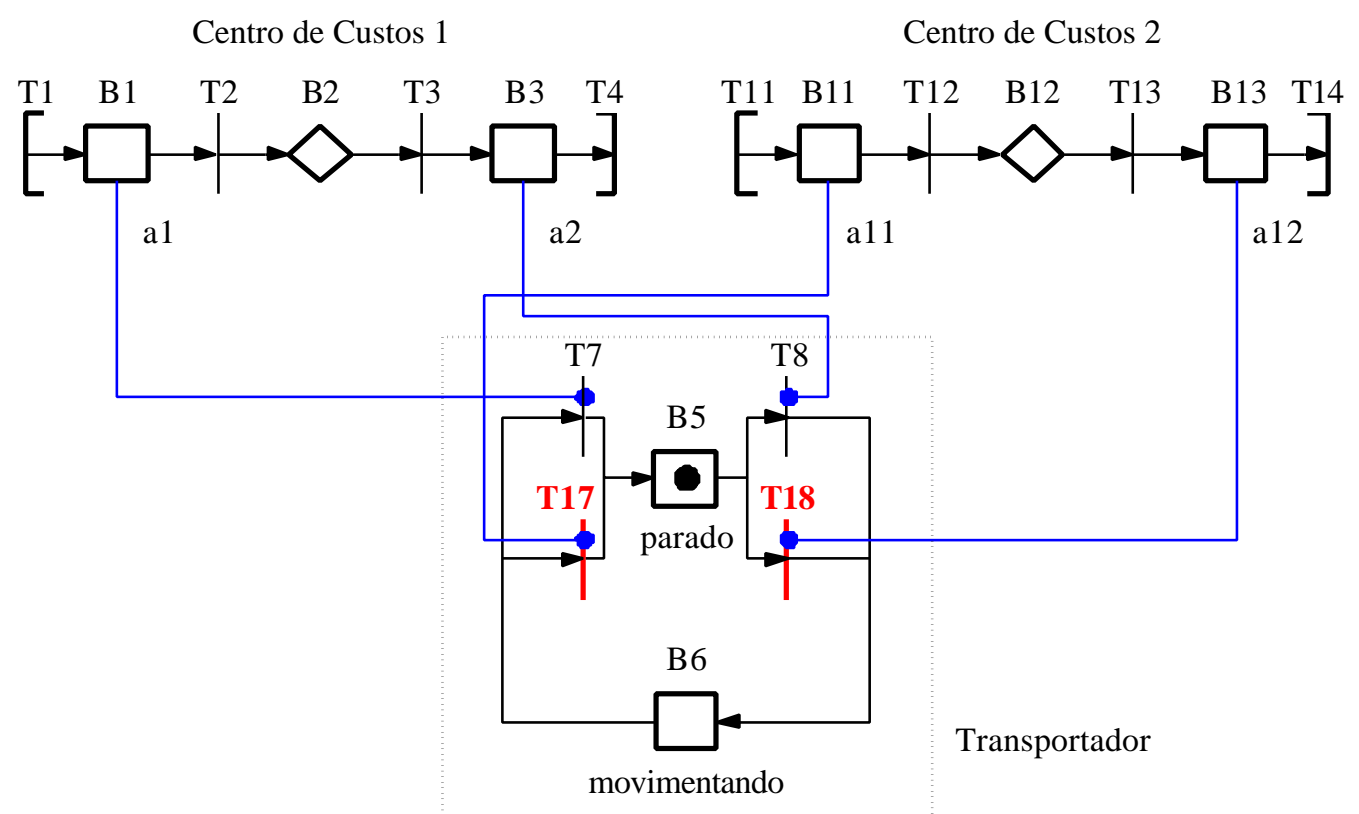

Figura 3.12 - Integração dos modelos dos Centros de Custos com o modelo dos transportadores.

Alterando-se a malha para conter três Centros de Custos (figura 3.13), o que se observa é que na parte do modelo referente ao transportador, o número de transições é novamente acrescida (figura 3.14). Desta forma, pode-se concluir que adotando-se a abordagem orientada apenas a processo o número de transições presentes no modelo do transportador será o dobro do número de Centros de Custos presentes na malha de movimentação.

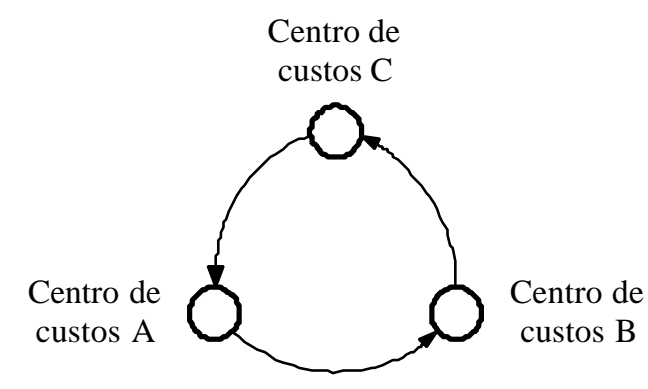

Figura 3.13 - Inclusão de mais um Centro de Custos à malha original (figura 3.8). 
Centro de Custos 1

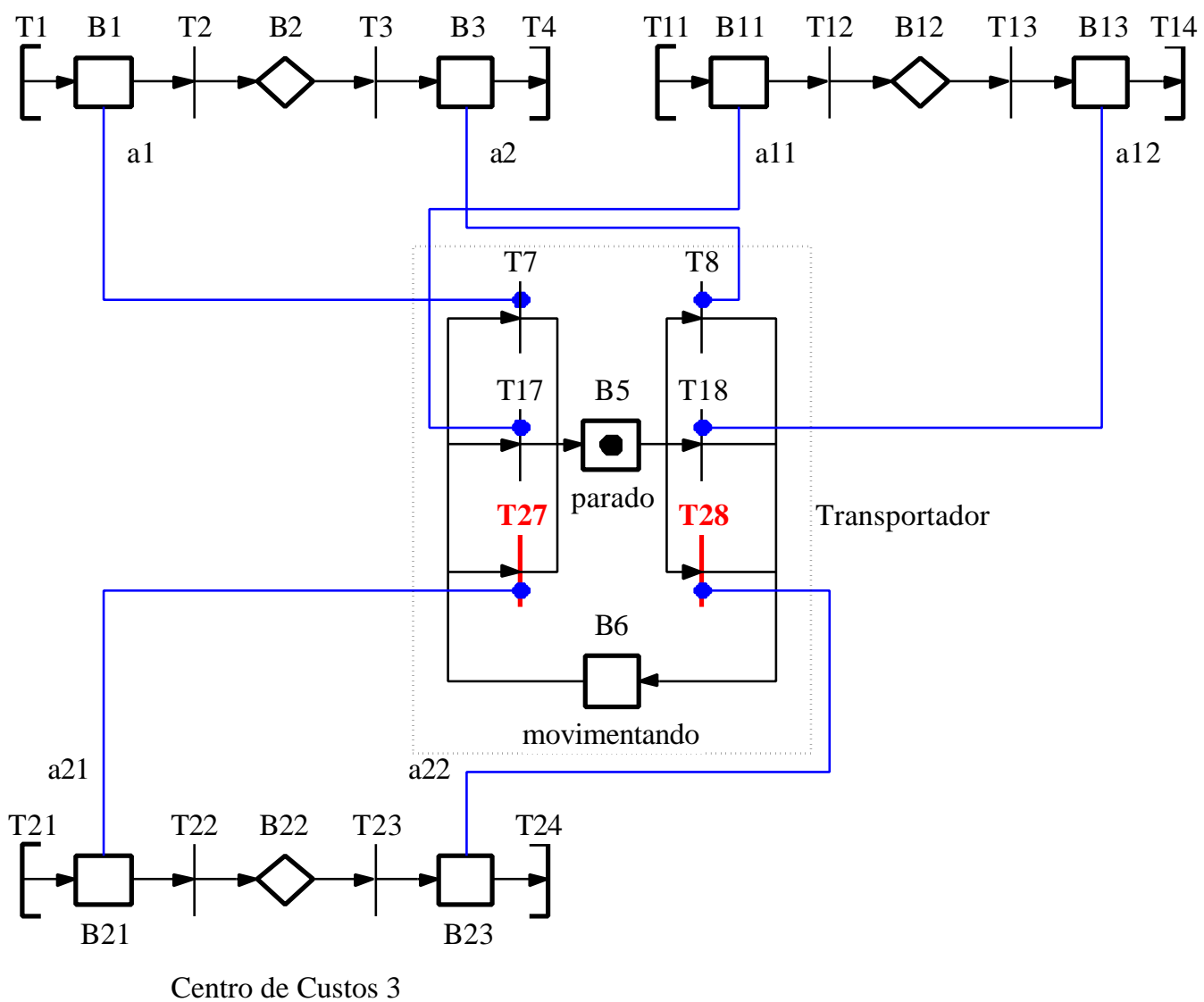

Figura 3.14 - Alteração do modelo da figura 3.12 ao se inserir um novo Centro de Custos.

Mantendo-se fixo o número de Centros de Custos e analisando a variação do número de transportadores, observa-se que existe a necessidade de inserir ou remover $\operatorname{arcos}(\mathbf{a 1}$ e a2) conectando os modelos sempre que o número de transportadores for alterado (figura 3.15). 


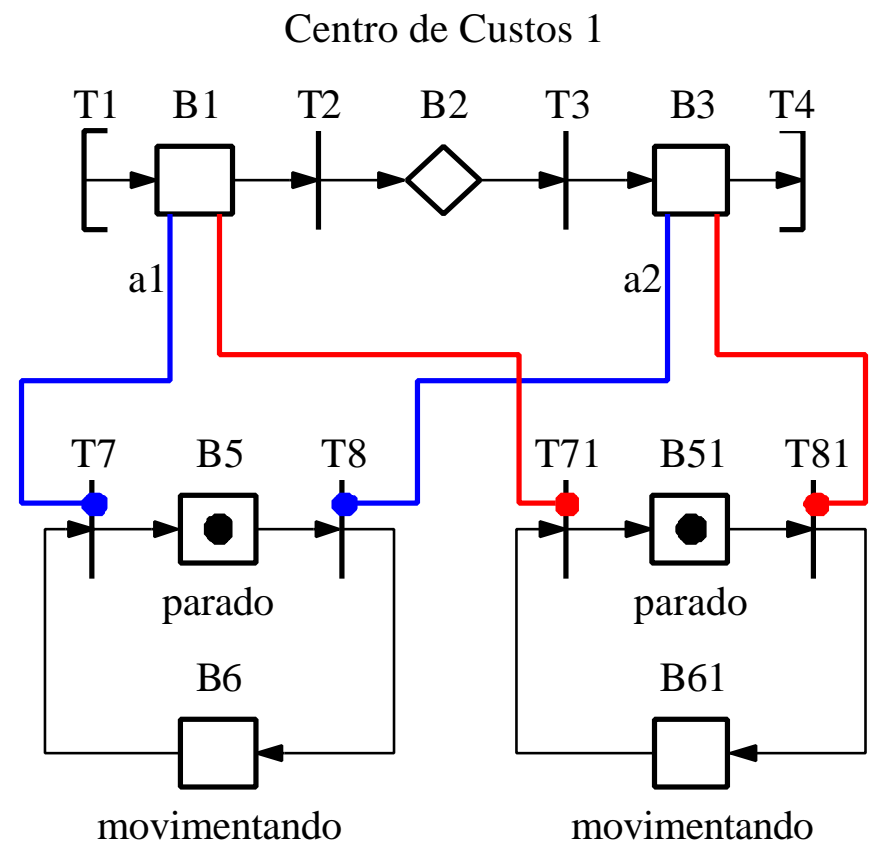

Figura 3.15 - Possíveis modificações no modelo ao se alterar o número de transportadores.

Utilizando-se a abordagem híbrida orientada a processos e a objetos, o modelo do Centro de Custos (figura 3.9) é alterado e as funções realizadas pelos arcos de sinal de saída a1 e a2 são realizados, respectivamente, pelos box controladores B1 e B3 (figura 3.16).

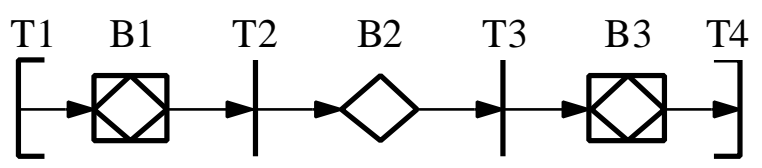

Figura 3.16 - Nova representação para o modelo do Centro de Custos (figura 3.9) ao se adotar a abordagem híbrida orientada a processos e a objetos.

Com relação ao transportador (figura 3.11), este sofre um encapsulamento na marca que percorre a malha de movimentação. As portas habilitadoras a1 e a2 que habilitavam respectivamente $\mathrm{T} 7$ e T8 passam a estar vinculados aos atributos da marca (a1 e a2). Ao chegar a um Centro de Custos, o box controlador B1 (figura 3.16) altera o atributo a1 de "0" para “1”, habilitando a transição T7 (figura 3.11). O arco conectando B1 a T2 (figura 3.16) filtra o atributo fazendo com que este volte ao seu estado original. 
Da mesma forma, o box controlador B3 (figura 3.16) altera o atributo a2, da marca, de "0" para "1", habilitando a transição T8 (figura 3.11). O arco que conecta B3 a T4 (figura 3.16) filtra o atributo fazendo com que ele retorne ao seu estado original. Por fim, o último atributo da marca é o próprio grafo (figura 3.11). A figura 3.17 ilustra o encapsulamento do transportador, onde pode-se observar que os atributos a1 e a2 são sua interface com o meio externo.

\footnotetext{
$\S_{\operatorname{marca} \bullet} \equiv \S_{1} 1, \mathrm{a} 2$, grafo $\bullet$
}

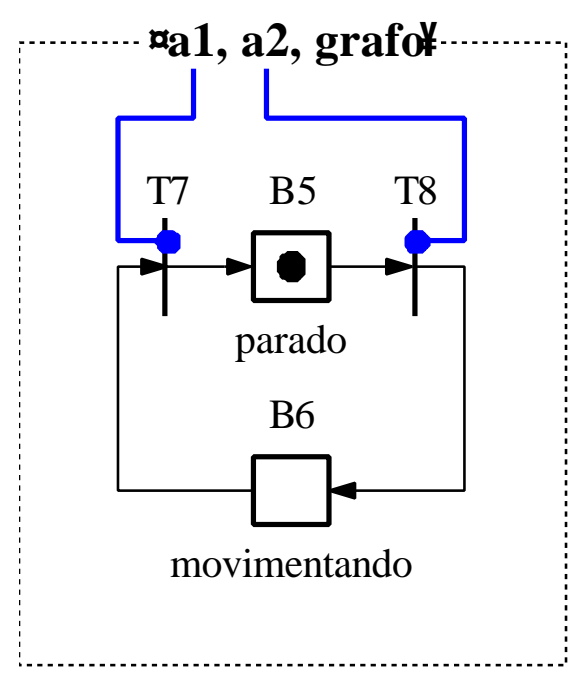

Figura 3.17 - Representação de encapsulamento do modelo do transportador (figura 3.11)

Utilizando-se a abordagem híbrida não há a necessidade de se introduzir ou retirar transições no modelo do transportador (figuras 3.12 e 3.14 ) e nem alterar o número de arcos que partem dos Centros de Custos e chegam aos transportadores (figura 3.15). Outra característica que o modelo passa a apresentar é o conceito de herança. Por exemplo, se for necessário considerar uma certa capacidade para o transportador basta criar uma nova classe de marcas (\$marca2•), baseada na classe já existente e incluir um novo atributo, definindo a sua capacidade. 


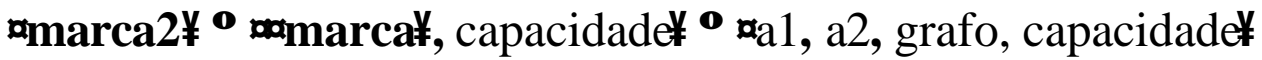

\subsection{Síntese do capítulo}

Como método para modelagem, a técnica do PFS / E-MFG foi considerada neste trabalho devido às suas qualidades de clareza e possibilidade de se realizar o controle (gerar automaticamente a especificação do controle). Outra grande vantagem desta técnica é que ela pode ser utilizada tanto na modelagem da planta - modelo funcional como na do processo - modelo voltado para o controle de atividades específicas. Porém, visando-se garantir maior flexibilidade na construção de modelos, foi introduzida uma abordagem híbrida de modelo orientado a processo e modelo orientado a objeto. 


\section{Metodologia para a modelagem de sistemas flexíveis de movimentação de materiais em ambiente fabril}

Neste capítulo procura-se demonstrar como a metodologia PFS/E-MFG apresentada no capítulo anterior pode ser empregada na modelagem dos componentes de sistemas de movimentação de materiais através de transportadores de alta flexibilidade, de uma forma genérica.

A metodologia para a modelagem de sistemas flexíveis de movimentação de materiais em ambiente fabril pode ser descrita em quatro passos / etapas como ilustra a figura 4.1 .

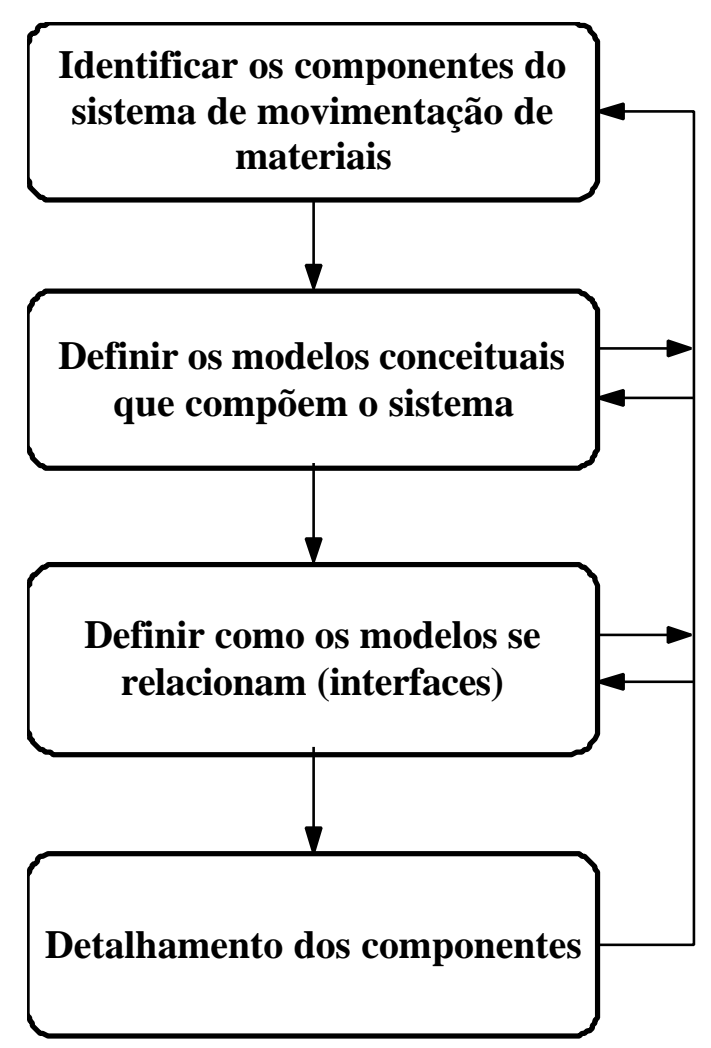

Figura 4.1 - Metodologia para a modelagem de sistemas de movimentação de materiais em ambiente fabril. 


\section{Passo 1: Identificar os componentes do sistema de movimentação de materiais.}

Nesta etapa identifica-se os componentes do sistema e suas características. Para o problema específico de sistemas flexíveis de movimentação de materiais em ambiente fabril, tem-se como exemplos de componentes do sistema:

- transportadores - frota homogênea ou heterogênea; quantidade; capacidade de carga que comporta; etc.;

- pontos de distribuição de transportadores (em alguns casos pode ser classificado como garagem) -quantidade, imposições de retorno dos transportadores aos centros; etc.;

- características da demanda - demanda determinística, estocástica ou a possibilidade de satisfação parcial da demanda;

- características da malha - número de centros de custos (nós) que compõem a malha; características da ligações entre os centros de custos (unidirecional, bidirecional, ou a coexistência de ambas);

- características dos centros de custos (nós) - que atividades são desempenhadas nos centros de custos;

- custos - quais os custos envolvidos (por exemplo: combustível, aquisição de novos transportadores, manutenção, etc).

\section{Passo 2: Definir os modelos conceituais que compõem o sistema.}

Baseando-se na tabela 2.1 do capítulo 2 e nas várias abordagens e problemas descritos ao longo do referido capítulo, destacam-se 2 elementos principais dos sistemas de movimentação de materiais, cujos modelos conceituais devem ser devidamente definidos: 
- [Malha de Movimentação] composta por nós e arcos que são representados, respectivamente, pelas atividades [Centro de Custos $i]$ e [Transporte entre $i$ e $j$ ];

- as marcas que percorrem a [Malha de Movimentação] e que podem representar instruções, transportadores, entre outros.

\section{Passo 3: Definir como os modelos se relacionam (interfaces).}

Num primeiro instante, define-se onde estão os relacionamentos e ao longo da etapa de detalhamento dos componentes é que são detalhadas as informações que estão sendo trocadas entre os modelos. Como exemplos de relacionamentos citam-se:

- [Centro de Custos] e o [Sistema de Controle] (externo ao modelo) - o [Centro de Custos] recebe, por exemplo, informações para serem repassadas ao transportador sobre as atividades que este deve desempenhar e informa ao [Sistema de Controle] a posição do transportador;

- [Transporte entre $i$ e $j$ ] e o [Sistema de Controle] (externo ao modelo) - o [Transporte entre $i$ e $j$ ] pode, por exemplo, transmitir ao [Sistema de Controle] informações sobre demanda nos arcos para um problema caracterizado como de carteiro chinês com restrição de capacidade (item 2.3.1 - caso G);

- [Centro de Custos] e transportadores - o [Centro de Custos] pode transmitir informações sobre as atividades que o transportador deve desempenhar.

\section{Passo 4: Detalhamento dos componente.}

Por fim, tem-se o detalhamento dos componentes do sistema partindo-se dos modelos conceituais até a obtenção dos modelos funcionais. Cada um destes itens será abordado de forma separada, onde procura-se mostrar possíveis variações que estes podem assumir. 


\subsection{Malha de movimentação}

A malha de movimentação é originalmente baseada em um grafo que pode ser ou não orientado composto por nós que podem representar a localização de garagens e centros de custo ${ }^{18}$ (esta é a nomenclatura adotada pela grande maioria dos problemas de programação e roteirização) ou mesmo simples conexões (problema do carteiro chinês) e $\operatorname{arcos}$, que são as possíveis ligações entre os nós.

Baseando-se na rede da figura 4.2, é possível gerar uma representação equivalente destacando os seus elementos (centros de custos e $\operatorname{arcos}$ ) utilizando-se o PFS (figura 4.3) e desta forma dar início a um processo de detalhamento das atividades ( [atividades] ). Cada nó é representado por uma atividade [centro de custo $i$ ] e cada arco, se for unidirecional, é representado por uma atividade [transporte entre $i$ e $j$ ] e, caso contrário, por duas atividades: [transporte entre $i$ e $j$ ] e [transporte entre $j$ e $i$ ].

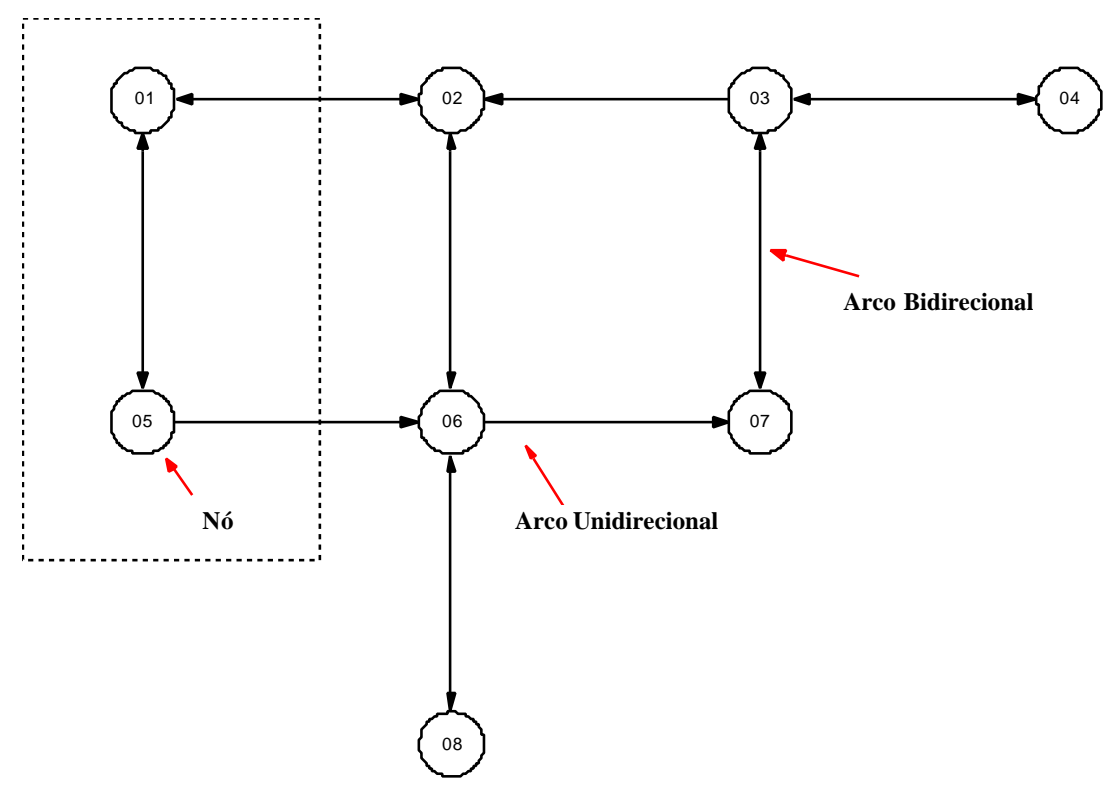

Figura 4.2 - Modelo representativo da malha de movimentação.

\footnotetext{
${ }^{18}$ Centro de custo é todo local onde se realiza uma atividade ou um conjunto de atividades nos materiais que ali são levados.
} 


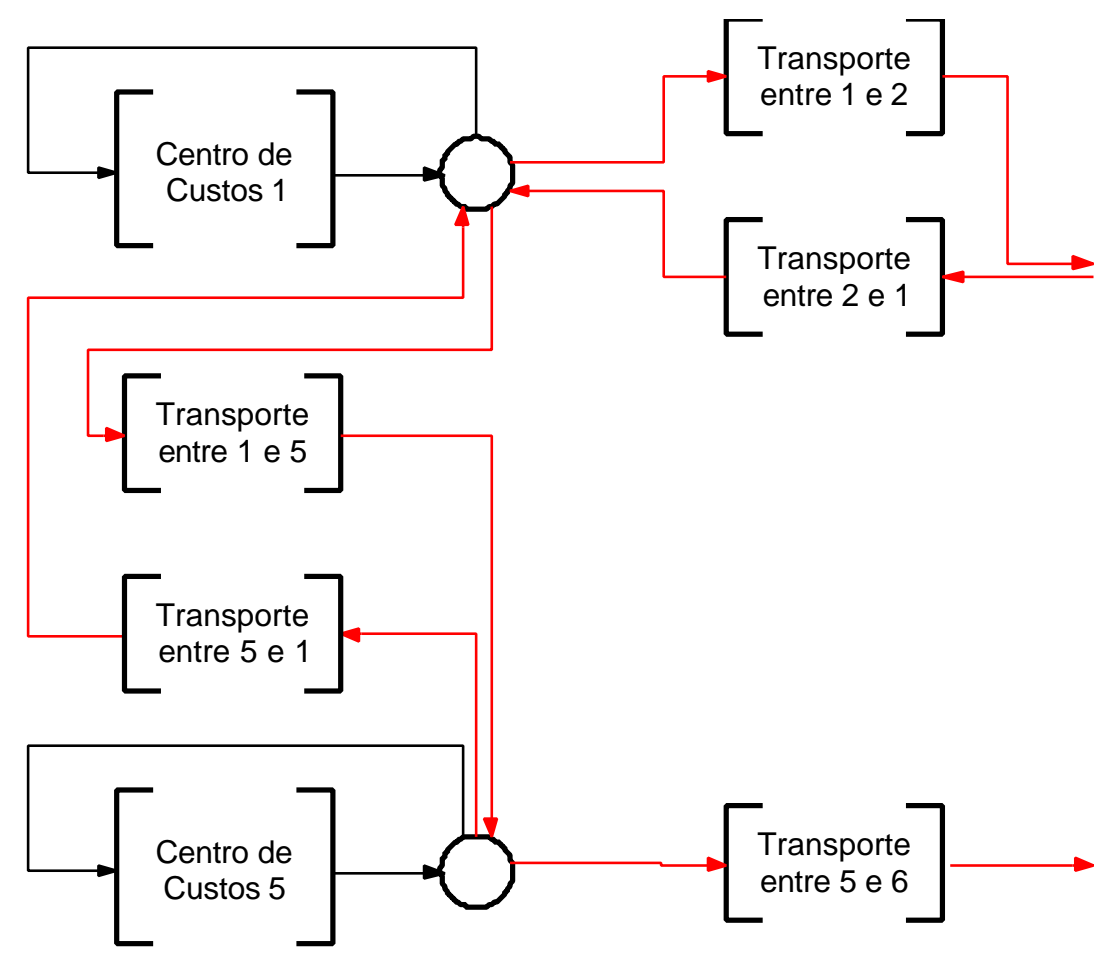

Figura 4.3 - Representação, em PFS, da região em destaque da figura 4.1.

Na figura 4.4 estão representados alguns exemplos de modelos em E-MFG para uma interligação (atividade de [transporte entre $i$ e $j$ ]) entre os centros de custo $i$ e $j$, representando a capacidade para um transportador, mas esta poderia ser expandida, ou mesmo ter sua capacidade reduzida. Ainda com relação aos possíveis modelos, tem-se:

- figura 4.4 (a) - é um modelo representando o tempo (box B2) necessário para se percorrer a distância entre dois nós, ou ainda, considerando-se a velocidade de movimentação constante e padronizada, pode-se considerar como sendo a distância que separa os referidos nós (pode ser utilizado para representar os arcos em problemas de roteirização de transportadores (item 2.3.1 - casos A, B, C, D, E e F) e problemas de roteirização e programação de tarefas para transportadores (item 2.3.3 - casos A e B);

- figura 4.4 (b) - este, além de representar o tempo (box B2) também considera outras restrições impostas ao percurso, como a distância máxima percorrida por cada 
transportador, que é especificada por B4 (pode ser utilizado para representar os arcos em problemas de programação de tarefas (item 2.3.2 - casos B, C e D));

- figura 4.4 (c) - neste modelos informa-se (através de a1) ao sistema de roteirização/ programação características, como a demanda, no caso de um problema de carteiro chinês com restrição de capacidade (pode ser utilizado para representar os arcos em problemas de roteirização de transportadores (item 2.3.1 - caso G));

- figura 4.4 (d) - neste modelo são sinalizadas (através de a1) ao sistema se roteirização / programação informações sobre o comprimento da rota, por exemplo, afim de se trabalhar com tal restrição (pode ser utilizado para representar os arcos em problemas de programação de tarefas (item 2.3.2 - caso A)). A diferença deste para o da figura 4.4 (b) é que neste a distância é explicitada.

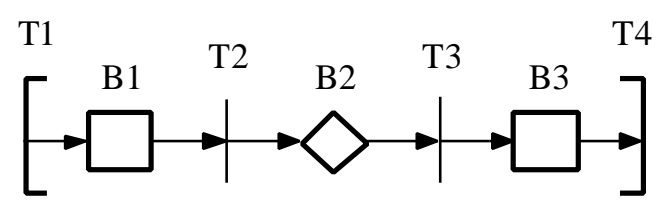

(a)

T1 a1

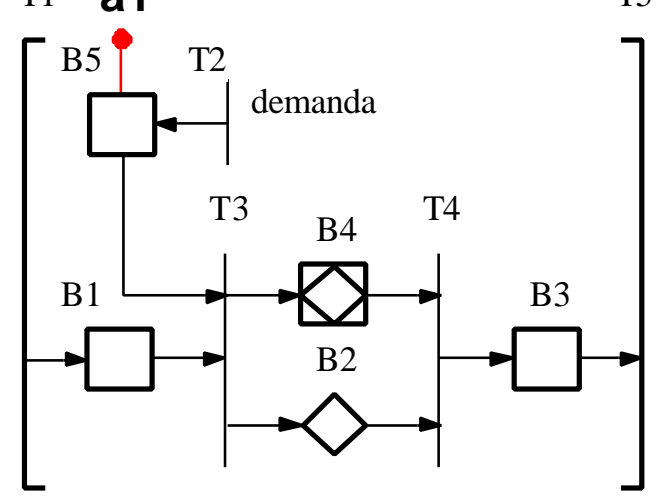

(c)

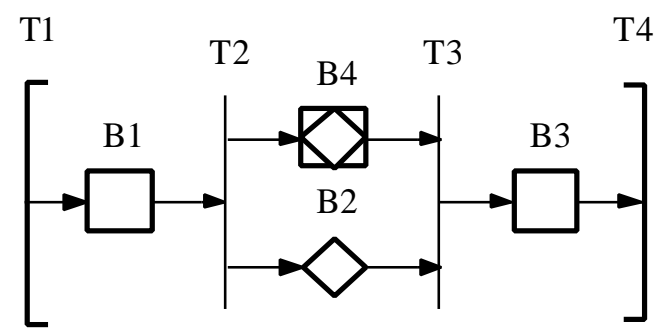

(b)

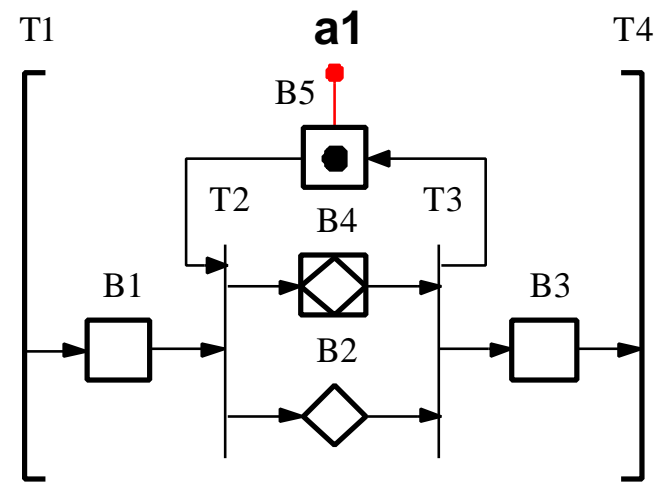

(d)

Figura 4.4 - Possíveis detalhamentos das ligações entre os nós da malha de movimentação (atividade de [transporte entre $i$ e $j]$ ). 
Os boxes representando "início" (B1 (figuras 4.4 (a), (b), (c) e (d))) e "fim" (B3 (figuras 4.4 (a), (b), (c) e (d))) da movimentação dos transportadores são utilizados para se ter um detalhamento do que ocorre na interligação. A seleção do caminho é arbitrada pelos atributos da marca.

A figura 4.5 ilustra possíveis detalhamentos da atividade [centro de custo $i$ ]:

- figura 4.5 (a) - esta representação do nó (centro de custos) onde o box B2 é encarregado de redirecionar a marca para o próximo centro de custos (pode ser utilizado para representar os nós em problemas de roteirização de transportadores (item 2.3.1 - casos A, B, C e G));

- figura 4.5 (b) - este difere do anterior pelo fato de contemplar o tempo da operação de carga / descarga (box B4) (pode ser utilizado para representar os nós em problemas de roteirização de transportadores (item 2.3.1 - casos A e B));

- figura 4.5 (c) - neste modelo, através de a1, são explicitadas informações para o controle como, por exemplo, a demanda, a janela de tempo em que a demanda deve ser atendida, assim como outras informações que sejam relevantes conforme o problema estudado (pode ser utilizado para representar os nós em problemas de roteirização de transportadores (item 2.3.1 - casos D, E e F) e problemas de programação de tarefas (item 2.3.2 - casos A, B, C e D));

- figura 4.5 (d) - esta é uma representação mais elaborada de um centro de custos onde as operações de carga (B2) e descarga (B4) são representadas individualmente, além de se contemplar que este possa ser um centro de custos intermediário da malha de movimentação por permitir que o transportador o transponha sem realizar nem operações de carga e nem de descarga de materiais (T2) e permitir uma sucessão de operações (descarga e logo após carga) através de T5 (pode ser utilizado 
para representar os nós em problemas de roteirização e programação de tarefas para transportadores (item 2.3.3 - caso A));

- figura 4.5 (e) - este é um variante do anterior por poder trabalhar com cargas parciais (em B6 é indicada a quantidade de carga a ser transportada e em B5 a quantidade que deve ser descarregada que são explicitadas ao sistema de roteirização / programação através de a1 e a2 respectivamente) (pode ser utilizado para representar os nós em problemas de roteirização e programação de tarefas para transportadores (item 2.3.3 - caso B)).

A figura 4.6 ilustra casos particulares de nós que são possíveis representações para os centros de distribuição ou garagens. A figura 4.6 (a) seria uma possível representação para o caso de um transportador e a figura 4.6 (b) para o caso de múltiplos transportadores.

\subsection{Marcas}

Tratando-se os sistemas de movimentação de materiais descritos no item 2.3, pode-se considerar que as marcas, na grande maioria dos casos, representam as entidades que realizam a movimentação dos materiais, como por exemplo, transportadores.

Tomando-se os exemplos das figuras 4.4, 4.5 e 4.6, poderia-se dizer que as marcas que são inseridas nos modelos através da transição $\mathrm{T} 1$ representam o transportador. As demais marcas, que são inseridas através de outras transições - como por exemplo T2 (figura 4.6 (a)) que pode representar instruções de caminho que o transportador deve percorrer - ou que já estão presentes no modelo - como em B5 
(figura 4.4 (d)) que pode servir para explicitar o comprimento entre dois centros de custos - representam informações necessárias para a dinâmica do modelo.

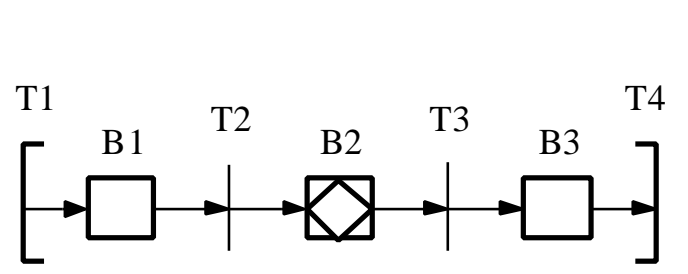

(a)

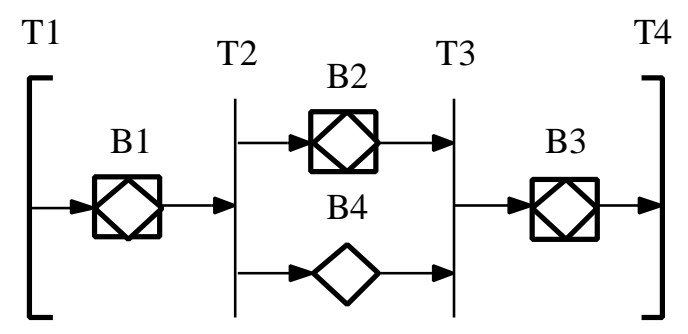

(b)

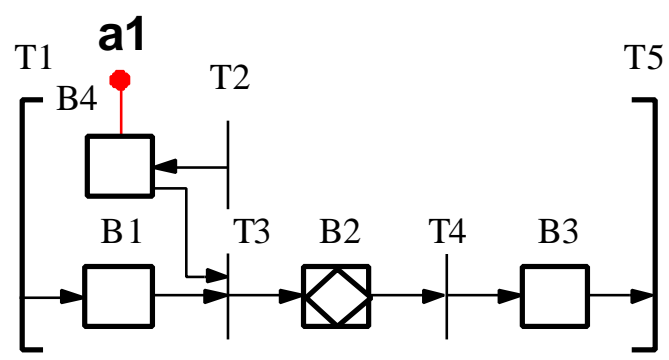

(c)

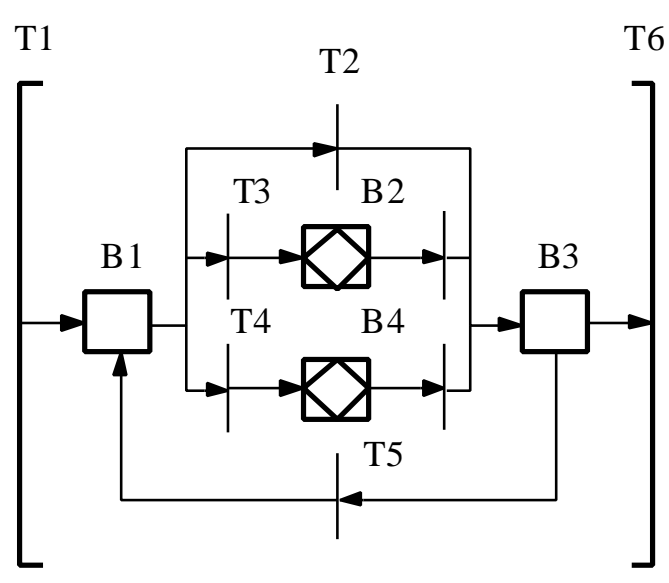

(d)

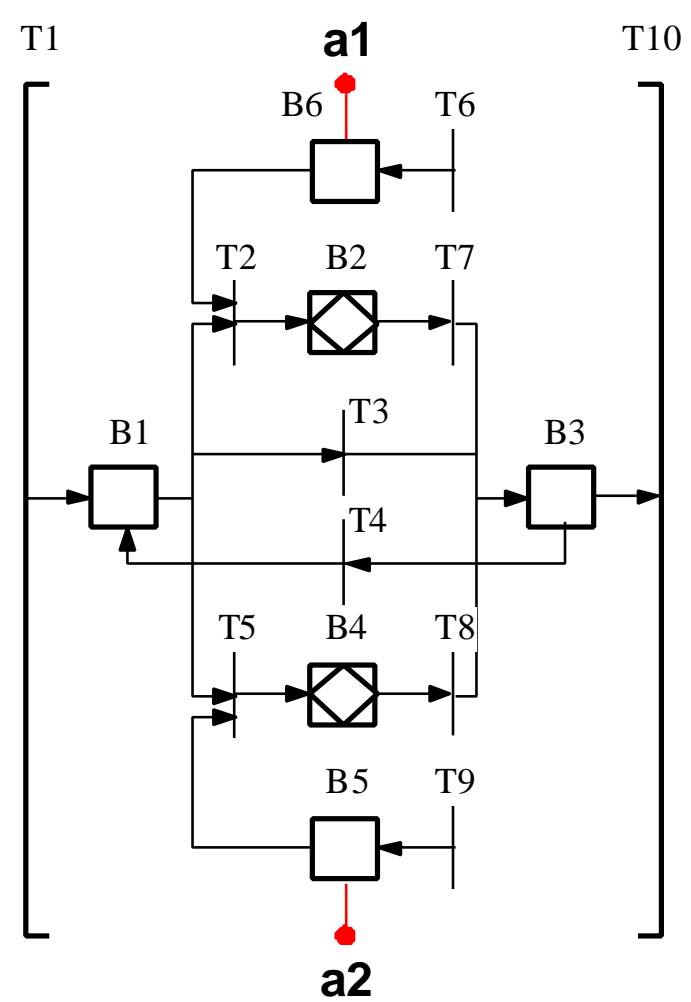

(e)

Figura 4.5 - Possíveis detalhamento da atividade [centro de custo $i$ ] referente ao tratamento dos transportadores. 


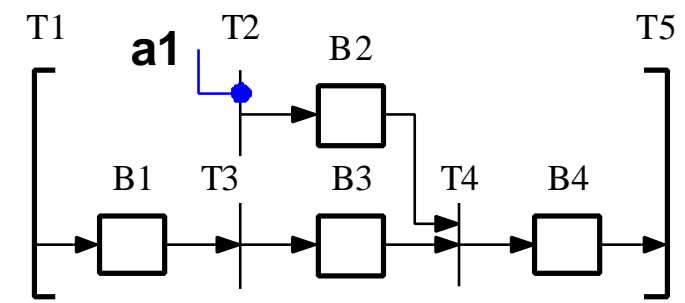

(a)

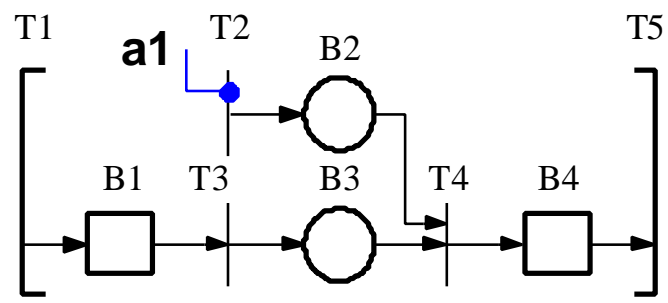

(b)

Figura 4.6 - Possíveis detalhamento da atividade [centro de custo $i$ ], sendo este um nó garagem / cento de distribuição.

Como forma de exemplificar, segue alguns problemas de roteirização / programação baseados no item 2.3 com as possíveis interpretações que as marcas podem assumir:

- problemas de roteirização de transportadores (item 2.3.1 - caso A) - pode-se compor um modelo para representar este problema compondo-se modelos de arcos da figura 4.4 (a) com modelos de centros de custos da figura 4.5 (a). Uma possível marca para ser utilizada neste problema pode conter informações sobre o caminho que um transportador deve percorrer para atender uma demanda.

\section{§marca $\bullet \equiv$ caminho $\bullet$}

O atributo $\S$ caminho $\bullet$ pode ser representado por uma lista encadeada, que é "desempilhada" de um elemento pelo box controlador B2 (figura 4.5 (a)) sempre que chega a um centro de custo, evidenciando-se, assim, o próximo destino. Um exemplo é apresentado na tabela 4.1, onde um transportador é instruído para se movimentar do centro de custos 1 ao 7 no contexto da malha na figura 4.2. 
Tabela 4.1 - Comportamento do atributo §caminho• para um exemplo de transportador se movimentar do centro de custos 1 para o centro de custos 7 (figura 4.2).

\begin{tabular}{|l|c|c|c|}
\hline & B1 & B2 & B3 \\
\hline Arco de 1 para 2 (figura 4.4 (a)) & $\mathbf{2} \rightarrow 6 \rightarrow 7$ & $\mathbf{2} \rightarrow 6 \rightarrow 7$ & $\mathbf{2} \rightarrow 6 \rightarrow 7$ \\
\hline Centro de Custos 2 (figura 4.5 (a)) & $\mathbf{2} \rightarrow 6 \rightarrow 7$ & $\mathbf{6} \rightarrow 7$ & $\mathbf{6} \rightarrow 7$ \\
\hline Arco de 2 para 6 (figura 4.4 (a)) & $\mathbf{6} \rightarrow 7$ & $\mathbf{6} \rightarrow 7$ & $\mathbf{6} \rightarrow 7$ \\
\hline Centro de Custos 6 (figura 4.5 (a)) & $\mathbf{6} \rightarrow 7$ & $\mathbf{7}$ & $\mathbf{7}$ \\
\hline Arco de 6 para 7 (figura 4.4 (a)) & $\mathbf{7}$ & $\mathbf{7}$ & - \\
\hline Centro de Custos 7 (figura 4.5 (a)) & $\mathbf{7}$ & - & $\mathbf{7}$ \\
\hline
\end{tabular}

- problemas de roteirização de transportadores (item 2.3.1 - caso D) - este problema pode ser composto por modelos de arcos da figura 4.4 (a) com modelos de centros de custos da figura 4.5 (c). As marcas geradas nos centros de custo através de T2 representam a demanda por um determinado material e esta é explicitada ao sistema de roteirização / programação através do arco de sinal de saída a1.

\section{§informação $\bullet \equiv$ \$lemanda $\bullet$}

As marcas que atingem os centros de custos através de T1 contêm informações sobre o caminho (como visto anteriormente) e a quantidade de material que está sendo transportada.

§marca $\bullet \equiv$ caminho, quantidade transportada, $-\bullet$ 
Ao atingirem B2 (figura 4.5 (c)) o box controlador atualiza o §caminho • desconta da §quantidade transportada • a §demanda •. A tabela 4.2 ilustra a dinâmica do modelo.

Tabela 4.2 - Dinâmica das marcas onde se aborda problemas de restrição de capacidade (grafo da figura 4.5 (c)).

\begin{tabular}{|c|c|c|c|c|}
\hline & \multicolumn{4}{|c|}{ Centro de Custo $i$} \\
\hline Instante & B4 & B 1 & B2 & B3 \\
\hline 1 & §demanda $\bullet$ & & & \\
\hline 2 & §demanda $\bullet$ & $\begin{array}{l}\text { \$caminho, quantidade } \\
\text { transportada, - } \bullet\end{array}$ & & \\
\hline 3 & & & $\begin{array}{l}\text { \$caminho, quantidade } \\
\text { transportada, demanda }\end{array}$ & \\
\hline 4 & & & & $\begin{array}{c}\text { \$caminho, quantidade } \\
\text { transportada - demanda, - • }\end{array}$ \\
\hline
\end{tabular}

- problemas de programação de tarefas (item 2.3.2 - caso A) - este problema pode ser composto por modelos de arcos da figura 4.4 (d) com modelos de centros de custos da figura 4.5 (c). As marcas geradas nos centros de custo através de T2 representam a demanda por um determinado bem e a janela de tempo que a demanda deve ser atendida. Estas informações são explicitadas ao sistema de roteirização / programação através do arco de sinal de saída $\mathbf{a 1 .}$

\section{Sinformação $1 \bullet \equiv$ Satender a partir de, atender até, demanda $\bullet$}

Já nos arcos, as marcas em B5 (figura 4.4 (d)) explicitam para o sistema de roteirização / programação a distância entre dois centros de custos ligados por um arco. 


\section{Sinformação $2 \bullet \equiv$ §listância •}

As marcas que atingem tanto os arcos como os centros de custos através de T1 contêm informações sobre o caminho (como visto anteriormente), quantidade de material que está sendo transportada e restrições de distância que o transportador pode percorrer.

§marca $\bullet §$ caminho, quantidade transportada, distância limite, $-\bullet$

A interação entre as marcas se dá da mesma forma como apresentado para o problema de roteirização de transportadores (item 2.3.1 - caso D) (\$marca• e §informação 1• interagem nos centros de custo (box controlador B4) e $\$$ marca • e Sinformação $2 \bullet$ interagem nos arcos (box controlador B4)).

- problemas de roteirização e programação de tarefas para transportadores (item 2.3.3 - caso A) - este problema pode ser composto por modelos de arcos da figura 4.4 (a), com modelos de centros de custos da figura 4.5 (d) e com centros de distribuição (figura 4.6 (b)). Nos centros de distribuição, as marcas transmitidas pelo sistema de controle através de a1 representam as instruções de controle que regem o movimento do transportador. Além disso, neste modelo o transportador foi explicitado através de um E-MFG e encapsulado na marca (ver item 3.5.2). Desta forma, pode-se obter modelos mais elaborados (figura 4.7) onde torna-se possível considerar tempos de engate e desengate de carretas, por exemplo. 


\section{§marca $\bullet \equiv$ \$instrução $\bullet$ \$transportador $\bullet$}

Sinstrução $\bullet \equiv$ §origem, destino, caminho $\bullet$

Stransportador $\bullet \equiv$ §identificação, a1, a2, a3, a4, a5, grafo •

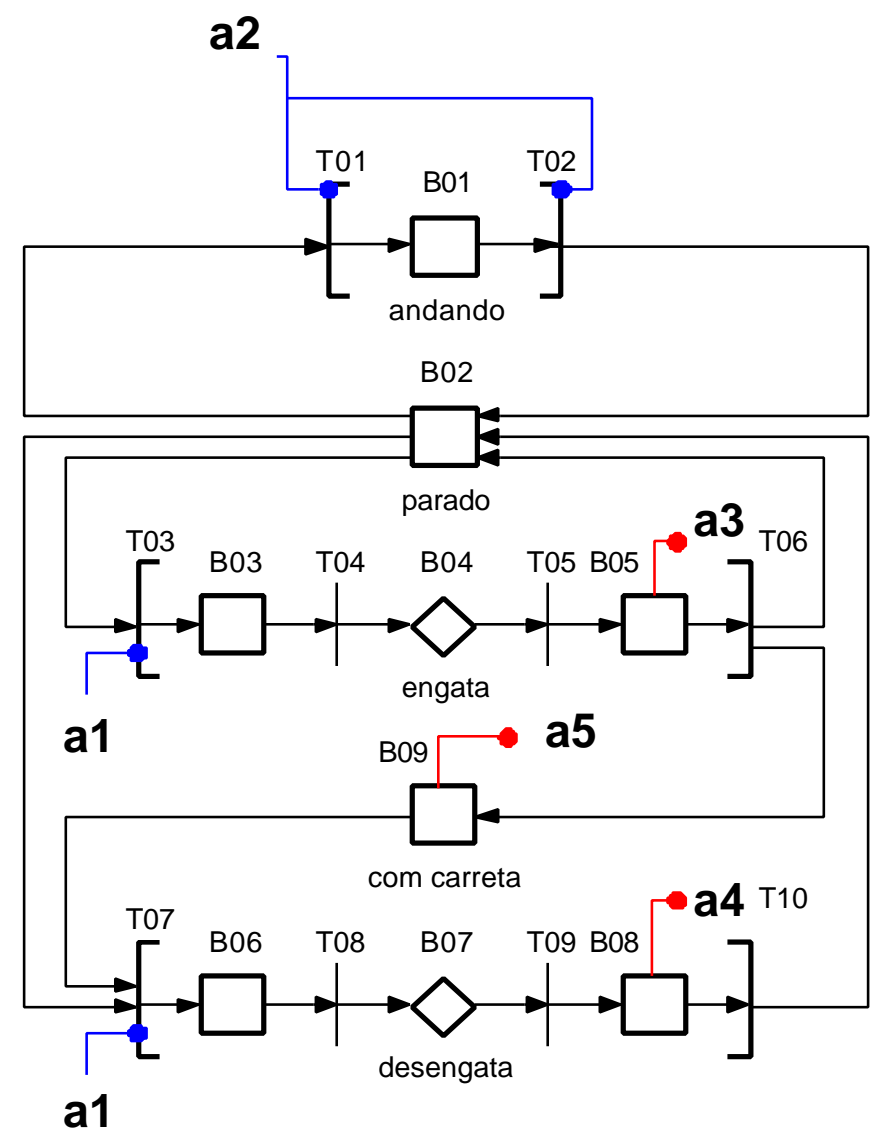

Figura 4.7 - Possível modelo de transportador para o problema de programação e roteirização de transportadores com carga total.

\subsection{Síntese do capítulo}

Neste capítulo, procurou-se introduzir uma metodologia para a modelagem de sistemas de movimentação de materiais partindo-se de um grafo da malha de movimentação, passando-se pela modelagem conceitual da malha em PFS e por fim, o 
detalhamento de suas atividades em E-MFG. Da mesma forma, esta metodologia foi empregada para a modelagem do transportador.

Apesar da metodologia ser genérica e poder ser utilizada na modelagem de vários sistemas de movimentação de materiais, deve-se ressaltar que para cada caso em particular existem variações dos modelos de forma a se obter uma representação tão fiel quanto possível do sistema real. 


\section{Aplicação para o projeto de um sistema de controle}

Neste capítulo é empregada a metodologia descrita no capítulo anterior para a modelagem de um sistema de movimentação de materiais em ambiente fabril baseado em um estudo de caso desenvolvido por Santos Filho [1998] relativo à planta da Mercedes Benz do Brasil localizada em São Bernardo do Campo, São Paulo. Neste sentido, o que se procura é demonstrar, de forma simplificada, a efetividade da metodologia desenvolvida para a modelagem de um sistema de controle de um sistema flexível de movimentação.

O primeiro passo é a definição do problema, identificando os componentes do sistema e suas características. Baseando-se na tabela 2.1, este problema pode ser caracterizado como a seguir:

- transportadores - frota homogênea, composta por um ou múltiplos transportadores,

e que não necessitam de base de distribuição, visto que a única tarefa destes é movimentar carretas (cheias ou vazias) entre os centros de custo. A restrição imposta a estes é que podem transportar, no máximo, uma carreta por vez. Ainda com relação aos transportadores, estes estão sujeitos às operações de engate e desengate de carretas;

- carreta - frota composta de uma ou mais carretas, podendo ou não serem homogêneas e são sujeitas a operações de carga e descarga de materiais;

- característica da demanda - quando se aborda o conceito de demanda no problema em questão, esta se refere à movimentação de carretas entre os centros de custos e não aos materiais. Considera-se que o número de unidades de um determinado material que são transportadas por cada carreta é determinada por uma entidade 
denominada PPCPE (planejamento, programação e controle da produção e estoques) e que não está sendo abordada neste caso;

- característica da rede - a rede é formada por centros de custos onde podem ser realizadas operações nos materiais (nós) e caminhos (segmentos) que podem ser utilizados para a movimentação de materiais entre os centros de custos que são não direcionais, ou seja, a movimentação pode ocorrer nos dois sentidos;

- custos - há dois tipos de custos envolvidos: o de movimentação dos transportadores que implicam em consumo de combustível e o custo de oportunidade ou atraso do processo que pode vir a prejudicar outras etapas do processo produtivo. Com base nestes custos e tendo-se em vista a competitividade do mercado, neste estudo de caso visa-se primeiro a minimização dos atrasos na linha de produção, seguido da otimização da alocação dos recursos de movimentação.

O segundo passo da modelagem é definir os modelos conceituais que compõem o sistema. Para o estudo, o modelo geral foi composto por cinco módulos (modelos básicos), agrupados em dois conjuntos: planta - composta pela [Malha de Movimentação] - e controle - composta por: [Processo Produtivo], [Banco de Dados], [Sistema de Monitoração de Necessidades e Solicitação de Recursos de Movimentação] e [Heurística de Designação de Recursos de Movimentação].

No terceiro passo são identificadas as relações ${ }^{19}$ entre os modelos conceituais. A figura 5.1 ilustra a integração entre os módulos (modelos básicos) descritos e as relações existentes:

\footnotetext{
${ }^{19}$ Destaca-se que num primeiro instante define-se onde estão os relacionamentos e ao longo da etapa de detalhamento dos modelos conceituais é que são detalhadas as informações que estão sendo trocadas entre os modelos.
} 
- [Malha de Movimentação] e [Processo Produtivo] - a [Malha de Movimentação] envia dois arcos de sinal de saída para [Processo Produtivo] (b1 e b2) que indicam, respectivamente, que uma peça está aguardando para ser processada e que existe a necessidade de movimentação;

- [Processo Produtivo] e [Banco de Dados] - o [Processo Produtivo] envia: sinais indicando que uma peça está sendo processada (p5) e desta forma é possível computar o tempo que esta esteve em processo; sinais indicando que uma peça está aguardando processamento (p3) e desta forma pode-se obter o tempo em que esta permaneceu em espera; sinais indicando que a peça está em movimentação (p1) e desta forma pode-se obter o tempo de movimentação e; sinais indicando que uma peça está aguardando por movimentação (p7), podendo-se calcular o tempo de espera. O conjunto dos tempos calculados é armazenado em um [Banco de Dados];

- [Malha de Movimentação] e [Heurística de Designação de Recursos de Movimentação] - [Malha de Movimentação] fornece as posições das carretas (b3) e dos transportadores (b4) para a [Heurística...] e recebe desta as instruções para movimentação (b5) e para reutilização das carretas no centro de custo em que ele já se encontra (b6);

- [Processo Produtivo] e [Sistema de Monitoração de Necessidades e Solicitação de Recursos de Movimentação] - o [Processo Produtivo] envia uma requisição de movimentação (p4) para o [Sistema de Monitoração...] (que recebe com sendo c1.i);

- [Banco de Dados] e [Sistema de Monitoração de Necessidades e Solicitação de Recursos de Movimentação] - o [Banco de Dados] fornece: informação de que o tempo de deslocamento entre os centros de custo de origem e destino é inferior ao tempo restante de processamento do material no centro de custos de destino (c2.i) 
para o [Sistema de Monitoração...] e; disponibilidade de carretas para transportar o material (c4.i). O [Sistema de Monitoração...] atualiza a estimativa de início de processamento de material (c3);

- [Sistema de Monitoração de Necessidades e Solicitação de Recursos de Movimentação] e [Heurística de Designação de Recursos de Movimentação] - o [Sistema de Monitoração...] envia a solicitação de movimentação para a [Heurística...].

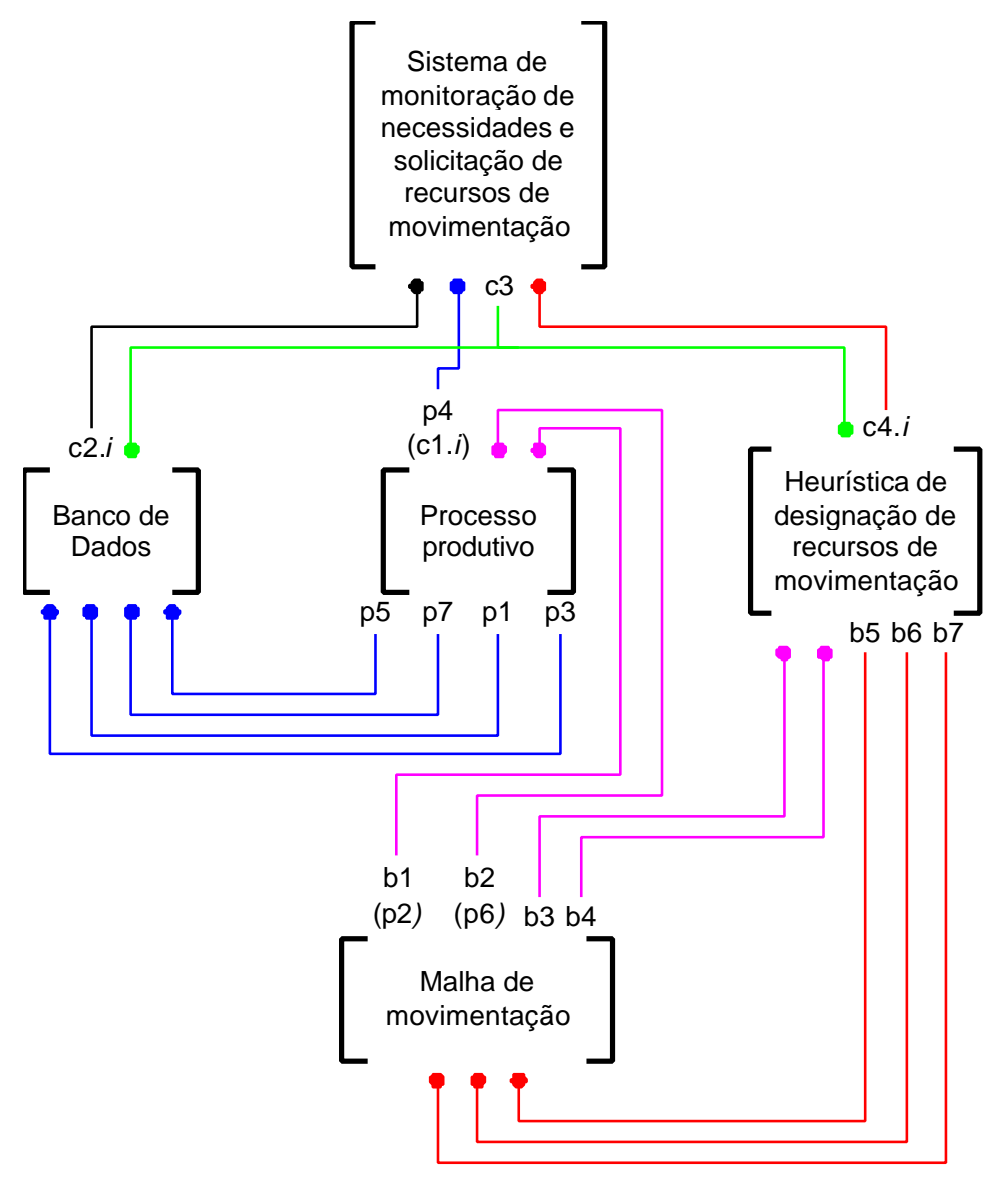

Figura 5.1 - PFS / E-MFG ilustrando a integração dos sub modelos.

Por fim, tem-se no quarto passo o detalhamento dos modelos conceituais que compõem o sistema: 


\subsection{Planta}

A planta é a parte do modelo onde estão representados todos os componentes operacionais do sistema como máquinas, transportadores, carretas, buffers, etc. No caso em questão esta é composta por cinco conjuntos de elementos: instrução, transportador, carreta, material - que utilizando-se o conceito de objetos foram encapsulados em marcas - e a [malha de movimentação] é composta por centros de custos e arcos.

Pôde ser observado no modelo da figura 5.1 que a planta foi apresentada apenas como sendo a [malha de movimentação]. Isso se deve ao fato dos demais elementos estarem presentes no sistema de forma implícita, ou seja, só quando se detalha a marca que percorre a [malha de movimentação] é que se evidencia a presença destes.

\subsubsection{Marca}

Como dito anteriormente, a marca é composta por quatro elementos (instrução, transportador, carreta e material):

- instrução - define as regras de movimentação como caminho a ser percorrido e a atividade a ser realizada;

- transportador - é o recurso ativo ${ }^{20}$ responsável pela movimentação dos materiais;

- carreta - é o recurso de movimentação passivo e tem como função prover a interface entre o transportador e os materiais;

- material.

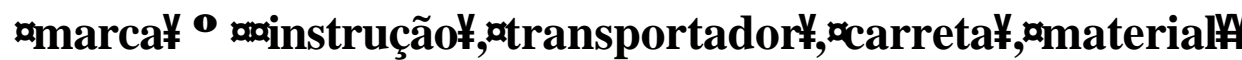


A seguir, cada um destes é melhor detalhado:

\section{A. Instrução}

A §instrução• é o macro atributo responsável por indicar ao transportador informações sobre as atividades que este deve realizar. Esta é composta por um

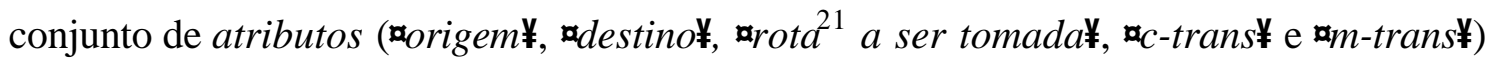
vindo da [Heurística de Designação de Recursos de Movimentação] através da porta b5 (pode ser visualizado a frente na figura 5.7), responsável por designar os transportadores para atenderem as requisições de movimentação geradas pela produção.

\section{§instrução $\bullet \equiv$ §origem, destino, rota a ser tomada, c-trans, m-trans $\bullet$}

Seus atributos representam:

- $\quad$ origem - indica o centro de custo onde existe uma carreta a ser transportada;

- destino - local onde a carreta que está sendo transportada deve ser levada,

- rota a ser tomada - conjunto de atributos ordenados em forma de lista que indica o caminho que o transportador deve utilizar desde o instante em que lhe é solicitado a movimentação de uma carreta até a sua entrega no devido centro de custo;

- $\quad c$-trans - identificação da carreta a ser transportada;

- $m$-trans - identificação do material a ser transportado.

Existe uma §instrução• mais simplificada que é utilizada para indicar que uma carreta será reutilizada no centro de custos onde esta foi descarregada e também para

\footnotetext{
${ }^{20}$ Provido de força motora.

${ }^{21}$ Rota é todo e qualquer caminho ligando dois centros de custo especificados (origem e destino).
} 
indicar aos encarregados da produção que a carreta será utilizada na movimentação do material ao final de seu processamento.

\section{§instrução $\bullet \equiv$ §-trans $\bullet$}

\section{B. $O$ transportador}

O transportador aqui considerado é um elemento do sistema que passa pelos centros de custo através de uma rota informada através do macro atributo §instrução $\bullet$

Considerando-se que o transportador possui quatro estados relevantes a serem modelados, que são:

- parado - o transportador está parado esperando por uma nova instrução de movimentação ou simplesmente esperando para a realização do engate ou desengate de uma carreta;

- em movimento - o transportador está se movimentando ou para pegar uma nova carreta ou está transportando uma carreta para o centro de custo de destino;

- engatando - ele está sendo engatado a uma carreta no centro de custo de origem para ser transportada até seu centro de custo de destino;

- desengatando - o transportador realizou a movimentação e está deixando a carreta em seu centro de custo de destino.

Chama-se a atenção para o fato de os tempos de engate e desengate estarem sendo considerados nas atividades do transportador pois estas são operações realizadas 
pelo seu operador ${ }^{22}$ ao passo que o tempo de movimentação está vinculado à rota - seu comprimento (já que a velocidade de movimentação é considerada constante).

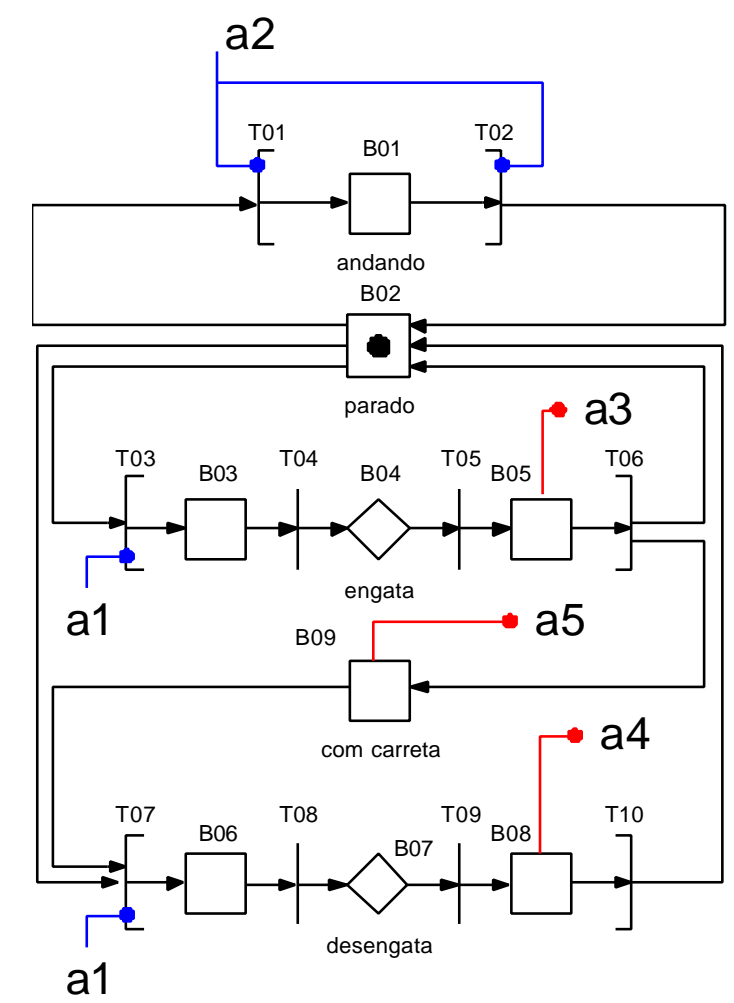

Figura 5.2 - Modelo do transportador.

O E-MFG da figura 5.2, descreve os estados do transportador. Quando a marca se encontra em B02 o transportador está parado. Caso a transição T01 seja disparada, a marca passa para B01, indicando que o transportador está em movimento e permanecerá até que a transição T02 seja disparada e este pare novamente. Parado, o transportador pode:

- engatar uma carreta (pelo disparo da transição T03 dando início ao engate (B03), e com o disparo de T04, o tempo de engate é considerado em B04; após o engate, a

\footnotetext{
${ }^{22} \mathrm{O}$ operador, no problema em questão é o condutor do transportador, a entidade (pode ser também uma pessoa) que o opera / controla / dirige o transportador.
} 
transição T05 dispara e o novo estado é indicado em B05; o disparo de T06 faz com que a marca indique que o transportador está parado);

- ou desengatar (pelo disparo da transição T07 dando início ao desengate (B06) e com o disparo de T08, o tempo de desengate é considerado em B07; após o desengate, a transição T09 dispara e o novo estado é indicado em B08; o disparo de T10 faz com que a marca indique que o transportador está parado sem carreta). B09 indica que há uma carreta sendo rebocada pelo transportador.

Ainda no modelo da figura 5.2 tem-se duas portas externas (a1 e a2) e três arcos de sinal de saída (a3, a4 e a5):

- a1 - é a porta que habilita o engate ou o desengate de carretas. Ele assume o valor “0” para indicar que não há engate ou desengate de carretas, “1” quando este estiver no centro de custo especificado para que este engate a carreta e "2" no centro de custo especificado para que este desengate a carreta;

- a2 - porta que habilita a movimentação do transportador - “0” para manter o estado; "1" para habilitar a movimentação - ou porque este recebeu uma instrução para rebocar uma carreta de um centro de custo a outro ou acabou de engatar a carreta e está se dirigindo ao centro de custo de destino; "2" para habilitar a sua parada ou porque chegou ao centro de custo para pegar uma carreta a ser transportada ou chegou ao centro de custo de destino para a deixar uma carreta;

- a3 - arco de sinal que indica que a carreta acabou de ser engatada e que a movimentação já pode ser iniciada;

- a4 - arco de sinal que indica que a carreta acaba de ser desengatada e o transportador pode atender a uma nova requisição de movimentação; 
- a5 - arco de sinal que indica que o transportador está sendo utilizado na movimentação de uma carreta.

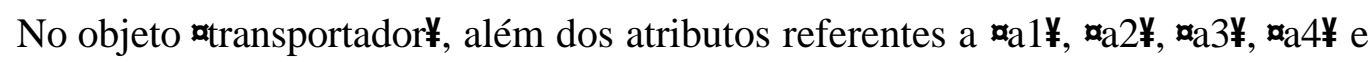

$\boldsymbol{\S} 5$ • a identificação do transportador $(1,2, \ldots$ n) e a estrutura de um grafo E-MFG que representa o elemento transportador (por exemplo: grafo da figura 5.2). Este conjunto de sete atributos agrupados definem a classe "transportador":

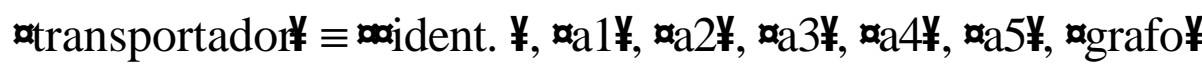

\section{Carreta}

A carreta é um recurso utilizado para a movimentação de um conjunto de materiais, realizando a interface entre este e o transportador, o que concede flexibilidade ao sistema através dos sistemas de engate / desengate e redução de custos visto que o custo do transportador é em geral muitas vezes superior ao de uma carreta e esta pode ser trabalhada enquanto os transportadores estão executando outras tarefas.

Considerando-se que os estados relevantes da carreta a serem modelados são:

- vazia - indica que a carreta está vazia e pronta para receber material para a movimentação;

- cheia - indica que ou esta está esperando ser descarregada em um centro de custo ou esta está sendo movimentada entre um par origem - destino;

- carregando - indica que a carreta está sendo carregada com material a ser movimentado;

- descarregando - indica que a carreta está sendo descarregada. 
O tempo de carga de uma carreta depende de fatores como dimensão, do tipo de material que está sendo carregado e do equipamento utilizado para se carregar a carreta. Neste caso, por simplificação, atribui-se todo o tempo de carga e descarga à carreta esta simplificação foi considerada para evitar um maior detalhamento do modelo, como por exemplo, a inclusão do modelo de uma empilhadeira para associar o tempo a esta.

O E-MFG da figura 5.3, descreve os estado da carreta. Quando a marca se encontra em B01 a carreta está vazia. O disparo da transição T01 é o início do carregamento (B02); o disparo da transição T02 inicia o tempo de carregamento considerado em B03; após o carregamento, a transição T03 dispara, indicando o fim do carregamento (B04); o disparo de T04 indica que a carreta, agora, está cheia (B08). Quando a transição T05 é disparada, inicia-se o descarregamento (B05); o disparo de T06 inicia o tempo de descarregamento considerado em B06; após o descarregamento, a transição T07 dispara, indicando o fim do descarregamento (B07); o disparo de T08 indica que a carreta está vazia.

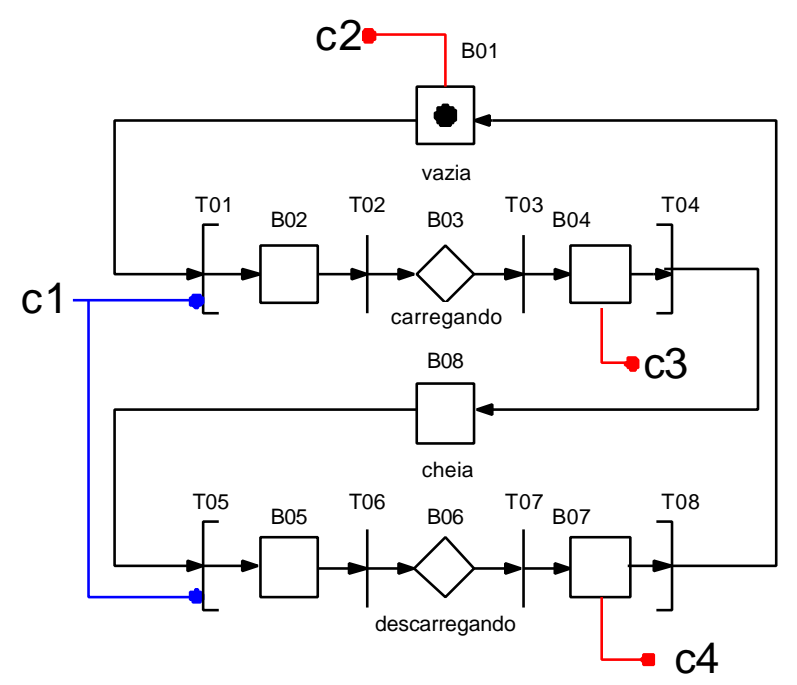

Figura 5.3 - Modelo da carreta. 
Ainda referente ao modelo da figura 5.3 tem-se uma porta externa (c1) e três arcos de sinal de saída (c2, c3 e c4):

- c1 - é a porta que habilita o carregamento ou descarregamento da carreta. Ele assume o valor “ 0 ” para indicar que não há nenhuma operação, "1” quando esta estiver no centro de custo de origem para ser carregada e "2" no centro de custo indicado como destino da carreta quando esta está para ser descarregada;

- c2 - arco de sinal que indica que a carreta está vazia (se o box B01 estiver marcado) ou cheia (caso esteja sem marcas);

- c3 - arco de sinal que indica que a carreta acabou de ser carregada;

- $\quad$ c4 - arco de sinal que indica que a carreta acaba de ser descarregada;

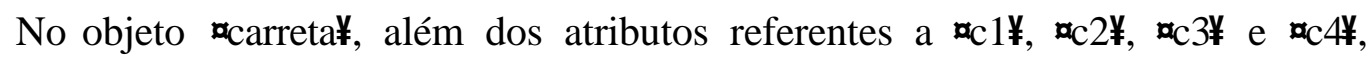
existem outros dois elementos (\$ident. $\bullet$ e §grafo $\bullet$ que representam, respectivamente, a identificação da carreta $(1,2, \ldots$ n) e o grafo E-MFG que representa o elemento carreta (por exemplo: grafo da figura 5.3). Este conjunto de seis elementos agrupados definem a classe "carreta":

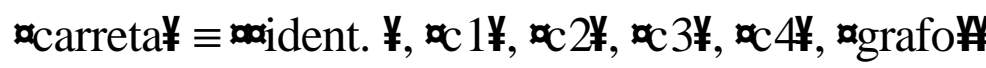

\section{Materiais}

O material é representado por um atributo que contem informações como lote de fabricação, cliente, ou qualquer outra identificação que seja útil para a empresa: 


\subsubsection{Malha de movimentação}

A malha de movimentação da planta considerada é relativamente complexa e assim aqui apresenta-se apenas a malha de movimentação simplificada afim de ilustrar o problema e obter um modelo para exemplificar a análise por simulação. A figura 5.4 ilustra a malha considerada.

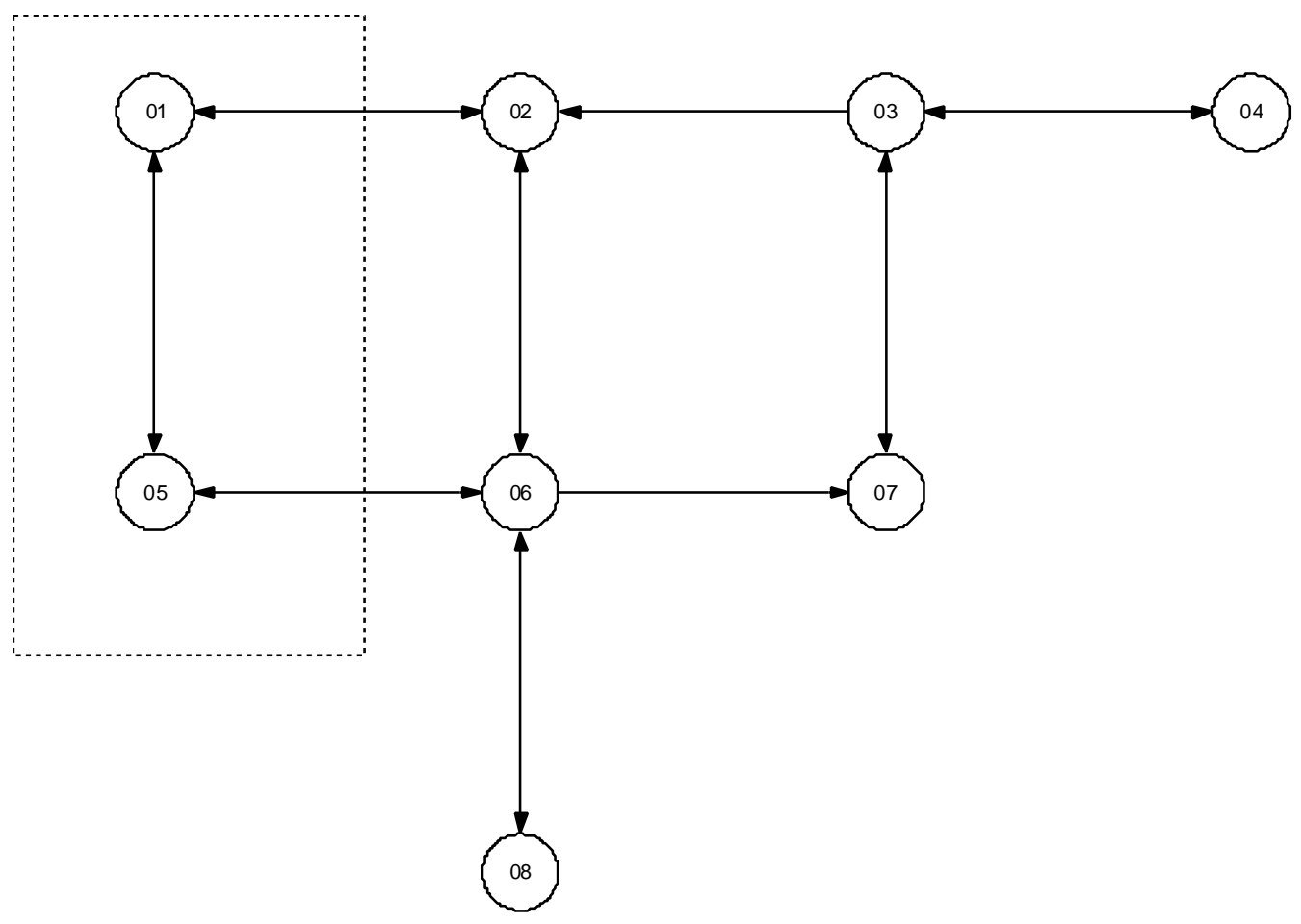

Figura 5.4 - Modelo representativo da malha de movimentação.

Utilizando-se a metodologia do capítulo 4, converte-se o modelo da figura 5.4 para uma representação de seus elementos (centros de custos e $\operatorname{arcos}$ ) utilizando-se o PFS (figura 5.5) e dando início ao processo de detalhamento das atividades ([centro de custos $i$ ] e [transporte de $i$ para $j])$.

No modelo em E-MFG da figura 5.6 está sendo representada uma interligação (atividade de [transporte]) entre os centros de custo $i$ e $j$, com capacidade para três transportadores, mas esta poderia ser expandida ou mesmo ter sua capacidade reduzida - no caso em estudo não se tem problema de restrição de capacidade nos arcos. O 
tempo de movimentação é o mesmo para todos quando se considera que o comprimento da interligação e a velocidade dos transportadores são as mesmas - frota homogênea.

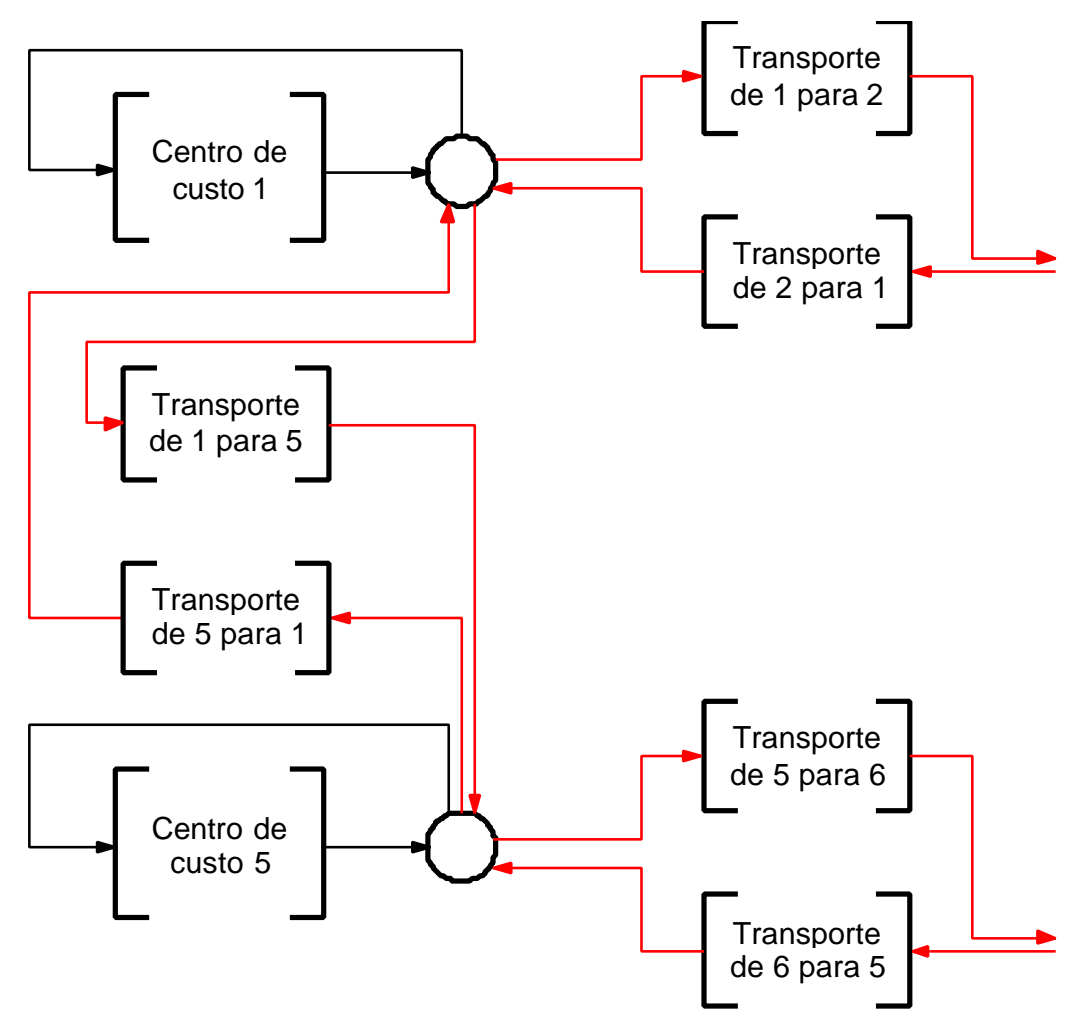

Figura 5.5 - Representação parcial da malha original utilizando-se o PFS.

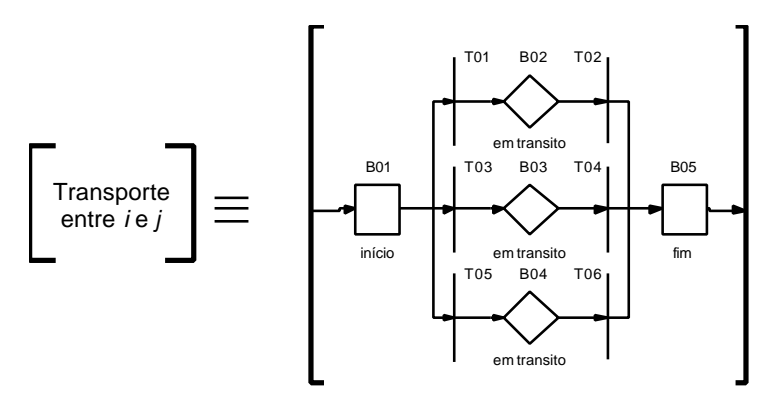

Figura 5.6 - Detalhamento das ligações de movimentação (atividade de [transporte entre $i$ e $j$ ]).

A figura 5.7 ilustra o procedimento de detalhamento da atividade de um centro de custos $i$. 


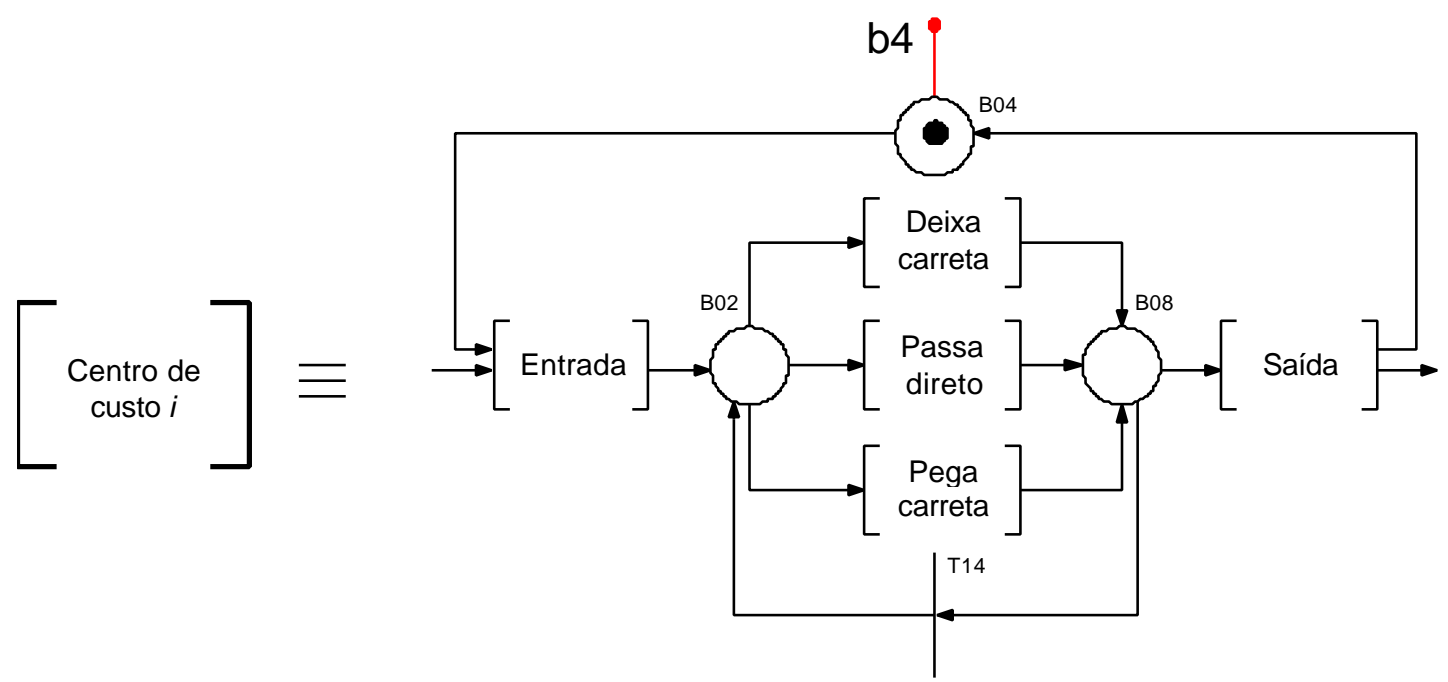

(a) Primeiro nível de detalhamento utilizando-se a metodologia PFS / MFG

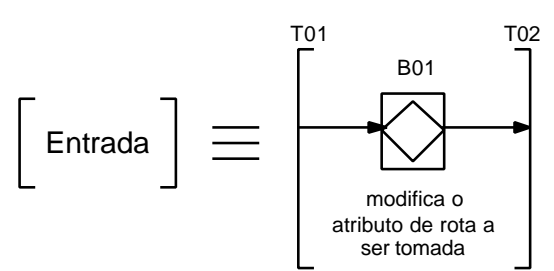

(b) detalhamento da atividade [entrada]

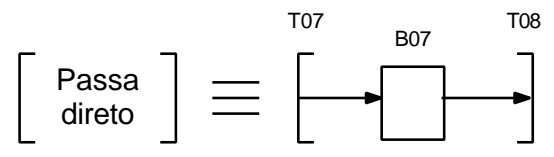

(c) detalhamento da atividade [passa direto]

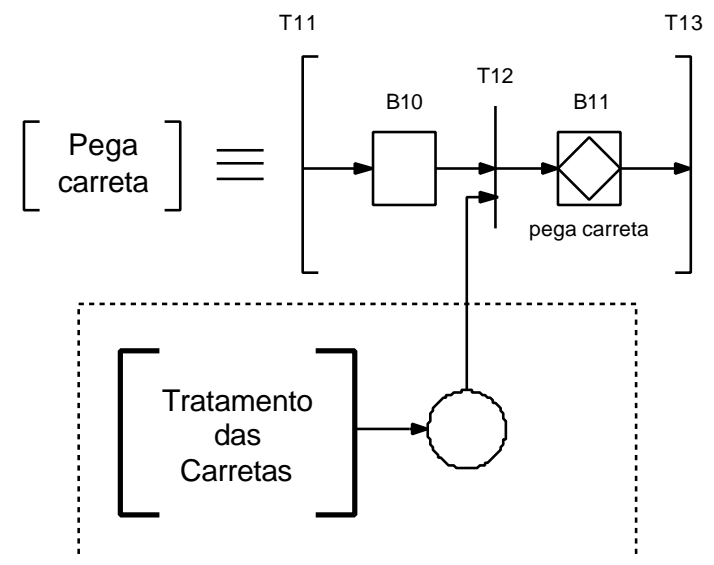

(d) detalhamento da atividade [pega carreta]

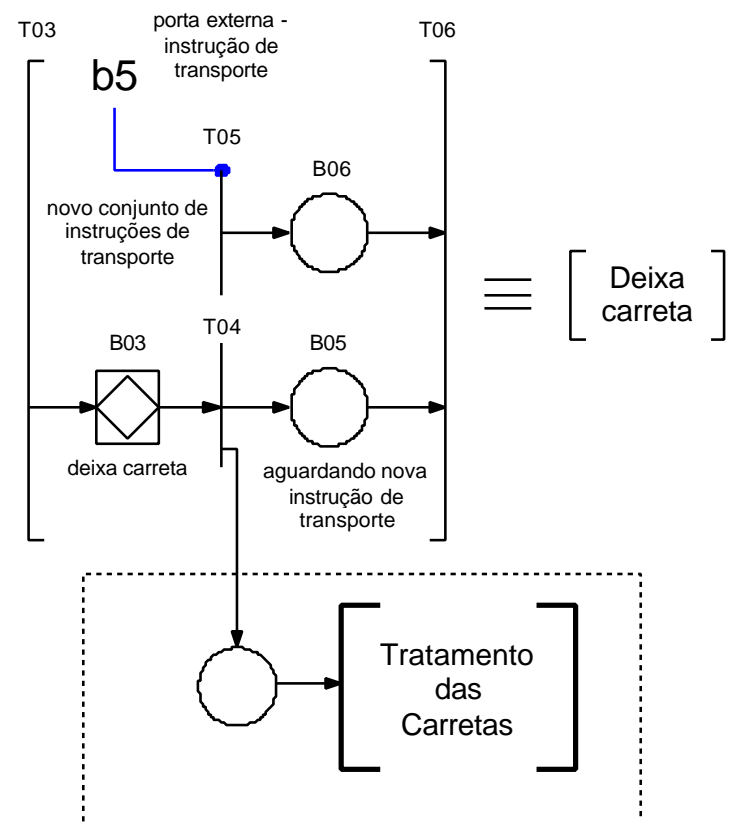

(e) detalhamento da atividade [deixa carreta]

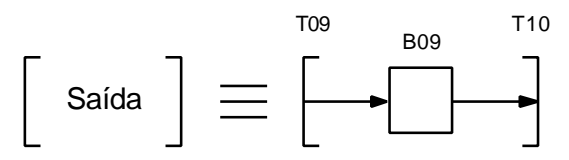

(f) detalhamento da atividade [saída]

Figura 5.7 - Detalhamento da atividade [centro de custo $i$ ] referente ao tratamento dos transportadores. 
Através da atividade [entrada], chega ao centro de custos a marca correspondente ao transportador (com ou sem carreta), composta pelos 4 macro atributos: instrução, transportador, carreta e material que vai para $\mathrm{B} 01^{23}$.

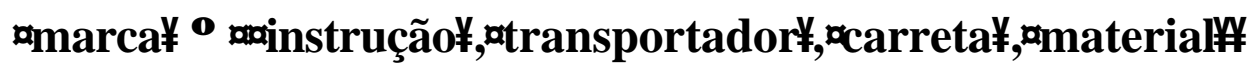

Note que a execução desta atividade altera o estado B04, indicando a presença do transportador no centro de custos em questão.

Neste nível de modelagem do centro de custos, os macro atributos §instrução $\bullet$ e $\boldsymbol{\S}$ transportador $\bullet$ devem estar, obrigatoriamente, presentes em B01, visto que neste nível de detalhamento estão representadas atividades que ocorrem com o transportador. Para o transportador, a §instrução• é um conjunto de atributos vindo da [Heurística de Designação de Recursos de Movimentação] através da porta b5 (figura 5.7), responsável por designar os transportadores para atenderem as requisições de movimentação geradas pela produção.

Da marca, contida em B01, é modificado o atributo $\boldsymbol{\&}$ rota a ser tomada $\bullet$ do macro atributo §instrução $\bullet$ e esta é transferida (disparo de T02) para B02 onde aguarda operação. Neste ponto a marca pode seguir três caminhos:

- passar diretamente pelo centro de custos em questão - ocorre o disparo da transição T07, indo a marca para a atividade [passa direto], e em seguida para a atividade [saída], deixando a marca seguir para o próximo centro de custos;

\footnotetext{
${ }^{23}$ No Anexo A é apresentado um exemplo de simulação do comportamento dos atributos das marcas nos principais elementos dos centros de custos.
} 
- se existe uma carreta que deve ser deixada no centro de custos em questão - há o disparo da transição T03, e ocorre o desengate da carreta (B03). Terminado o desengate (T04), o a marca (que indica o transportador sem carreta) fica a disposição do controle aguardando nova instrução (B05) e a parte da marca (correspondente a carreta) contendo os macro atributos $\boldsymbol{\S}$ carreta $\bullet$ e $\boldsymbol{\S}$ naterial $\bullet$ são transferidos para a atividade [tratamento das carretas]. Estando o transportador disponível, a [Heurística de Designação de Recursos de Movimentação] envia uma nova instrução (b05 o que dispara a transição T05). Com o disparo de T06 tem-se a marca resultante em $\mathrm{B} 08$ onde o transportador pode ir para o próximo centro de custos seguindo para a [saída] ou rebocar uma carreta presente no centro de custos em questão (disparo de T14);

- se o transportador foi designado para movimentar uma carreta - neste caso há o disparo da transição T11 e o engate da carreta (B11) (combinação dos atributos da marca vinda de B02 com os atributos da marca vinda da atividade [tratamento das carretas]). Findo o engate (disparo de T13), a marca segue para B08 e em seguida para a [saída] e o próximo centro de custos (disparo de T10).

Na figura 5.8 encontra-se detalhada a atividade [tratamento das carretas]. A marca proveniente do desengate da carreta, contendo obrigatoriamente o macro atributo §carreta , é duplicada: a primeira vai para B12 indicando para a [Heurística de Designação de Recursos de Movimentação] a sua localização (b3) e a segunda vai para B14 para ser processada:

- se estiver com carga, há o disparo da transição T15 e esta é descarregada (B13); findo o processo de descarregamento (disparo de T16) a carreta é separada do material, sendo que esta fica aguardando (B17) as instruções (vindas da [Heurística 
de Designação de Recursos de Movimentação] através de b06) para ser reutilizada no centro de custos em questão (disparo da transição T19) ou para que espere um transportador que a venha rebocar. O material vai para a atividade [tratamento dos materiais];

\section{Sinstrução $\bullet \equiv$ c-trans $\bullet$}

- se estiver vazia, há o disparo de T17 e ocorre o carregamento da carreta (B18) combinação dos atributos de uma marca vinda da atividade [tratamento dos materiais] com a marca de B14 - findo o processo (disparo de T18) esta marca fica aguardando ser transportada (B17).

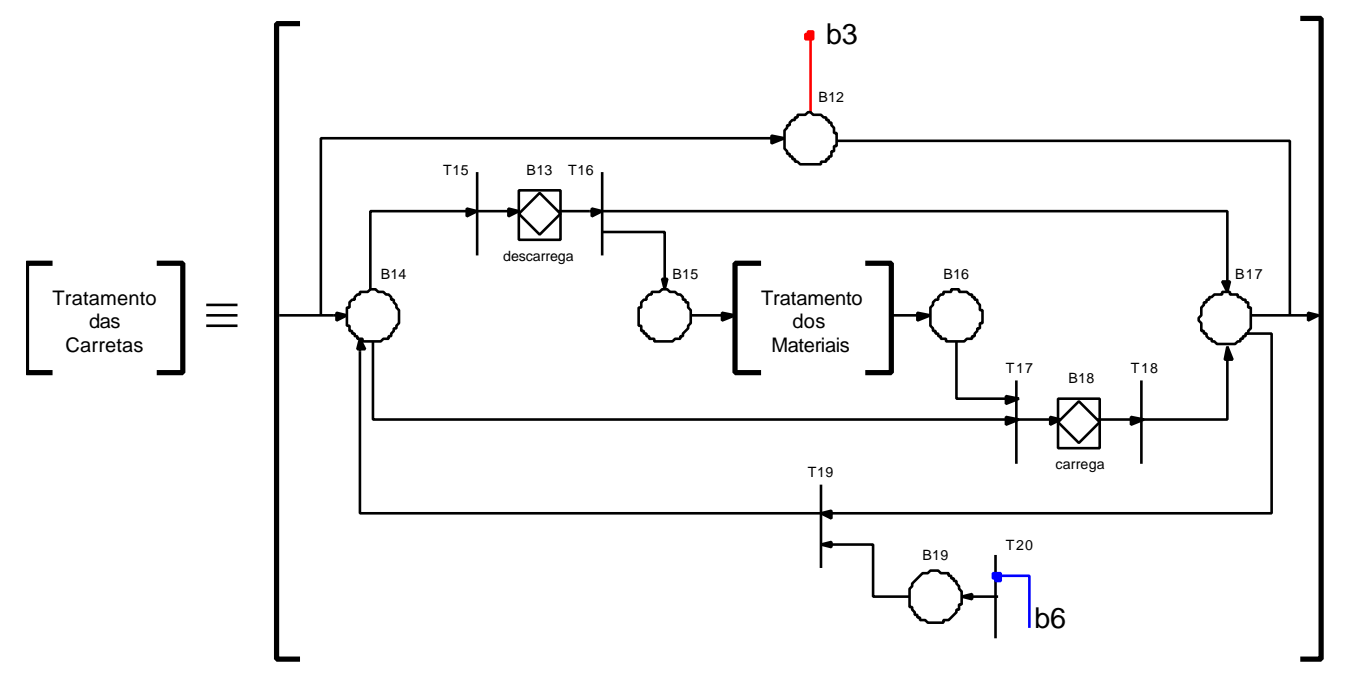

Figura 5.8 - Detalhamento da atividade [tratamento das carretas].

Na figura 5.9 tem-se um exemplo de processo produtivo como detalhamento da atividade [tratamento dos materiais ]. O material que chega para ser processado aguarda a sua vez de ser processado (B21) - esta situação é indicada para o [Processo produtivo] através de (b1). Em seguida inicia-se o processamento do material (disparo de T21 e marca em B22) e, enquanto isto a [Heurística de Designação de Recursos de 
Movimentação] envia uma instrução (b7) indicando a carreta que deverá ser usada para a movimentação do material.

\section{§instrução $\bullet \equiv \boldsymbol{\Phi}$-trans $\bullet$}

Findo o processamento do material (disparo de T22) é indicado para o [Processo produtivo] o fim desta atividade (b2) e o material permanece aguardando (B23) a disponibilização da carreta para seu carregamento.

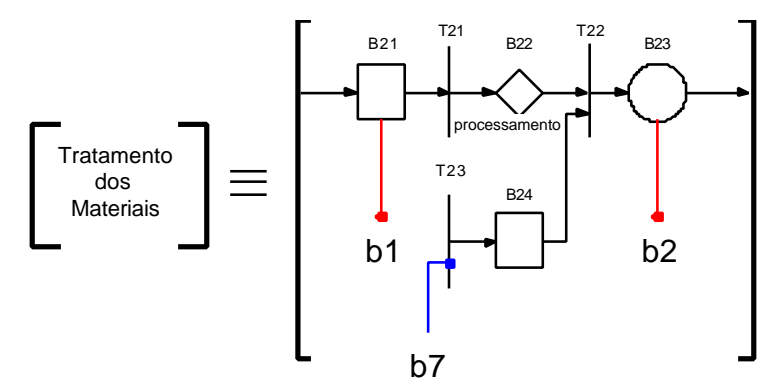

(a)

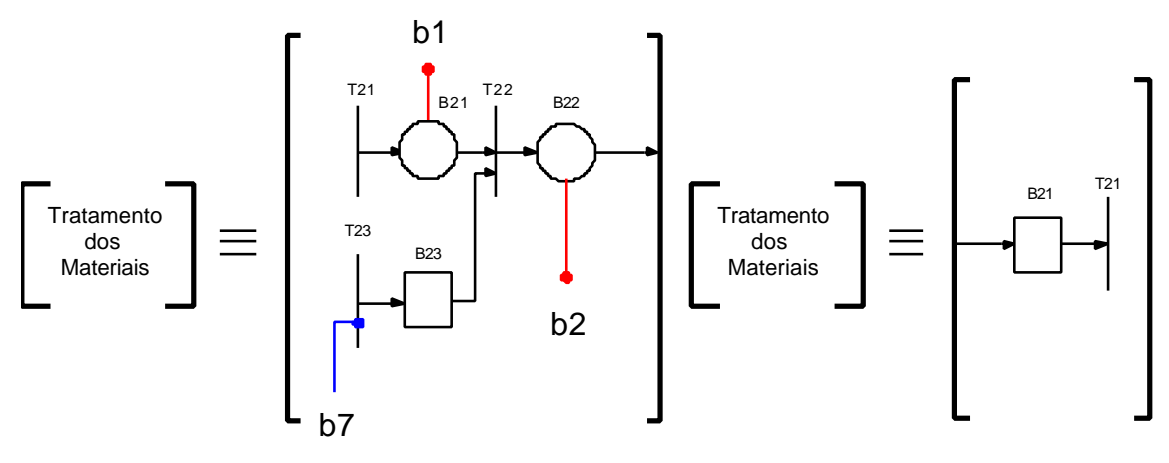

(b)

(c)

Figura 5.9 - Detalhamento do PFS referente ao tratamento dos materiais: (a) em centros de custos onde ocorre processamento de materiais, (b) em centros de custos que desempenham função de almoxarifado ou fonte de materiais e (c) em centros de custos que desempenham função de expedição ou "sorvedouro" de materiai. 


\subsection{Controle}

O sistema de controle engloba funções que estão ligadas ao controle da produção e que são normalmente desempenhadas pelo $\operatorname{PPCPE}^{24}$ com o auxílio de sistemas como ERPs $^{25}$.

Nesta etapa não se visa desenvolver propriamente o sistema de controle para gerenciar de forma eficiente os recursos de movimentação, mas sim, como, a partir da metodologia proposta, as informações geradas na planta podem ser utilizadas na implementação de um sistema de controle.

Como podem ser observados nos modelos da planta anteriormente expostos (figuras 5.7, 5.8 e 5.9) existem portas e arcos de sinal de saída responsáveis pela interface com o sistema de controle. Demonstra-se nos próximos itens como estas informações podem ser utilizadas.

\subsubsection{Processo Produtivo}

Neste exemplo, considera-se três processos produtivos para três materiais distintos:

$$
\begin{aligned}
& \text { Material A: } 1 \rightarrow 2 \rightarrow 3 \rightarrow 5 \rightarrow 8 \\
& \text { Material B: } 1 \rightarrow 4 \rightarrow 5 \rightarrow 7 \rightarrow 8 \\
& \text { Material C: } 1 \rightarrow 6 \rightarrow 7 \rightarrow 3 \rightarrow 8
\end{aligned}
$$

\footnotetext{
${ }^{24}$ Planejamento, Programação e Controle da Produção e Estoques.

${ }^{25}$ Enterprise Resource Planning.
} 
Nota-se que neste caso o centro de custos 1 representa a o almoxarifado da empresa, onde as peças são submetidas ao processamento somente quando há uma requisição por parte de um cliente, e o centro de custos 8 representa a expedição.

Utilizando-se o modelo da malha de movimentação (figura 5.4), identifica-se as etapas do processo para cada material (figura 5.10).

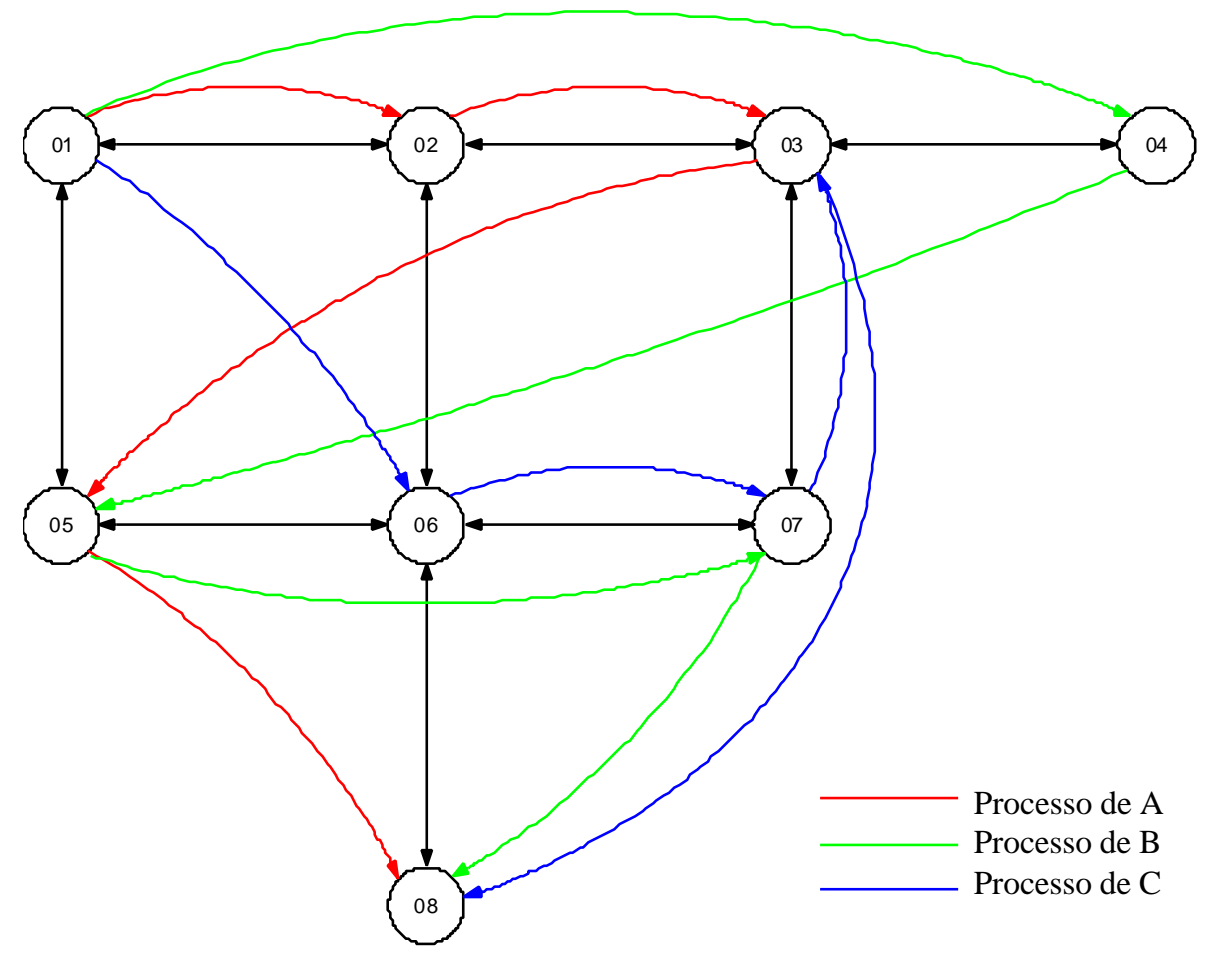

Figura 5.10 - Representação gráfica dos processos produtivos utilizando o modelo da malha de movimentação.

Com base na figura 5.10 é feito o detalhamento dos processos utilizando-se a metodologia PFS / E-MFG (figura 5.11). 


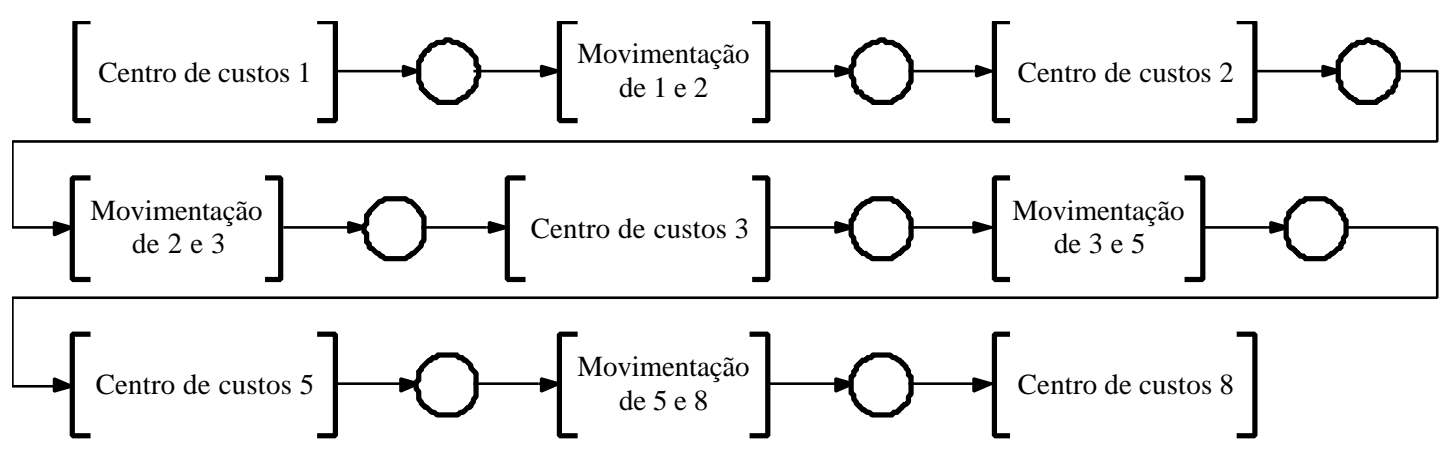

(a)

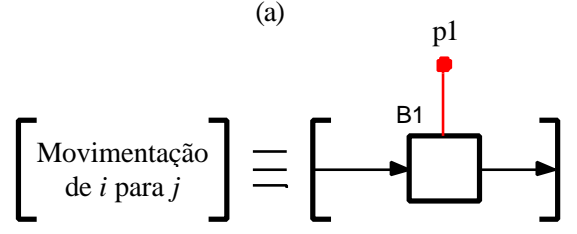

(b)

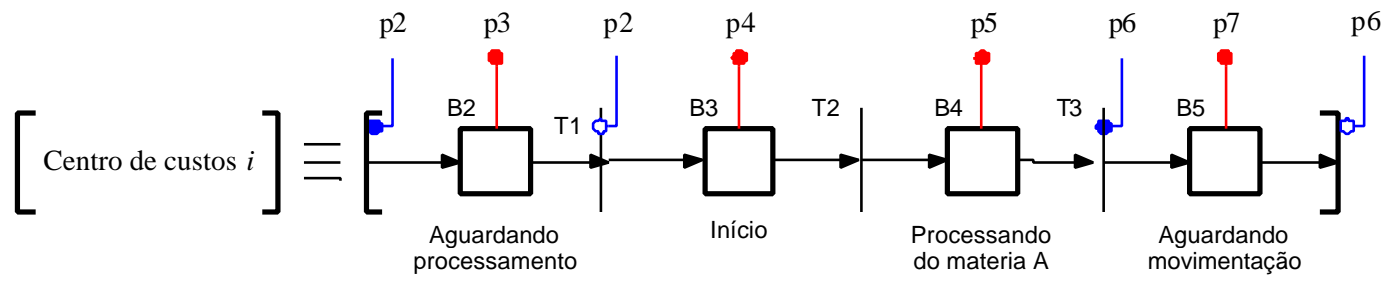

(c)

Figura 5.11 - Detalhamento em PFS / E-MFG do processo produtivo do material A: (a) detalhamento em PFS; (b) detalhamento da atividade [movimentação de $i$ para $j$ ] e; (c) detalhamento da atividade [centro de custos $i$ ].

Pode-se observar no modelo (figura 5.11) cinco arcos sinal de saída (p1, p3, p4, p5 e p7), e duas portas (p2 e p6), que se comunicam com:

- p1 - arco de sinal de saída que indica que o material está sendo transportado - serve para monitorar o tempo gasto na movimentação e enviá-lo ao [banco de dados];

- p2 - porta externa cujo sinal provém da [malha de movimentação] (b1 da figura 5.9) que indica a chegada de material para processamento e o início do processamento - idem ao item anterior com relação à habilitação das transições;

- p3 - arco de sinal de saída que indica que o material está aguardando processamento e desta forma pode ser utilizado para levantar dados sobre o desempenho do sistema; 
- $\mathrm{p} 4$-arco de sinal de saída que indica que um material iniciou processamento em um centro de custos;

- p5 -arco de sinal de saída que indica que o material está em processamento servem para monitorar o tempo gasto no processamento e enviá-lo ao [banco de dados];

- p6 - porta externa cujo sinal provém da [malha de movimentação] (b2 da figura 5.9) que indica a espera de movimentação pelo material e a chegada deste - as transições só são habilitadas se o atributo do material, que indica o tipo de peça, corresponder ao do processo em questão;

- p7 - arco de sinal de saída que indica que o material está aguardando movimentação e desta forma pode ser utilizado para medir o desempenho do sistema.

\subsubsection{Banco de Dados}

Neste módulo são armazenadas informações referentes aos processos produtivos e que são úteis no planejamento da produção e em outras decisões como, por exemplo, dimensionamento de capacidade.

Para o caso em estudo, tem-se como principais informações:

- tempo de processamento dos materiais nos centros de custos;

- tempo de movimentação entre os centros de custos.

Com estes dados é possível trabalhar com os conceitos de média e desvio padrão e desta forma estimar o tempo necessário para a realização de cada uma das etapas do processo. 
Além disso, pode-se também dizer que quando maior a complexidade do processo, maiores as incertezas associadas a este. Desta forma, para se garantir maiores níveis de atendimento (redução do tempo de espera dos materiais por recursos de movimentação) pode-se trabalhar não somente com a média, mas sim incrementar ou decrementar esta de uma parcela do desvio padrão, obtendo-se assim maiores ou menores níveis de atendimento (figura 5.12).

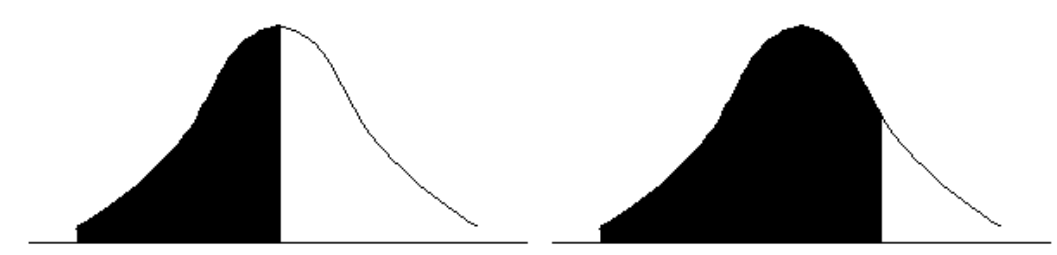

(a)

(b)

Figura 5.12 - Curvas normais: (a) $50 \%$ de nível de atendimento e (b) $70 \%$.

\subsubsection{Sistema de monitoração de necessidades e solicitação de recursos de movimentação}

Este módulo é responsável por monitorar as necessidades por recursos de movimentação (transportadores e / ou carretas) e, conforme a disponibilidade destes, fazer uma pré-eleição das requisições a serem atendidas.

Os blocos de monitoração são gerados com base no destino do material - no exemplo ilustrado pela figura 5.13 os materiais estão sendo deslocados para o centro de custos 5. Cada bloco é composto por um conjunto de portas oriundas do processo (c1.i), um conjunto de portas oriundas do [Banco de Dados] com informação de que o tempo de deslocamento entre os centros de custo de origem e destino é inferior ao tempo restante de processamento do material no centro de custos de destino (c2.i), um arco de sinal de saída (c3) e um conjunto de portas que informam a disponibilidade de carretas para realizar o transporte $(\mathrm{c} 4 . i)$ : 
- $\mathrm{c} 1 . i$ - conjunto de portas, oriundas do modelo do processo, que sinalizam a necessidade da movimentação de um material;

- $\quad$ c2.i - conjunto de porta que permanecem habilitadas quando não houver material aguardando processamento no centro de custos de destino (box B21 da [malha de movimentação] - figura 5.9 (a)) ou, caso haja material aguardando, que o tempo restante de processamento no centro de custos de destino (box B22 da [malha de movimentação] - figura 5.9 (a)) seja igual ou inferior ao tempo necessário para a movimentação do material do centro de custos de origem ao de destino, evitando-se o acumulo de inventário em espera ao longo do processo;

- $\mathrm{c} 3$ - arcos de sinal de saída que atualizam o [Banco de Dados] indicando que mais um material foi alocado para processamento no centro de custos de destino e o horário estimado sua liberação e, também, dispara a requisição de movimentação para a [Heurística de Designação de Recursos de Movimentação];

- $\quad 4 . i$ - portas externas que informam se a carreta utilizada para se movimentar o material em questão está ou não disponível. 


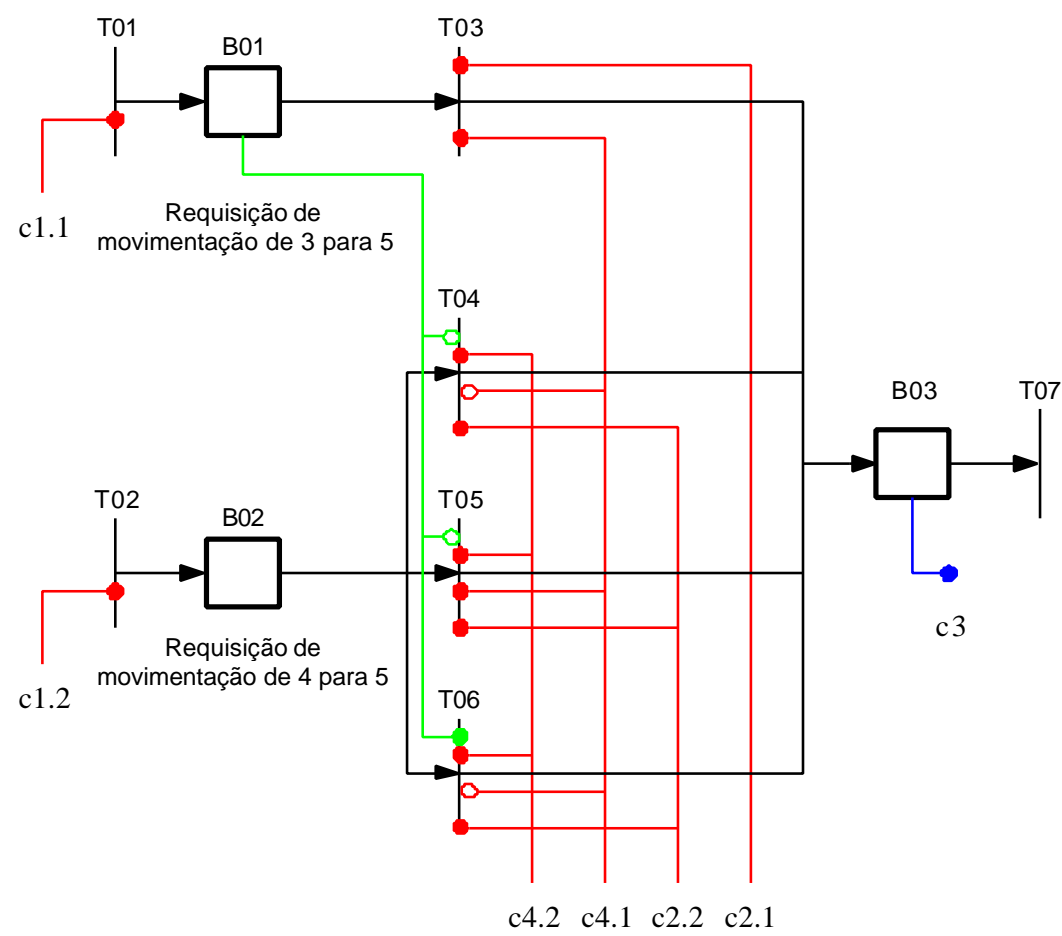

Figura 5.13 - Modelo de um componente ${ }^{26}$ do [Sistema de monitoração de necessidades e solicitação de recursos de movimentação].

Assim que é iniciado o processamento de um material em um centro de custos, uma requisição (c1.i) é enviada ao sistema de monitoração. Para cada requisição de recursos de movimentação que é recebida, o sistema de monitoração:

- coleta estimativas sobre o tempo necessário para que o produto seja processado;

- verifica a disponibilidade da carreta necessária para a realização de movimentação;

- zela para que não ocorra acúmulo de materiais no centro de custos de destino pois a requisição só é enviada à heurística quando o tempo que resta para o fim do processamento do material no centro de custos de destino for igual ou inferior ao tempo de movimentação do material do centro de custos atual para o centro de custos de destino;

- atualiza a seqüência de processamento no banco de dados. 
Como resultado de saída tem-se uma marca composta de 4 atributos $\$ \mathrm{~d} 1 \bullet$, $\mathbf{d} 2 \bullet$

$\S \mathrm{d} 3 \bullet \boldsymbol{\S d} 4 \boldsymbol{\bullet}$ que representam respectivamente:

- $\mathrm{d} 1$ - origem do carregamento;

- $\mathrm{d} 2$ - destino do carregamento;

- d3 - tempo estimado para o final do processamento da peça no centro de custos de destino;

- d4 - tempo estimado de movimentação.

\subsubsection{Heurística de designação de recursos de movimentação}

No capítulo 2 foram apresentados alguns problemas de programação e / ou roteirização e, de forma ilustrativa, também foram apresentadas algumas heurísticas que poderiam ser utilizadas na solução destes problemas.

Uma característica destas heurísticas é o fato delas serem empregadas para problemas bem determinados, por exemplo:

- no caso do caixeiro viajante (item 2.3.1 - caso A) tem-se que escolher um caminho que passe por todos os nós uma única vez e que resulte no menor caminho;

- no caso de programação de transportadores com um único centro de distribuição com restrição de comprimento de rota (item 2.3.2 - caso A) as entregas do período são todas definidas, assim como todas as restrições. Logo, basta executar a heurística uma vez para se ter o roteiro de cada veículo definido para o período.

\footnotetext{
${ }^{26}$ Neste exemplo: c1.1 - requisição de recurso de movimentação de 3 para 5; c1.2 - idem, porém de 4 para 5; c2.1 - habilita movimentação de A; c2.2 - idem, porém para o material B; c4.1 - disponibilidade de carreta para movimentar material A; e c4.2 - idem, porém para movimentar material B.
} 
Como o enfoque deste trabalho é o desenvolvimento de uma metodologia para a modelagem de sistemas flexíveis de movimentação de materiais onde a variabilidade das condições impõe uma análise por técnicas de simulação, heurísticas similares às do capítulo 2 podem ser aplicadas porém, não garantem que o resultado obtido ao final da simulação seja o mais próximo do ótimo pois em uma simulação os eventos podem ocorrer aleatoriamente e o sistema de controle deve reagir sempre que isto acontece. Desta forma, cada decisão tomada por este influenciará as próximas decisões, implicando na não garantia da obtenção de uma alocação ótima de recursos considerando-se os sistemas de movimentação de materiais.

No estudo de caso apresentado, a heurística de designação é responsável por designar transportadores e carretas vazias para atenderem uma chamada de movimentação (figura 5.14) e, também, designar transportadores para atender a movimentação das carretas já cheias (figura 5.15).

Quando uma nova solicitação de carreta e / ou transportador é realizada ou mesmo quando um destes recursos é disponibilizado, a heurística é executada de forma a rever a alocação dos recursos e, em sendo necessário, processar uma realocação. Desta forma, o que se considera é que dado um conjunto de requisições e um conjunto de recursos disponíveis, para cada execução da heurística, tem-se como resultado a alocação de recursos que não incorra em atrasos e, ao mesmo tempo, que garanta a menor distância percorrida.

Supondo-se que a primeira solicitação de movimentação da lista não pode ser atendida sem atraso, designa-se o conjunto transportador / carreta que atenda a solicitação com o menor atraso possível.

No modelo de designação para carretas vazias (figura 5.14): 
- no primeiro nível, representado por círculos azuis, indicam-se os materiais que estão requisitando uma carreta, não o seu lugar físico;

- no segundo nível, representados por círculos verdes, indicam-se as carretas vazias disponíveis para transporte;

- no terceiro nível, representados por círculos pretos, indicam-se os transportadores disponíveis;

- as setas que conectam estes círculos indicam as possíveis soluções e incluem informações sobre as distâncias entre os centros de custos onde se localizam cada um dos itens acima descritos e, só são considerados quando o tempo de atendimento não acarretar atraso na produção.

Assim que uma requisição de movimentação de carreta vazia é atendida (b3 figura 5.8), o sistema gera o seu complemento, ou seja, a necessidade de movimentação para esta carreta para quando estiver cheia, utilizando-se as estimativas de tempo para se chegar até o centro de custos requisitante da carreta vazia e o tempo estimado de carregamento.

No modelo de designação para carretas cheias (figura 5.15):

- no primeiro nível, representado por círculos azuis, indicam-se os destinos das carretas cheias (local onde o material deve ser entregue), não o seu lugar físico;

- no segundo nível, representados por círculos vermelhos, indicam-se as carretas que já foram carregadas e estão aguardando para serem movimentadas;

- no terceiro nível, representado por círculos pretos, indicam-se os transportadores disponíveis;

- as setas que conectam estes círculos indicam as possíveis soluções e incluem informações sobre as distâncias entre os centros de custos onde se localizam cada 
um dos itens acima descritos e, só são considerados quando o tempo de atendimento não acarretar atraso na produção.

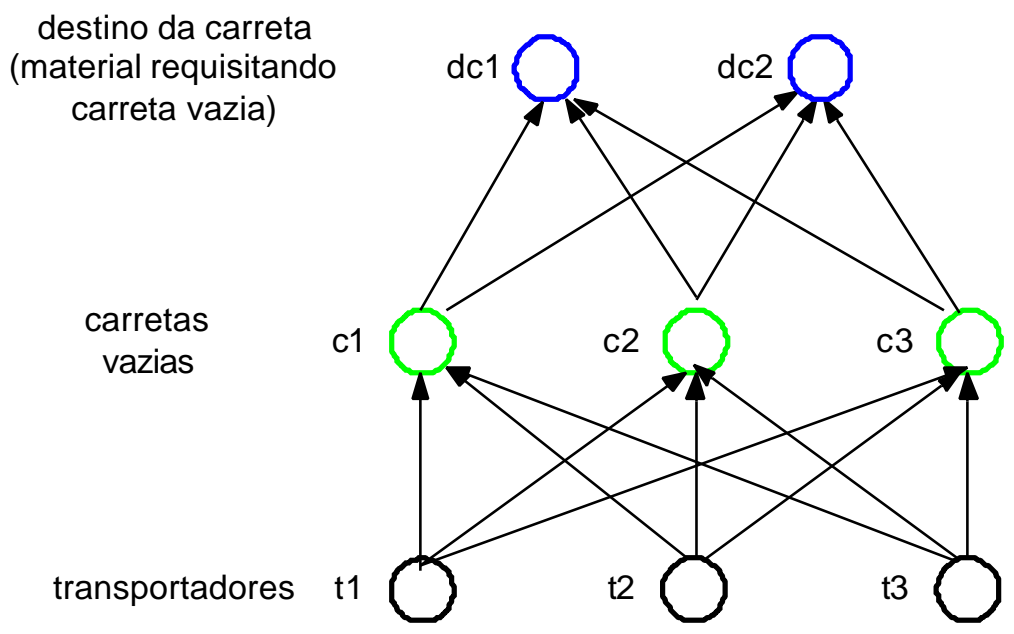

Figura 5.14 - Grafo que identifica as possibilidades de designação de transportadores e carretas vazias para atenderem uma necessidade de movimentação.

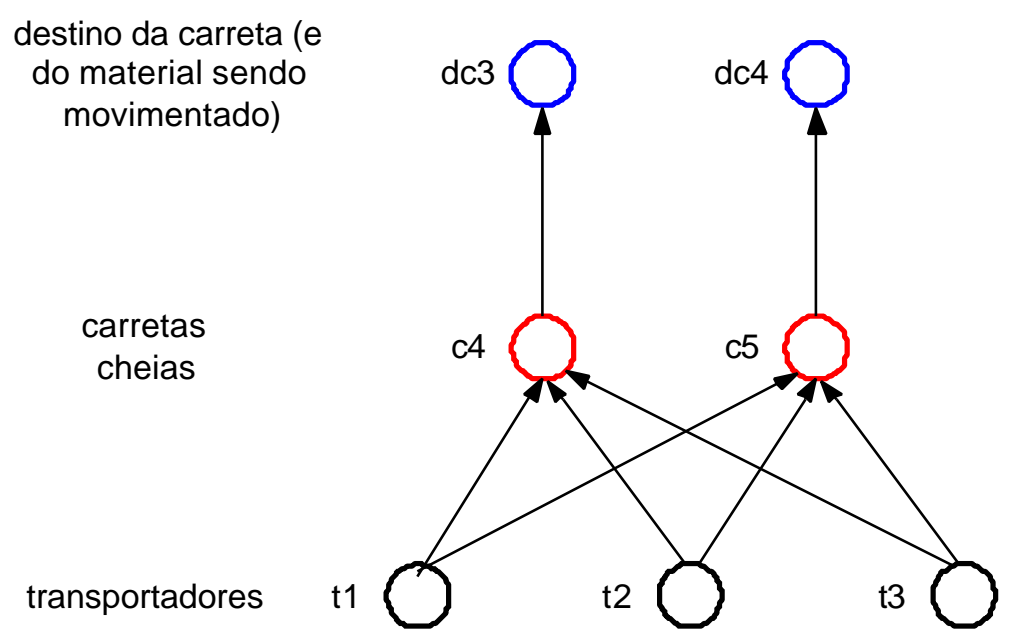

Figura 5.15 - Grafo que identifica as possibilidades de designação de transportadores para atenderem a necessidade de movimentação de carretas cheias.

As figura 5.14 e 5.15 representam os dois casos de designação, porém, estes devem ser resolvidos concomitantemente pois compartilham a mesma classe de recursos, o transportador. Desta forma, o modelo completo passa a ser o grafo da figura 5.16: 


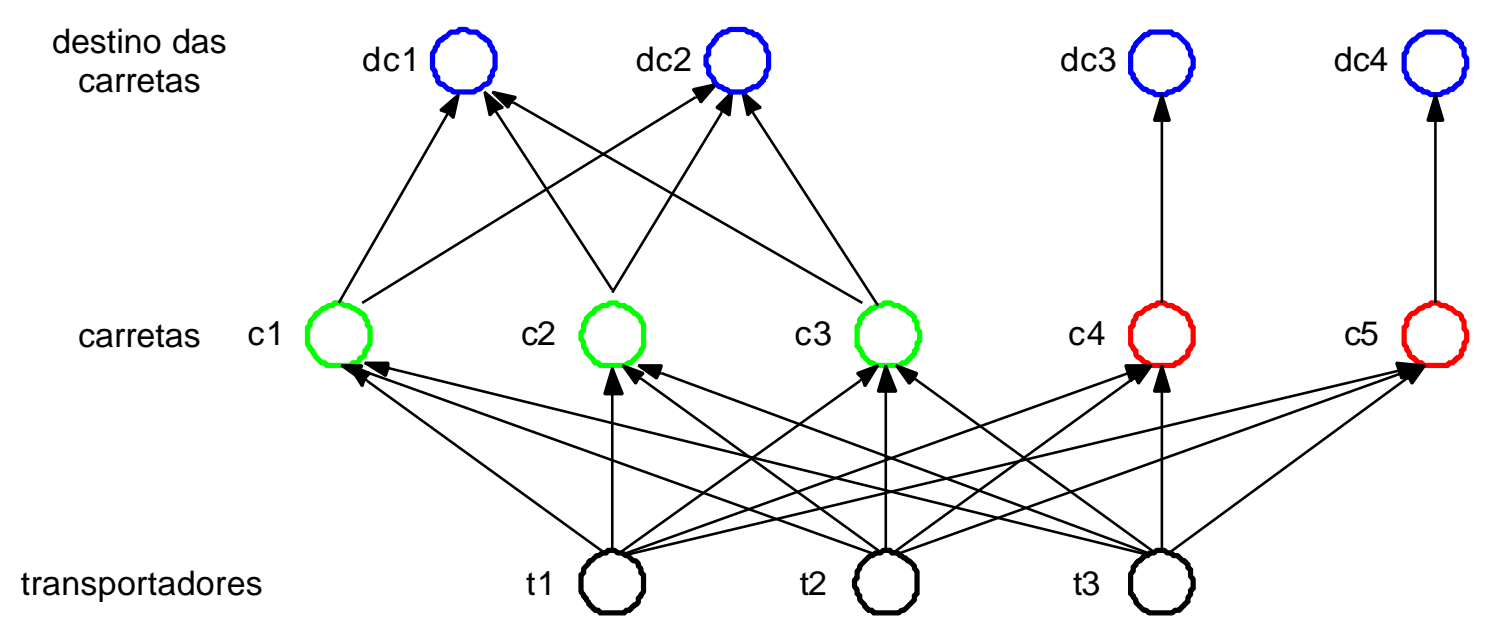

Figura 5.16 - Grafo que identifica as possibilidades de designação de transportadores e carretas, considerando os casos das figuras 5.14 E 5.15 simultâneamente.

A próxima etapa é aplicar um procedimento de designação para alocar os recursos de movimentação aos referidos requisitantes. Para tanto, o primeiro passo é verificar se há escassez de recursos. Tomando-se como exemplo a figura 5.16, observase que existe menos transportadores que solicitações de movimentação. Neste caso, aplica-se a [Heurística de Designação de Recursos de Movimentação] apenas para os três primeiros solicitantes (considera-se que a ordem de solicitação está organizada da esquerda para a direita), como por exemplo os destacados em lilás na figura 5.17.

Em seguida monta-se o problema de designação (figura 5.18) e escreve-se sua formulação matemática de forma a se utilizar algoritmos, como, por exemplo, o simplex, para proceder a designação.

Define-se:

- $\quad \mathrm{c}_{\mathrm{ijk}}$ como sendo o custo de se utilizar o transportador i e a carreta j para se atender à solicitação k. Caso exista a possibilidade de se combinar o transportador i com a carreta j para atender k, $\mathrm{c}_{\mathrm{j} k \mathrm{k}}$ é o custo desta combinação, do contrário é um valor majorado de forma a que esta combinação nunca seja considerada; 
- $\mathrm{a}_{\mathrm{ijk}}$ como sendo a célula que representa a combinação do transportador i com a carreta j para atender à solicitação $\mathrm{k}$.

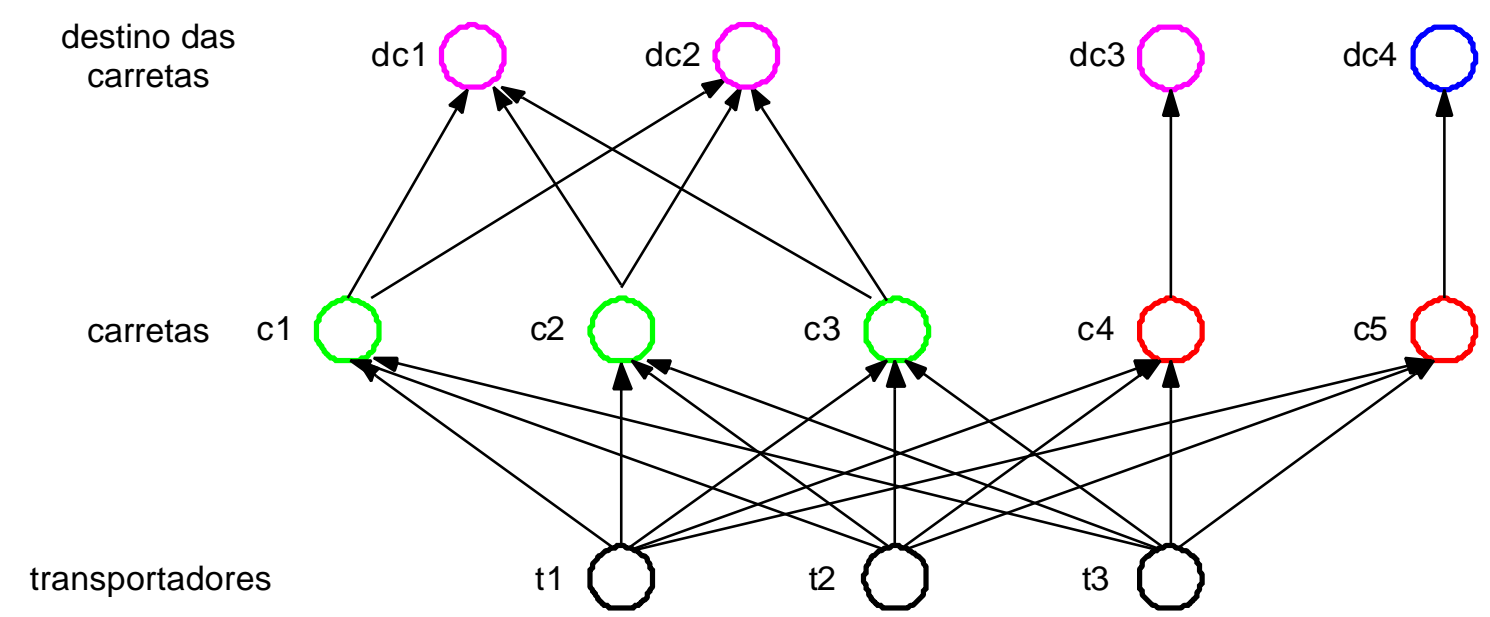

Figura 5.17 - Grafo com as requisições selecionadas para serem atendidas pelos recursos de movimentação.

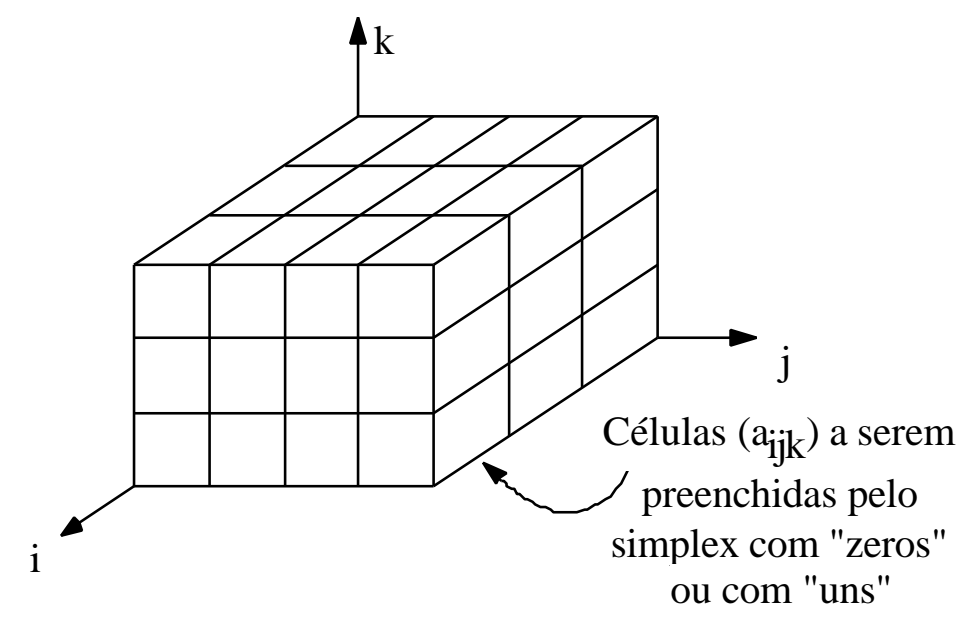

Figura 5.18 -Visualização tridimensional do problema de designação da figura 5.17.

Função objetivo:

$$
\operatorname{Min} \mathrm{Z}=\Sigma_{\mathrm{i}} \Sigma_{\mathrm{j}} \Sigma_{\mathrm{k}} \mathrm{c}_{\mathrm{ijk}} \cdot \mathrm{a}_{\mathrm{ijk}}
$$

Restrições:

$\mathrm{a}_{\mathrm{ijk}} \geq 0$ 
Utilização de uma única carreta para cada movimentação:

$$
\begin{aligned}
& \sum_{i} \sum_{k} a_{i j k} \leq 1 \\
& a_{111}+a_{211}+a_{311}+a_{112}+a_{212}+a_{312}+a_{113}+a_{213}+a_{313} \leq 1 \\
& a_{121}+a_{221}+a_{321}+a_{122}+a_{222}+a_{322}+a_{123}+a_{223}+a_{323} \leq 1 \\
& a_{131}+a_{231}+a_{331}+a_{132}+a_{232}+a_{332}+a_{133}+a_{233}+a_{333} \leq 1 \\
& a_{141}+a_{241}+a_{341}+a_{142}+a_{242}+a_{342}+a_{143}+a_{243}+a_{343} \leq 1
\end{aligned}
$$

Utilização de um único transportador para cada movimentação:

$$
\begin{aligned}
& \sum_{j} \sum_{k} a_{i j k} \leq 1 \\
& \mathrm{a}_{111}+\mathrm{a}_{121}+\mathrm{a}_{131}+\mathrm{a}_{141}+\mathrm{a}_{112}+\mathrm{a}_{122}+\mathrm{a}_{132}+\mathrm{a}_{142}+\mathrm{a}_{113}+\mathrm{a}_{123}+\mathrm{a}_{133}+\mathrm{a}_{143} \leq 1 \\
& \mathrm{a}_{211}+\mathrm{a}_{221}+\mathrm{a}_{231}+\mathrm{a}_{241}+\mathrm{a}_{212}+\mathrm{a}_{222}+\mathrm{a}_{232}+\mathrm{a}_{242}+\mathrm{a}_{213}+\mathrm{a}_{223}+\mathrm{a}_{233}+\mathrm{a}_{243} \leq 1 \\
& \mathrm{a}_{311}+\mathrm{a}_{321}+\mathrm{a}_{331}+\mathrm{a}_{341}+\mathrm{a}_{312}+\mathrm{a}_{322}+\mathrm{a}_{332}+\mathrm{a}_{342}+\mathrm{a}_{313}+\mathrm{a}_{323}+\mathrm{a}_{333}+\mathrm{a}_{343} \leq 1
\end{aligned}
$$

Que uma única solicitação seja atendida pelo par transportador - carreta:

$$
\begin{aligned}
& \sum_{i} \sum_{j} a_{i j k} \leq 1 \\
& a_{111}+a_{121}+a_{131}+a_{141}+a_{211}+a_{221}+a_{231}+a_{241}+a_{311}+a_{321}+a_{331}+a_{341} \leq 1 \\
& a_{112}+a_{122}+a_{132}+a_{142}+a_{212}+a_{222}+a_{232}+a_{242}+a_{312}+a_{322}+a_{332}+a_{342} \leq 1 \\
& a_{113}+a_{123}+a_{133}+a_{143}+a_{213}+a_{223}+a_{233}+a_{243}+a_{313}+a_{323}+a_{333}+a_{343} \leq 1
\end{aligned}
$$

\subsection{Síntese do capítulo}

Apresentou-se neste capítulo como a metodologia apresentada no capítulo 4 pode ser empregada na modelagem de um sistema flexível de movimentação de materiais. O caso apresentado deriva da simplificação de um problema da planta da Mercedes Benz do Brasil localizada em São Bernardo do Campo, São Paulo. Além disso, pode-se demonstrar neste exemplo como informações oriundas da planta (objeto de controle) podem ser utilizadas na especificação de sistemas de controle considerando as limitações dos recursos. 


\section{Comentários finais e Conclusões}

O estudo de um metodologia para a modelagem de sistemas de movimentação de materiais em ambiente fabril vem de encontro a uma necessidade por parte das empresas de dominar os processos e serem competitivas. Um modelo representativo do sistema flexível de movimentação de materiais permite que se possa desenvolver análises através de simulações e, desta forma, por exemplo, otimizar a sua frota de recursos de movimentação (por exemplo, transportadores e carretas) bem como estudar técnicas de controle que atendam suas necessidade produtivas e / ou institucionais (designar recursos de movimentação de forma a minimizar a distância percorrida e desta forma economizar combustível, ou reduzir o tempo de espera para movimentação, etc.).

Focou-se o estudo em sistemas flexíveis de movimentação de materiais baseados em VATs (Veículos Autônomos de Transporte) cuja característica de não possuírem restrições quanto ao movimento (não existem guias ou trilhos limitando o seu movimento) agiliza mudanças de arranjo físico em instalações fabris, o que é um fator importante quando se procura adotar uma estratégia de flexibilidade.

A abordagem do sistema de movimentação de materiais em ambiente fabril como uma classe de sistemas a eventos discretos, permite a utilização de técnicas como as Redes de Petri Interpretadas, dentre elas a metodologia PFS/E-MFG (Production Flow Schema / Enhanced Mark Flow Graph), na sua modelagem. Esta metodologia provou ser eficiente como técnica de modelagem pois proporciona uma modelagem hierárquica onde se parte de um modelo conceitual em PFS até se obter um modelo funcional detalhado em E-MFG.

Utilizando-se o conceito de classes, herança e polimorfismo, herdados de conceitos de objetos, os grafos E-MFG foram redefinidos de modo que sub-grafos pudessem fazer parte dos atributos das marcas, implicando na ampliação da capacidade 
de modelagem do E-MFG. Como conseqüência, tem-se uma simplificação no processo de desenvolvimento e alteração de modelos, em especial quando há recursos móveis como transportadores e carretas que necessitam interfacear com muitos outros modelos.

Outra consequiência do encapsulamento de modelos no interior das marcas é a exigência de um maior nível de abstração por parte das pessoas envolvidas na modelagem visto que os modelos encapsulados passam a conter muitas informações não explicitas (exemplo disso pode ser ilustrado pela figura 5.1 onde o que se considera como planta é apenas a [malha de movimentação] enquanto que ao se iniciar o processo de detalhamento, percebe-se que além desta existem outros elementos: instrução, transportador, carreta e material), porém esta característica é menos relevante quando se leva em consideração a simplificação oferecida no processo de modelagem.

Ao longo do processo de estudo e modelagem de sistemas flexíveis de movimentação de materiais baseados em VATs, pode-se observar a possibilidade de utilizar a metodologia apresentada no capítulo 4 na modelagem de sistemas de movimentação de materiais entre empresas e também entre máquinas ou células de manufatura (Anexo B).

Por fim, foi exemplificado através de um estudo de caso como as informações geradas no objeto de controle (planta) podem ser utilizadas na especificação de sistemas de controle, assim como o oposto, ou seja, instruções possam ser passadas para o objeto de controle de forma a "guiar" seu comportamento.

Quanto à trabalhos futuros propõe-se:

- estudo da possibilidade de se inserir sub-grafos E-MFG em outros componentes da rede como arcos e transições; 
- desenvolvimento de uma ferramenta genérica de simulação baseada na metodologia PFS / E-MFG, procurando-se explorar a sua característica de modelagem hierárquica partindo-se de modelos em nível conceitual até se obter modelos funcionais detalhados em E-MFG;

- estudar e desenvolver uma metodologia para a modelagem dos componentes da cadeia logística (a movimentação fora da industria, a compra, estocagem, produção, movimentação interna, expedição) além de procurar definir as interfaces destes componentes como outros departamentos da empresa como financeiro e marketing. 


\section{Anexo A}

Neste anexo, procura-se demonstrar o procedimento para a variação dos atributos da marca em dois centros de custos - onde se retira um material para movimentar e onde se deixa o material - utilizando-se, como exemplo, uma etapa de um dos processos descrito no item 5.2.1.

Considera-se a seguir um exemplo onde um material deva ser transportado do centro de custo 3 para o centro de custo 5, passando-se pelos centros de custo 1 e 2 (primeiro macro atributo), e utilizando-se o transportador 1 que está disponível (segunda macro atributo).

\section{§marca $\bullet \equiv \S 3,5,3 \rightarrow 2 \rightarrow 1 \rightarrow 5$, carreta 1 , peça $A^{{ }^{27}}$, Stransportador $1,0,0,0,0$,

$$
\text { 0, grafo } \bullet^{28}, \boldsymbol{\zeta} \bullet^{29}, \boldsymbol{\xi} \bullet^{30} \bullet
$$

Atributos originais da marca no grafo das figuras 5.7, 5.8 e 5.9.

O transportador chega ao centro de custo 3, que modifica o atributo \$rota a ser tomada $\bullet$ que passa a indicar que o próximo centro de custo que o transportador deverá passar é o 2. Isto é ilustrado na figura A.1.

\footnotetext{
${ }^{27}$ Macro atributo instrução: §instrução $\bullet \equiv$ Sorigem, destino, rota a ser tomada, c-trans, m-trans $\bullet$

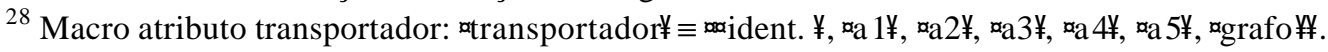

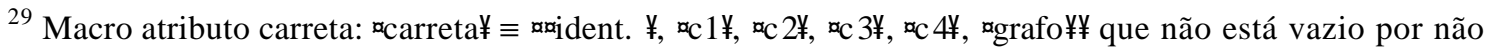
estar transportando carreta.

${ }^{30}$ Macro atributo material: §material • ミ §identificação do material•, que não está vazio por não estar transportando material.
} 
Centro de Custo 3

$\S 3,5, \underline{3 \rightarrow 2 \rightarrow 1 \rightarrow 5}$, carreta 1 , peça $A \bullet$ Stransp. 1, 0, 0, 0, 0, 0, grafo $\bullet$ §॰, §॰•

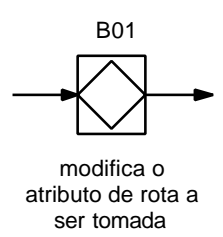

$\$ 3,5, \underline{2 \rightarrow 1 \rightarrow 5}$, carreta 1 , peça A ;

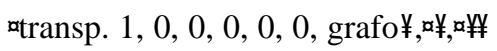

Figura A.1 - Modificação do atributo §rota a ser tomada •(parte do grafo da figura 5.7).

Como o atributo §origem• corresponde ao centro de custo que está sendo visitado, ou seja, 3, o transportador deve executar a atividade de engatar a carreta que na figura A.2 corresponde à composição (disparo de T12) dos atributos das duas marcas de entrada (a marca contendo os atributos \$transportador • e §instrução • e a marca contendo os atributos $\boldsymbol{\S}$ carreta $\bullet$ e a $\$$ materialø), formando a marca de saída. Notase que desta forma o atributo $\S 4$ • relacionado com o transportador muda de "0" para "1" indicando que este terminou o engate e o atributo $\mathbf{\S} 6 \bullet$ (carreta acoplada ao transportador) também passa para " 1 ".

O box controlador (B11) altera o atributo $\mathbf{\S} 1 \bullet$ do transportador (habilita engate) e quando o processo de engate termina, o atributo $\$$ §a $\bullet$ (fim do engate) é modificado, indicando o fim da operação ao box controlador e o atributo $\$$ a $\bullet$ (indicador de que o transportador possui uma carreta engatada a ele) passa a "1", indicando que existe uma carreta engatada. Em seguida o box controlador restitui o valor original do atributo $\mathbf{\S} 1 \bullet$ do transportador (figura A.3). 
Verifica se o atributo corresponde ao

do arco - no exemplo em questão, sim.

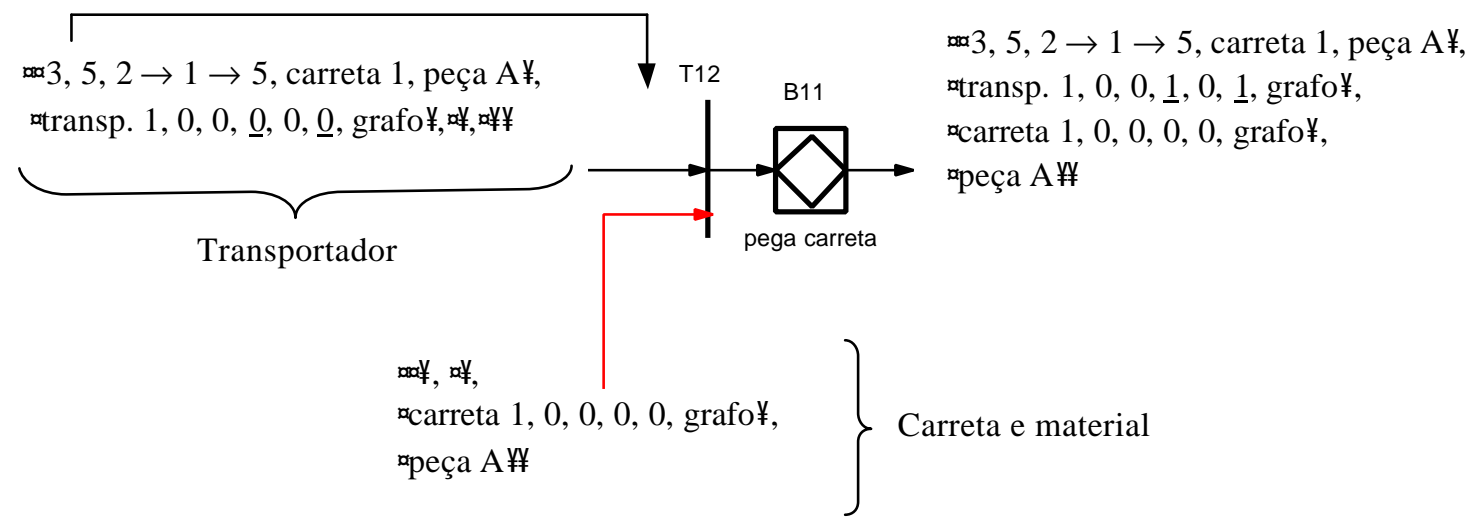

Figura A.2 - Atributo das marcas quando o transportador engata a carreta (parte do grafo da figura 5.7)

$\$ \$ 3,5,2 \rightarrow 1 \rightarrow 5$, carreta 1 , peça A Stransp. 1, $1,0, \underline{0}, 0, \underline{0}$, grafo: Scarreta $1,0,0,0,0$, grafo Speça A ••
$\$ \$ 3,5,2 \rightarrow 1 \rightarrow 5$, carreta 1 , peça A•, §transp. 1, $1,0, \underline{1}, 0, \underline{1}$, grafo; Scarreta 1, 0, 0, 0, 0, grafo ; Speça A ••
$\$ 3,5,2 \rightarrow 1 \rightarrow 5$, carreta 1 , peça A Stransp. 1, $\underline{0}, 0, \underline{1}, 0, \underline{1}$, grafo: Scarreta 1, 0, 0, 0, 0, grafo Speça A ••

Figura A.3 - Alteração dos atributos das marcas na operação de engate.

A seguir, como o atributo $\S a 1 \bullet$ do transportador é “0” e o de final de engate (atributo §a3•) está confirmado (é igual a “1”), ou seja, a atuação do box controlador terminou, o disparo de T13 indica que o transportador pode seguir para o próximo centro de custo (figura A.4).
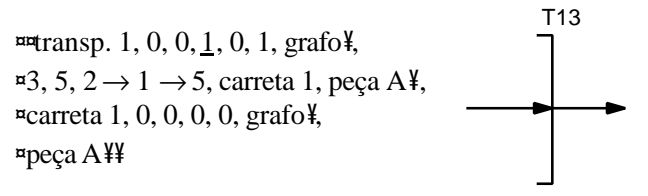

$\S \S 3,5,2 \rightarrow 1 \rightarrow 5$, carreta 1 , peça A $\bullet$

Stransp. 1, 0, 0, $0,0,1$, grafo

Scarreta 1, 0, 0, 0, 0, grafo ;

§peça A ••

Figura A.4 - Final da operação de engate (a inversão das linhas foi feita apenas para facilitar a indicação dos atributos que são levados em consideração) - (parte do grafo da figura 5.7).

Quando o transportador chega em seu destino o atributo §rota a ser tomada $\bullet$ é modificado (idem ao procedimento de engatar carreta) (figura A.5). 
$\$ 3,5, \underline{5}$, carreta 1 , peça A ; Sransp. 1, 0, 0, 0, 0, 1, grafo • Scarreta 1, 0, 0, 0, 0, grafo $\bullet$ §peça A •

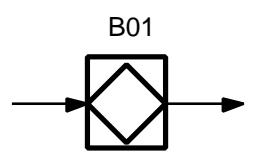

modifica o atributo de rota a ser tomada
$\$ 3,5$, , , carreta 1 , peça A ; Stransp. 1, 0, 0, 0, 0, 1, grafo $\bullet$ Scarreta 1, 0, 0, 0, 0, grafo $\bullet$ speça A •

Figura A.5 - Modificação do atributo §rota a ser tomada •(parte do grafo da figura 5.7).

O atributo §destino $\bullet$ corresponde ao centro de custo que está sendo visitado, ou seja, neste caso igual a 5. O transportador executa assim a atividade de deixar a carreta que corresponde à decomposição dos atributos da marca de entrada, formando duas marcas de saída. Nota-se que neste instante o atributo $\S \mathbf{a} 4 \bullet$ do transportador muda de "0" para "1" indicando que este terminou o desengate e o atributo $\$$ a 5 (carreta acoplada ao transportador) passa para "0", indicando que a carreta foi desacoplada. Pode-se notar também que o macro atributo §instrução •é eliminado (figura A.6).

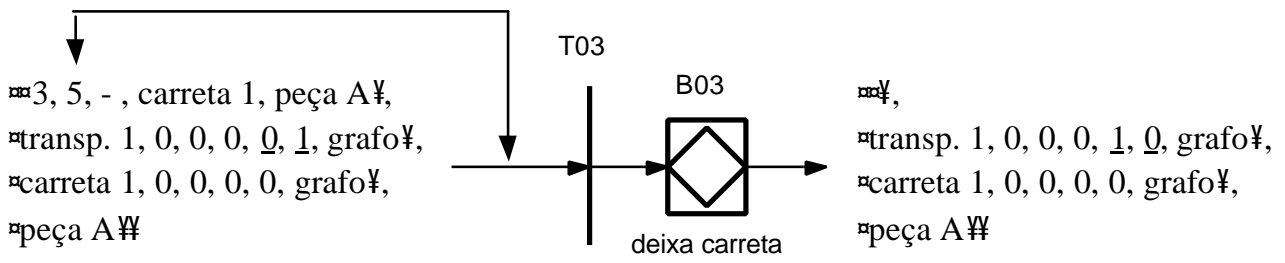

Figura A.6 - O transportador deixa a carreta (parte do grafo da figura 5.7).

O box controlador (B03) altera o atributo $\$ a 1 \bullet$ do transportador para 2 (habilita desengate) e quando o processo de engate termina, o atributo $\$ 4 \bullet($ fim do desengate) é

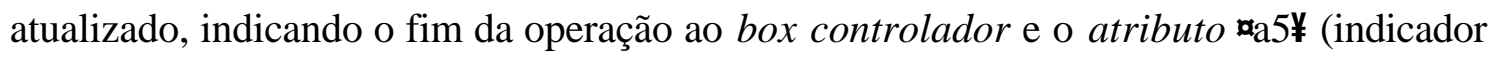
de que o transportador possui uma carreta engatada a ele) passa a "0", indicando que não mais existe uma carreta engatada. Em seguida o box controlador restitui o valor original do atributo $\S \mathbf{a} 1 \bullet$ do transportador para “0” (figura A.7). 
§̧;

Stransp. 1, 2, 0, 0, $\underline{0}, \underline{1}$, grafo Scarreta 1, 0, 0, 0, 0, grafo ;

§peça A ••
$\$ \$$

Stransp. 1, 2, 0, 0, $1, \underline{1}$, grafo

Scarreta 1, 0, 0, 0, 0, grafo ; Speça A ••
§;

Stransp. 1, $\underline{0}, 0,0, \underline{1}, 0$, grafo

Scarreta 1, 0, 0, 0, 0, grafo ; Speça A ••

Figura A.7 - Alteração dos atributos das marcas na operação de desengate.

A seguir, como o atributo $\S a 1 \bullet$ do transportador é “ 0 ” e o de final de desengate (atributo §a4 •) é “1”, ou seja, a atuação do box controlador terminou, o disparo de T04 indica que o transportador está disponibilizado para uma nova movimentação (figura A.8).

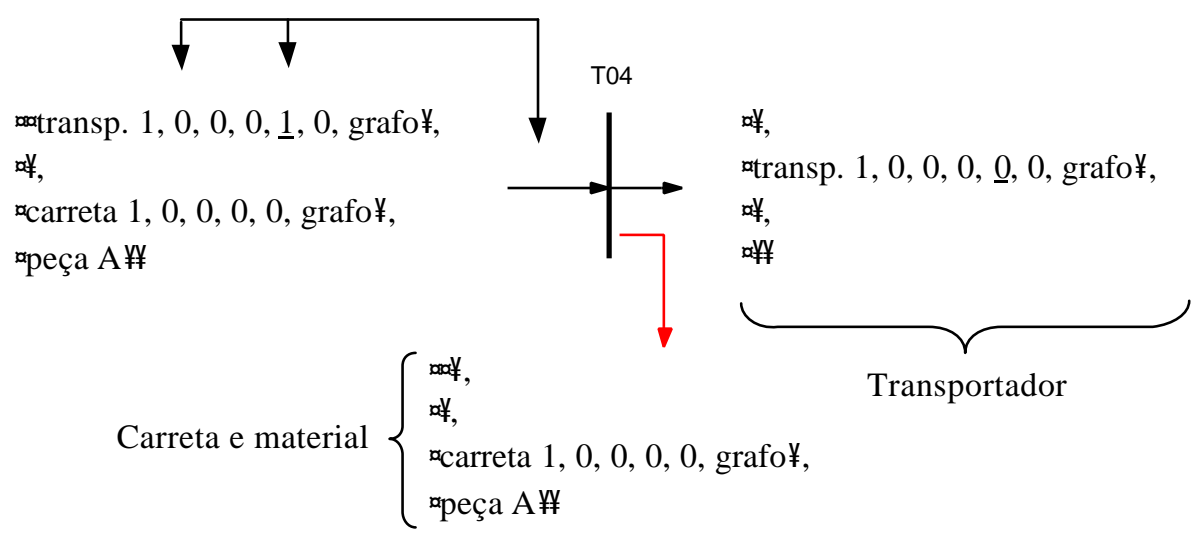

Figura A.8 - Final da operação de desengate (a inversão das linhas foi feita apenas para facilitar a indicação dos atributos que são levados em consideração) - (parte do grafo da figura 5.7). 


\section{Anexo B}

Neste anexo, é apresentado um processo de modelagem partindo-se da movimentação de materiais entre empresas até a movimentação entre máquinas de um mesmo centro de custos.

\section{B.1. Modelagem do sistema de movimentação de materiais entre} empresas

O primeiro passo é a identificação dos componentes do sistema. Neste exemplo está-se supondo 6 empresas / industrias relacionadas através de uma malha de movimentação como mostra a figura B.1. e pela qual trafegam caminhões.

Com base no exposto, pode-se passar ao segundo passo que constitui na definição dos modelos conceituais, os quais são: [Empresa $i$ ], [Transporte entre $i \mathrm{e} j$ ] $\mathrm{e}$ [Caminhão].

No terceiro passo, tem-se a definição das relações entre os modelos conceituais: troca de informações de carga/descarga entre [Empresa $i$ ] e [Caminhão].

No quarto e último passo, tem-se o detalhamento dos componentes do sistema ${ }^{31}$.

Na figura B.1 é apresentado um exemplo de malha de movimentação conectando empresas pertencentes a uma mesma cadeia de suprimentos.

\footnotetext{
${ }^{31}$ Devido ao fato da metodologia já ter sido apresentada no capítulo 4 e ter sido aplicada no capítulo 5, não se tem o intuito de tecer muitas explicações sobre os modelos e seus comportamentos dadas as semelhanças com os modelos do capítulo 5.
} 


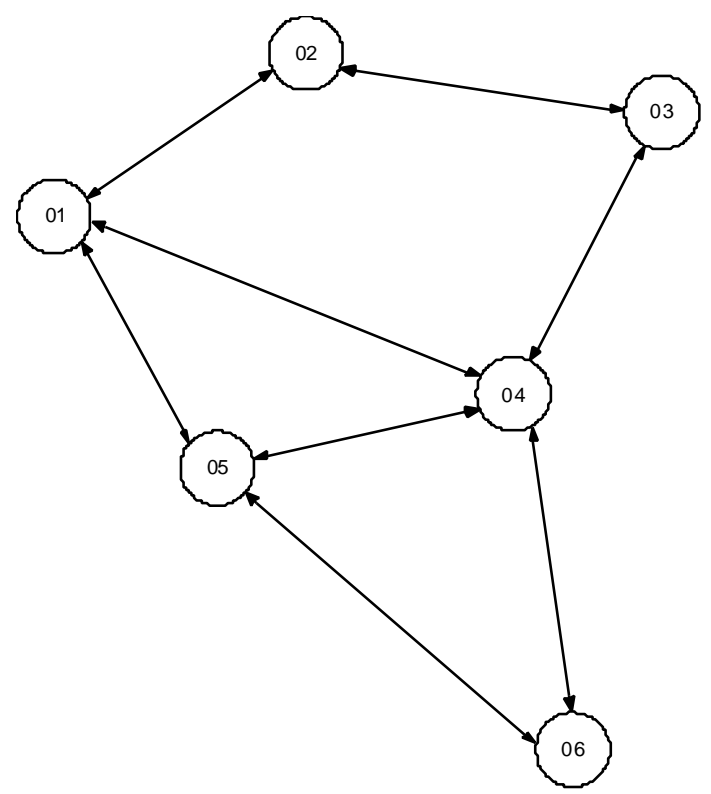

Figura B.1 - Malha de movimentação conectando empresas de uma mesma cadeia de suprimentos.

Na figura B.2 tem-se a representação da malha de movimentação (figura B.1) através da utilização do PFS.

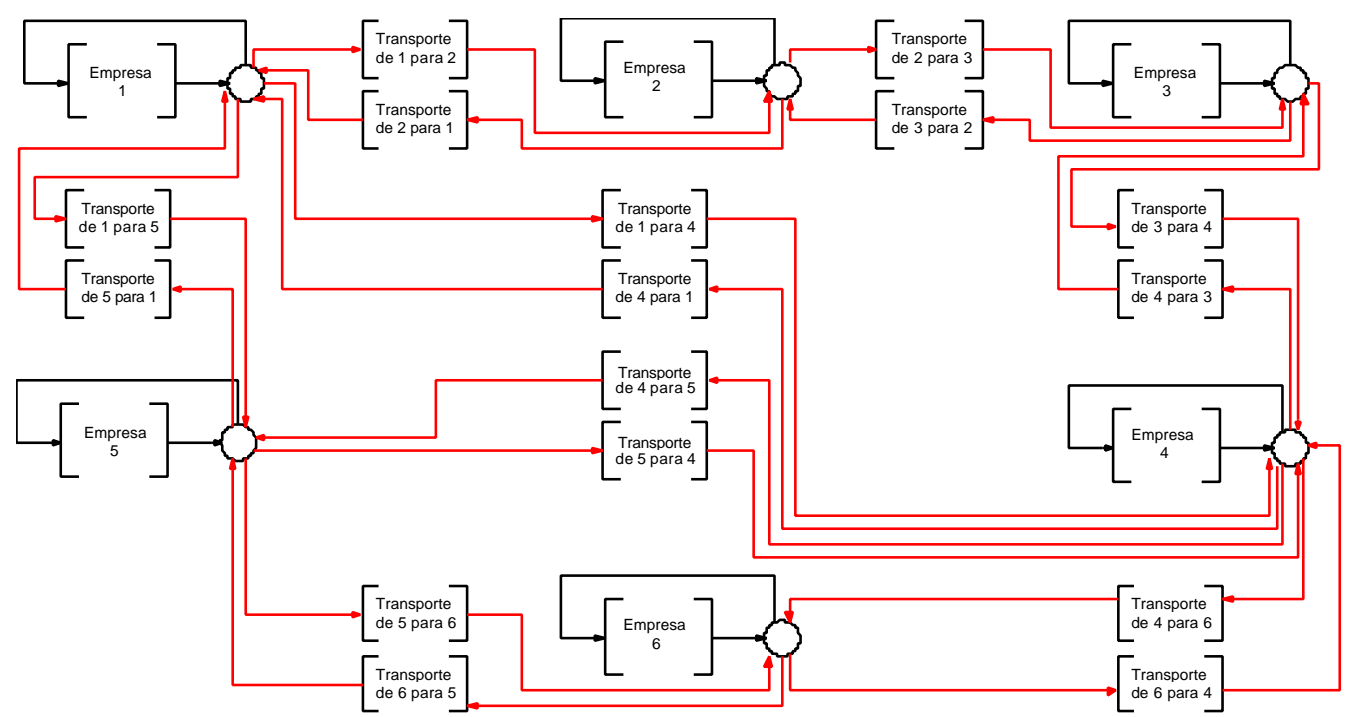

Figura B.2 - Representação, em PFS, da malha de movimentação que interliga empresas (figura B.1).

É exposto na figura B.3 um possível detalhamento para a atividade [Transporte entre $i$ e $j$ ] e, na figura B.4, o detalhamento da atividade [Empresa $i$ ]. 


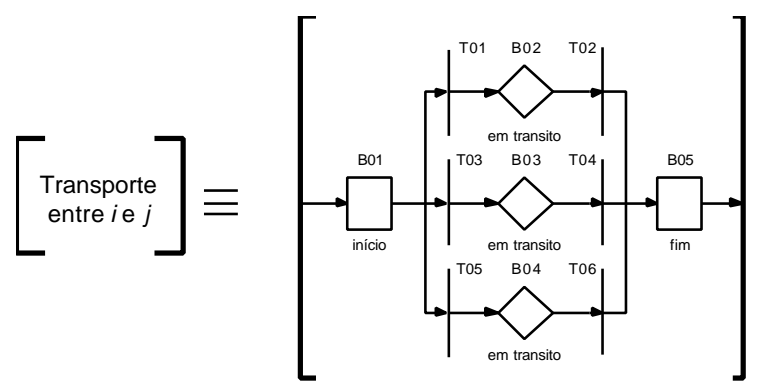

Figura B.3 - Possível representação da atividade [Transporte entre $i$ e $j$ ].

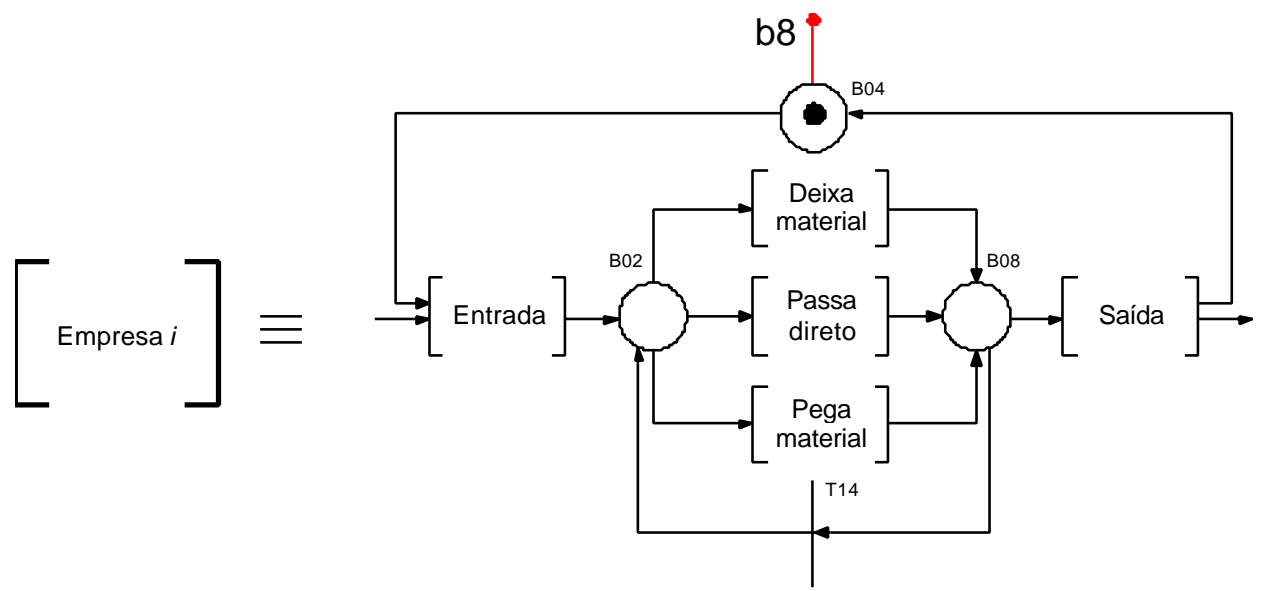

(a) Primeiro nível de detalhamento utilizando-se a metodologia PFS / MFG

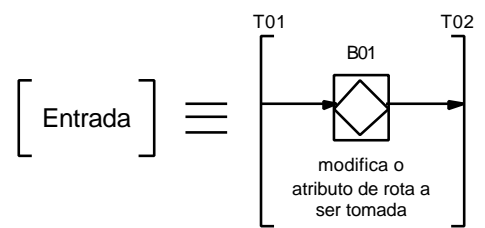

(b) detalhamento da atividade [entrada]

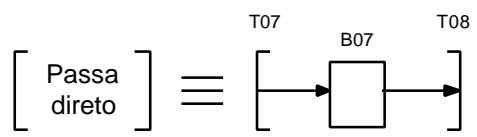

(c) detalhamento da atividade [passa direto]

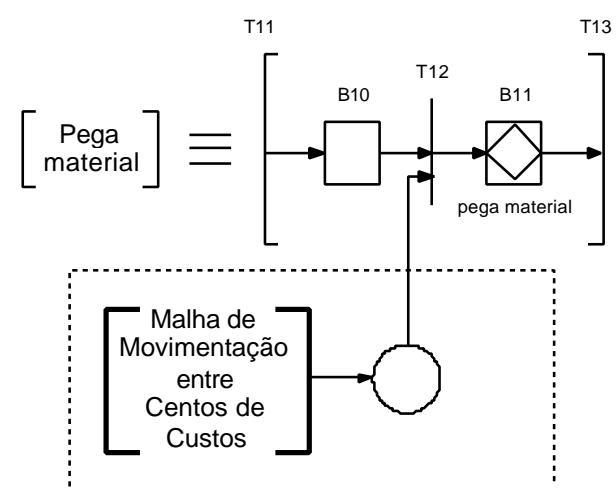

(d) detalhamento da atividade [pega material]

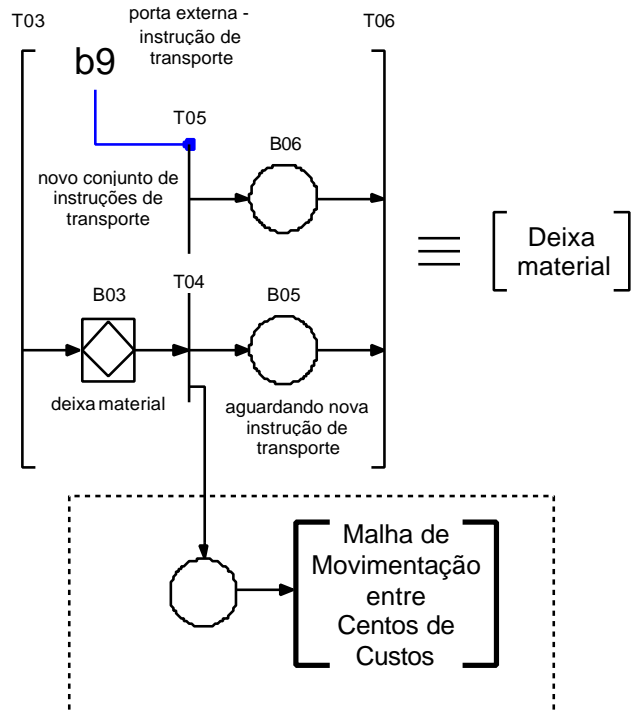

(e) detalhamento da atividade [deixa material]

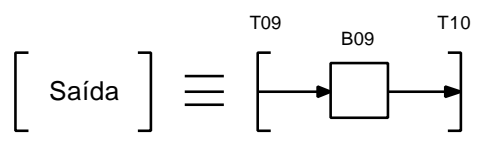

(f) detalhamento da atividade [saída]

Figura B.4 - Possível representação da atividade [Empresa $i$ ]. 
O detalhamento da atividade [Malha de movimentação entre Centros de Custo] corresponde à próxima etapa da modelagem que será descrita no item B.2.

De forma similar ao apresentado no capítulo 5, com relação ao transportador, é apresentado um modelo para o transportador (o mais comumente utilizado no Brasil é o caminhão), responsável pela movimentação de materiais entre empresas (a figura B.5 ilustra uma possível representação deste e, em seqüência, têm-se sua representação em forma de atributos - encapsulamento do modelo).

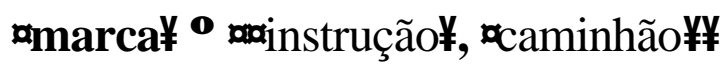

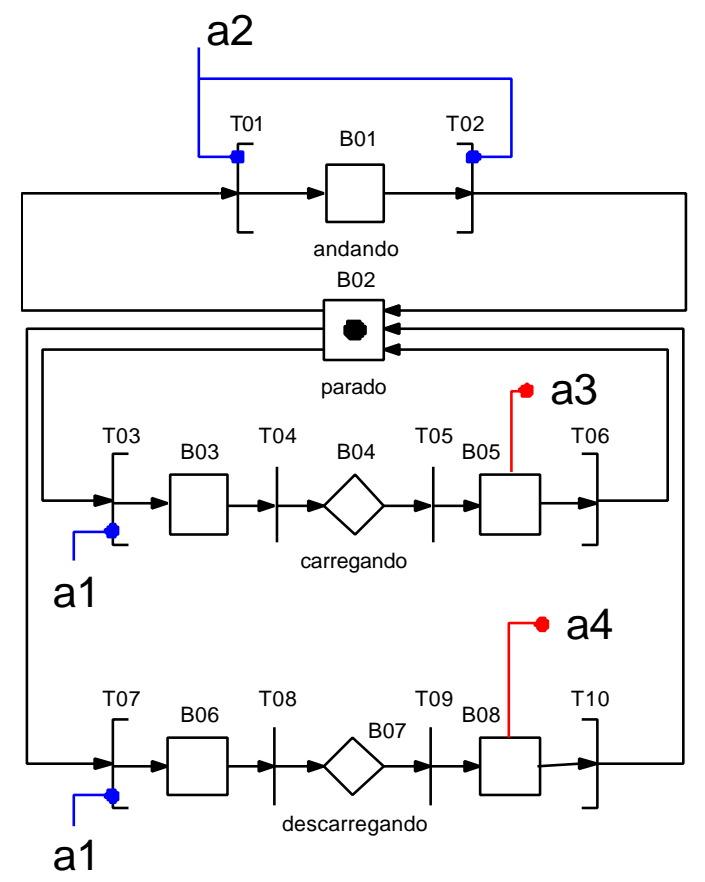

Figura B.5 - Possível representação de um modelo de transportador (caminhão) para realizar a movimentação de materiais entre empresas.

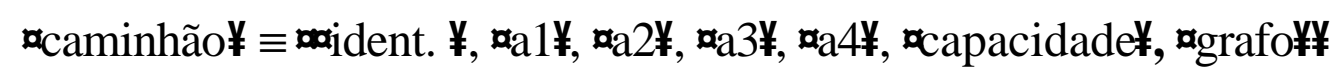




\section{B.2. Modelagem do sistema de movimentação de materiais entre centros de custos de uma empresa}

Esta etapa da modelagem é exemplificada no capítulo 5, item 1 (Planta) onde se tem a modelagem dos componentes o sistema de movimentação de materiais internos a uma empresa.

\section{B.3. Modelagem do sistema de movimentação de materiais entre máquinas de um centro de custos}

Como última etapa da modelagem, tem-se a aplicação da metodologia proposta no capítulo 4 para o detalhamento do sistema de movimentação de materiais.

O primeiro passo é a identificação dos componentes do sistema. Neste exemplo está-se supondo 6 máquinas, um buffer de entrada e um centro de expedição relacionados através de uma malha de movimentação e cujos materiais, apoiados em paletes, são transportados por empilhadeiras.

Com base no exposto, pode-se passar ao segundo passo que constitui na definição dos modelos conceituais, os quais são: [Máquina $i$, [Transporte entre $i$ e $j$ ] e [Empilhadeira].

No terceiro passo, tem-se a definição das relações entre os modelos conceituais: troca de informações de carga/descarga entre [Máquina $i$ ] e [Empilhadeira].

No quarto e último passo, tem-se o detalhamento dos componentes do sistema.

Retomando os modelos apresentados no capítulo 5, tem-se em substituição ao detalhamento da atividade [Tratamento dos materiais] apresentado nas figuras 5.8 e 5.9 o detalhamento que se inicia através da figura B.6 (movimentação de materiais em um dos centros de custos). 


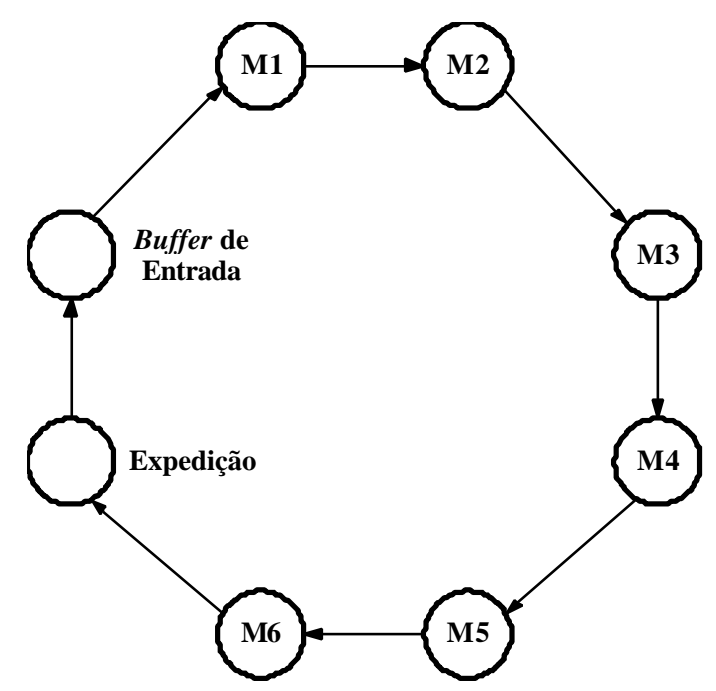

Figura B.6 - Representação de uma possível malha de movimentação interna a um Centro de Custos.

Em seguida, o grafo da figura B.6 é representado utilizando-se o PFS (figura B.7).

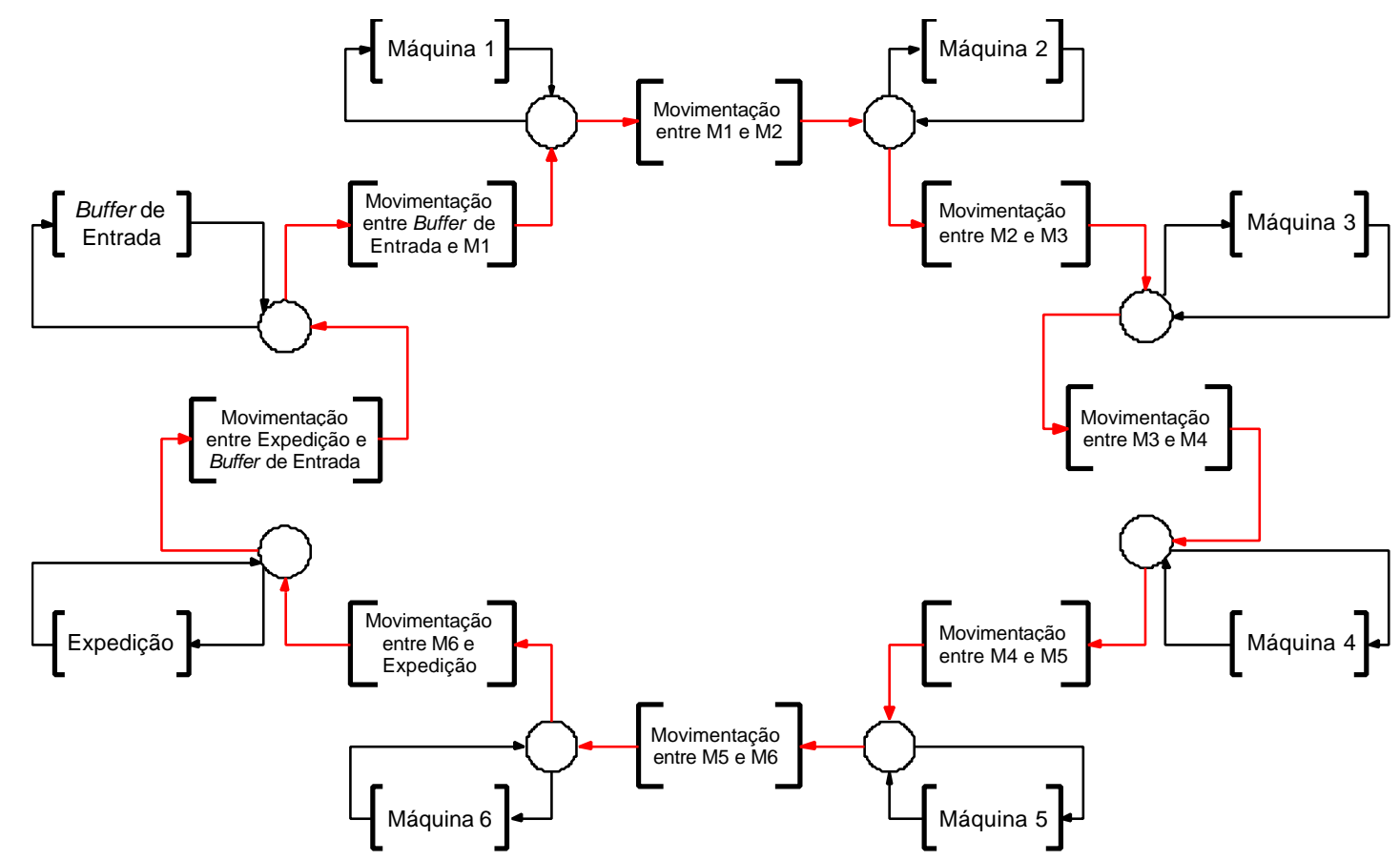

Figura B.7 - Representação, em PFS, da malha de movimentação que interliga as máquinas (figura B.6). 
A figura B.8 ilustra uma possível representação para a atividade [Transporte entre $\mathrm{M} i$ e Mj] e, a figura B.9, uma possível representação para o comportamento das máquinas.

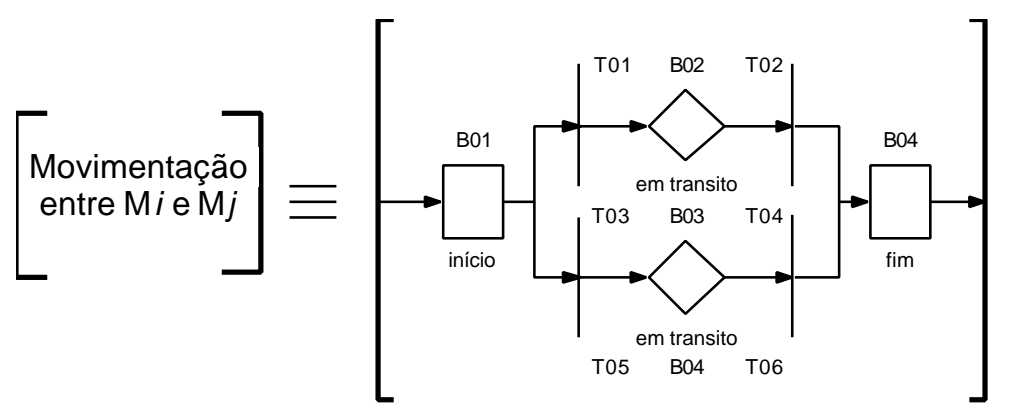

Figura B.8 - Possível representação da atividade [Movimentação entre Mi e Mj].

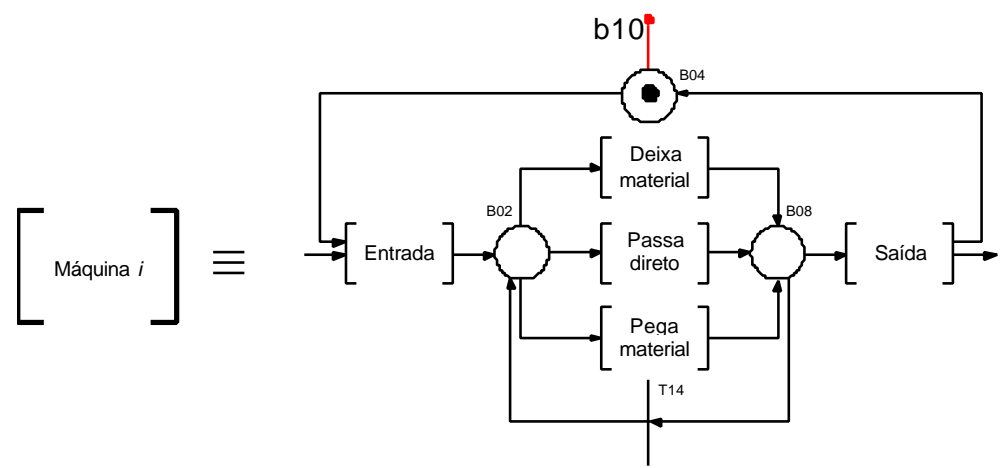

(a) Primeiro nivel de detalhamento utilizando-se a metodologia PFS / MFG

[Entrada $] \equiv \overbrace{\substack{\text { modifica o } \\ \text { atributo de rota a } \\ \text { ser tomada }}}^{\text {T01 }}$

(b) detalhamento da atividade [entrada]

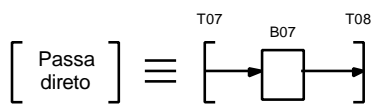

(c) detalhamento da atividade [passa direto]

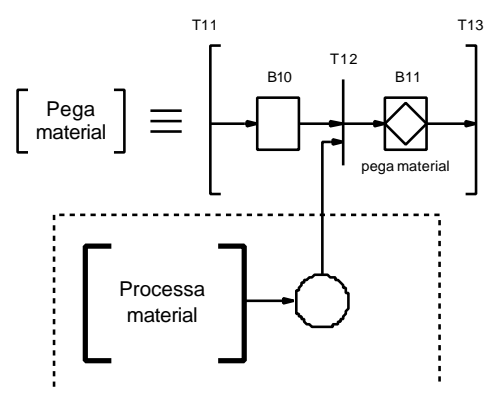

(d) detalhamento da atividade [pega material]

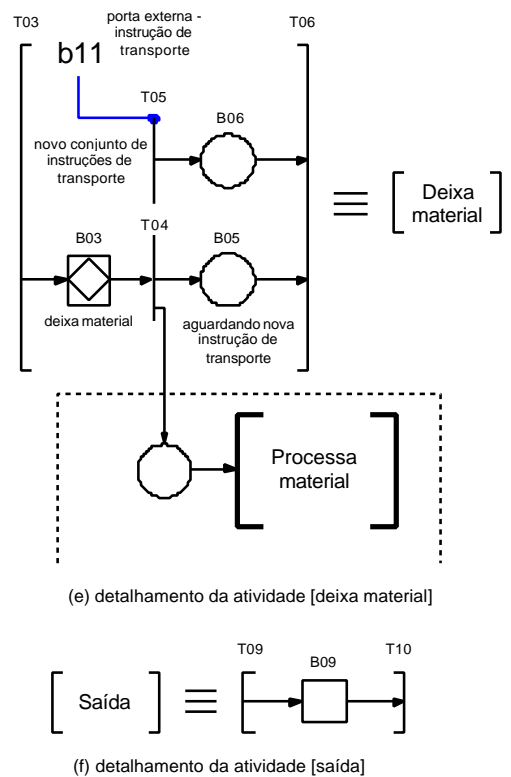

(f) detalhamento da atividade [saída]

Figura B.9 - Possível representação da atividade [Máquina $i$ ]. 
De forma similar ao apresentado no capítulo 5 (figura 5.9) tem-se o detalhamento da atividade de processamento do material pela máquina (figura B.10).

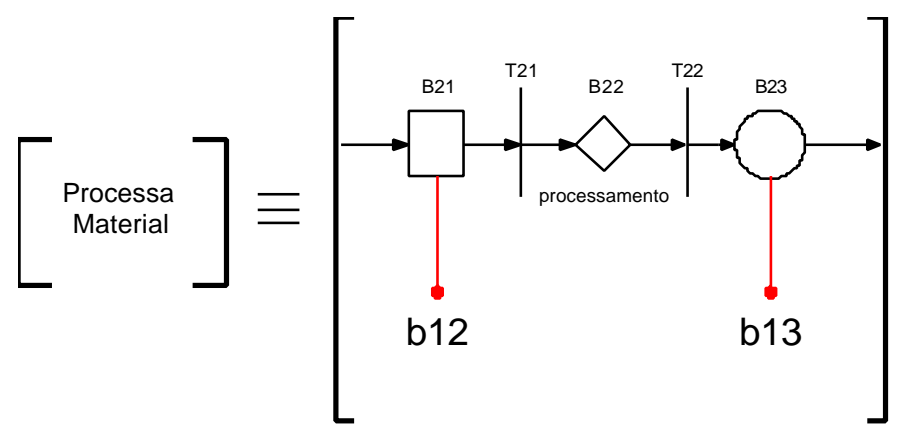

Figura B.10 - Possível detalhamento da atividade [Processa Material].

Por fim, é apresentado um possível modelo para o elemento empilhadeira, responsável pela movimentação de materiais entre as máquinas (a figura B.11 ilustra uma possível representação desta e, em seqüência, têm-se sua representação em forma de atributos - encapsulamento do modelo).

\section{§marca $\bullet \equiv$ §instrução $\bullet$ §empilhadeira}




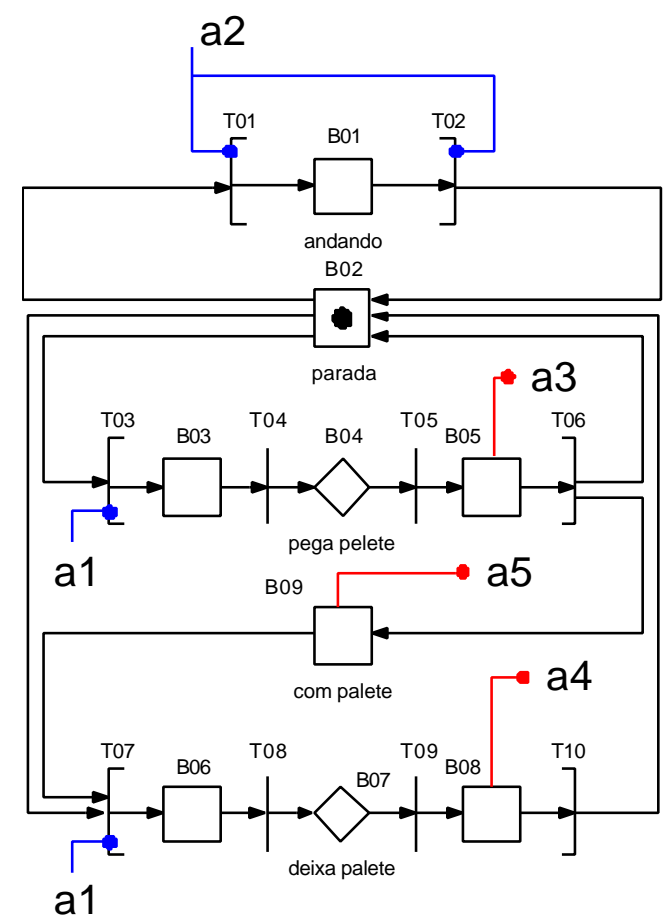

Figura B.11 - Possível representação de uma empilhadeira empregada na movimentação de materiais entre máquinas utilizando paletes.

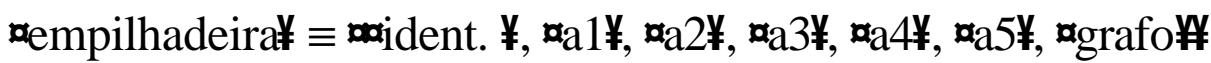

\section{B.4. Síntese do anexo}

Apresentou-se neste anexo como a metodologia proposta no capítulo 4 pode ser empregada na modelagem de diversos sistemas de movimentação de materiais relacionados com a cadeia logística. 


\section{Referências bibliográficas}

BAIRD, S.P.; LEAVY, J.J. Simulation Modeling Using Promodel for Windows. Proceedings of the 1994 Winter Simulation Conference.

BANKS, J. Software for Simulation. Proceedings of the 1995 Winter Simulation Conference.

BASTIDE, R. Approaches in unifying Petri Nets and the Object-Oriented Approach. Turin, Italy. 1st. Workshop on Object-Oriented Programming and Models of Concurrency within Applications and Theory of Petri Nets 1995 Conference, 16 th International Conference. June 1995.

BODIN, L., GOLDEN, B., ASSAD, A., BALL, M. Routing and Scheduling of Vehicles and Crews. Computers \& Operations Research, Vol. 10, N 1. New York, Pergamon Press, 1983.

BOLWIJN, P.; KUMPE, T. Manufacturing in the 1990's - productivity, flexibility and inovation. Long Range Planning, vol. 23, n.4, pp. 44-57, 1990.

CALVEZ, J.P. Embedded Real-Time Systems. John Wiley \& Sons, 1993.

CANTÙ, M. Dominando o Delphi - “A Bíblia”. São Paulo. Makron Books do Brasil Editora Ltda., 1995.

CARDoso, J.; VAletTe, R. Redes de Petri. Editora da UFSC, Florianópolis, 1997.

CASSANDRAS, C. G., STRICKLAND, S. G Sample Path Properties of timed Discrete Event Systems in Discrete Event Dynamic Systems - Analizing Complexity and Performance in the Modern World. New York, IEEE Press, 1992.

CHRISTOFIDES, N. Graph Theory: an Algorithmic Approach. London, Academic Press, Inc. 1986.

DAVID, R.; ALLA, H. Petri Nets and Grafcet - Tools for Modelling Discrete Event Systems. Prentice Hall, 1992.

DELATOUR, J. PALUDETTO, M. UML/PNO: a way to merge UML and Petri Net Objetcts for the analysis of real-time systems. Bruxelles, OO Technology and Real Time Systems Workshop (ECOOP'98), 20-21 Juillet 1998.

DELL'AMICO, M., FISCHETTI, M., TOTH, P. Heuristic Algorithms for the Multiple Depot Vehicle Scheduling Problem. Management Science, Vol 39, No $1,1993$.

FERREIRA, A. B. H. Novo Dicionário da Língua Portuguesa, $2^{\underline{a}}$ Ed. Rio de Janeiro, Nova Fronteira, 1994.

GENDREAU, M., HERTZ, A., LAPORTE, G A Tabu Search Heuristic for the Vehicle Routing Problem. Management Science, Vol 40, No 10, 1994.

GOLDEN, B. L., LAPORTE, G., TAILlARD, É. D. An Adaptive Memory Heuristic for a Class of Vehicle Routing Problems with Minmax Objective. Computers \& Operations Research, Vol. 24. New York, Pergamon Press, 1997. 
HASEGAWA, K. et al.: Application of the Mark Flow Graph to Represent Discrete Event Production Systems and System Control. Transactions of the Society of Instrumet and Control Engineers, v.24, nº $1,1988$.

HO, Y.C.; CAO, X.R.: Pertubation Analysis of Discrete Event Dynamic Systems. Kluwer Academic Publishers, 1991.

INAMASU, R.Y. Modelo de FMS: Uma Plataforma para Simulação e Planejamento. Tese de Doutorado, Escola de Engenharia de São Carlos da USP, São Carlos, 1995.

JENSEN, K Coloured Petri Nets: Basic Concepts, Analysis Methods and Practical Use, Vol. 1. Springer-Verlag, Berlin, 1992.

KELTON, W.D. A Tutorial on Design and Analysis of Simulation Experiments. Proceedings of the 1995 Winter Simulation Conference.

LAKOS C., The Object Orientation of Object Petri Nets. Torino, Italy. Workshop on Object Oriented Programming and Models of Concurrency, 1995a.

LAKOS C., From Coloured Petri Nets to Object Petri Nets. Torino, Italy. 16th International Conference on the Application and Theory of Petri Nets, pp. 278-297, 1995b.

LAKOS, C., The consistent use of names and polymorphism in the definition of Object Petri Nets. Osaka, Japan. 17th International Conference on the Application and Theory of Petri Nets, pp. 380-399, 1996.

MARTINS, P. G., LAUGENI, F. P. Administração da Produção. São Paulo, Saraiva, 1998.

MATSUSAKI, C. T. M. Redes F-MFG (Functional Mark Flow Graph) e sua aplicação no projeto de sistemas antropocêntricos. Dissertação de Mestrado, Escola Politécnica da USP, São Paulo, 1998.

MIYAGI, P.E. Controle Programável - Fundamentos do Controle de Sistemas a Eventos Discretos. São Paulo, Editora Edgard Blücher, 1996.

MIYAGI, P.E.; ARATA, W.M. Application of PFS Model (Production Flow Schema) Based Analysis of Manufacturing Systems for Performance Assessment. Revista Brasileira de Ciências Mecânicas, V.19, N,1, pp.58-71, 1997

MOORE, K. E., BRENNAN, J. E. Alpha/SIM Simulation Software Tutorial. Proceedings of the 1996 Winter Simulation Conference.

MOREIRA, D. A. Administração da Produção e Operações. São Paulo, Pioneira, 1993.

MURATA, T. Petri Nets - Properties, Analysis and Applications. Proceedings of the IEEE, V.77, N.4, 1989.

MUSCAT, A.; FLEURY, A. Indicadores da Qualidade e Produtividade na Indústria Brasileira, Revista Indicadores da Qualidade, N.2, pp.82-107, 1993.

PEARN, W. L., CHIEN, R. C. Improved Solutions for the Traveling Purchaser Problem. Computers \& Operations Research, Vol. 25. New York, Pergamon Press, 1998.

PEARN, W. L., LIU, C. M. Algorithms for the Chinese Postman Problem on Mixed Networks. Computers \& Operations Research, Vol. 22, N 5. New York, Pergamon Press, 1995. 
PETERSON, J. L. Petri Net Theory and the Modeling of Systems. New Jersey, Prentice Hall Inc., 1981.

REISIG, W. Petri Nets - An Introduction. Springer-Verlag, Berlin, 1982.

REISIG, W. A Primer in Petri Design. Springer-Verlag, Berlin, 1992.

ROBINSON, S., BHATIA, V. Secrets of Successful Simulation Projects. Proceedings of the 1995 Winter Simulation Conference.

RODRIGUEZ, P., NUSSBAUM, M., BAEZA, R., LEÓN, G., SEPÚLVEDA, M., COBIÁN, A. Using Global Search Heuristics for the Capacity Vehicle Routing Problem. Computers \& Operations Research, Vol. 25. New York, Pergamon Press, 1998.

SANTOS FILHO, D.J. Proposta do Mark Flow Graph Estendido para a Modelagem e Controle de Sistemas Integrados de Manufatura. Dissertação de Mestrado, Escola Politécnica da USP, São Paulo, 1993.

SANTOS FILHO, D.J. Sistemas Antropocêntricos de Produção Baseado em Redes de Petri Interpretadas. Tese de Doutorado, Escola Politécnica da USP, São Paulo, 1998.

SANTOS FILHO, D.J.; MIYAGI, P.E. Enhanced MFG to Control Flexible Manufacturing Systems. Revista Brasileira de Ciências Mecânicas, V.17, N,2, pp.232-248, 1996.

SEILA, A.F. An Introduction to Computer Simulation. Proceedings of the 1994 Winter Simulation Conference.

SEILA, A.F. Introduction to Simulation. Proceedings of the 1995 Winter Simulation Conference.

SRINIVASAN, R., VENKATASUBRAMANIAN, V. Automating HAZOP analysis of batch chemical plant: Part I. The knowledge representation framework. Great Britain, Computers Chem. Engng, Vol. 22, № 9, pp. 1345 1355, 1998.

SUMICHRAST, R. T., MARKHAM, I. S. A Heuristic and Lower Bound for a Multi-Depot Routing Problem. Computers \& Operations Research, Vol. 22. New York, Pergamon Press, 1995.

SWAIT JR., JOFFRE DAN. Fundamentos Computacionais, Algoritmos e Estruturas de Dados. São Paulo, Makron Books do Brasil, 1990.

WANG, L., WU, S. Modeling with Colored Timed Object-Oriented Petri Nets for Automated Manufacturing Systems. Great Britain, Computers ind. Engng, Vol 34, № 2, pp. 463-481, 1998.

ZHA, X. F. An object-oriented knowledge based Petri net approach to intelligent integration of design and assembly planning. Artificial Intelligence in Engineering, № 14 pp. 83-112, 2000. 